\title{
Alternative cardioprotective approaches and their effects on myocardial peroxynitrite, RISK and SAFE pathways
}

\author{
PhD thesis
}

\section{Márton Pipicz MD}

\author{
Supervisors: \\ Tamás Csont MD, PhD and Csaba Csonka MD, $\mathrm{PhD}$ \\ Metabolic Diseases and Cell Signaling Research Group \\ Department of Biochemistry \\ Faculty of Medicine \\ University of Szeged
}

Szeged

2017 


\section{List of publications}

\section{List of full papers directly related to the subject of the thesis}

I. Pipicz M.; Kocsis G.F.; Sarvary-Arantes L.; Bencsik P.; Varga Z.V.; Ferdinandy P.; Csont T. Low-dose endotoxin induces late preconditioning, increases peroxynitrite formation, and activates STAT3 in the rat heart. Molecules 2017, 22. [IF: 2.861]

II. Pipicz M.; Varga Z.V.; Kupai K.; Gaspar R.; Kocsis G.F.; Csonka C.; Csont T. Rapid ventricular pacing-induced postconditioning attenuates reperfusion injury: Effects on peroxynitrite, RISK and SAFE pathways. British Journal of Pharmacology 2015, 172, 3472-3483. [IF: 5.259]

Cumulative impact factors of papers directly related to the subject of thesis: 8.120

\section{List of other full papers}

I. Kocsis G.F.; Sarkozy M.; Bencsik P.; Pipicz M.; Varga Z.V.; Paloczi J.; Csonka C.; Ferdinandy P.; Csont T. Preconditioning protects the heart in a prolonged uremic condition. American Journal of Physiology. Heart and Circulatory Physiology 2012, 303, H1229-1236. [IF: 3.708]

II. Varga Z.V.; Zvara A.; Farago N.; Kocsis G.F.; Pipicz M.; Gaspar R.; Bencsik P.; Gorbe A.; Csonka C.; Puskas L.G.; Thum T.; Csont T.; Ferdinandy P. MicroRNAs associated with ischemia-reperfusion injury and cardioprotection by ischemic preand postconditioning: ProtectomiRs. American Journal of Physiology. Heart and Circulatory Physiology 2014, 307, H216-227. [IF: 3.838]

III. Csont T.; Murlasits Z.; Menesi D.; Kelemen J.Z.; Bencsik P.; Pipicz M.; Fekete V.; Zvara A.; Puskas L.G.; Ferdinandy P. Tissue-specific gene expression in rat hearts and aortas in a model of vascular nitrate tolerance. Journal of Cardiovascular Pharmacology 2015, 65, 485-493. [IF: 2.462]

IV. Sarkozy M.; Szucs G.; Pipicz M.; Zvara A.; Eder K.; Fekete V.; Szucs C.; Barkanyi J.; Csonka C.; Puskas L.G.; Konya C.; Ferdinandy P.; Csont T. The effect of a preparation of minerals, vitamins and trace elements on the cardiac gene 
expression pattern in male diabetic rats. Cardiovascular Diabetology 2015, 14, 85. [IF: 4.534]

V. Schreckenberg R.; Rebelo M.; Deten A.; Weber M.; Rohrbach S.; Pipicz M.; Csonka C.; Ferdinandy P.; Schulz R.; Schluter K.D. Specific mechanisms underlying right heart failure: The missing upregulation of superoxide dismutase-2 and its decisive role in antioxidative defense. Antioxidants \& Redox Signaling 2015, 23, 1220-1232. [IF: 7.093]

VI. Csonka C.; Sarkozy M.; Pipicz M.; Dux L.; Csont T. Modulation of hypercholesterolemia-induced oxidative/nitrative stress in the heart. Oxidative Medicine and Cellular Longevity 2016, 2016, 3863726. [IF: 4.593]

VII. Gaspar R.; Pipicz M.; Hawchar F.; Kovacs D.; Djirackor L.; Gorbe A.; Varga Z.V.; Kiricsi M.; Petrovski G.; Gacser A.; Csonka C.; Csont T. The cytoprotective effect of biglycan core protein involves Toll-like receptor 4 signaling in cardiomyocytes. Journal of Molecular and Cellular Cardiology 2016, 99, 138-150. [IF: 5.680]

VIII. Sarkozy M.; Szucs G.; Fekete V.; Pipicz M.; Eder K.; Gaspar R.; Soja A.; Pipis J.; Ferdinandy P.; Csonka C.; Csont T. Transcriptomic alterations in the heart of nonobese type 2 diabetic Goto-Kakizaki rats. Cardiovascular Diabetology 2016, 15, 110. [IF: 4.752]

Cumulative impact factors of other full papers: 36.660

Total cumulative impact factors: $\mathbf{4 4 . 7 8 0}$ 


\section{Table of contents}

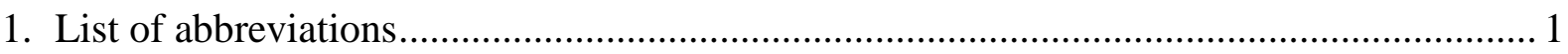

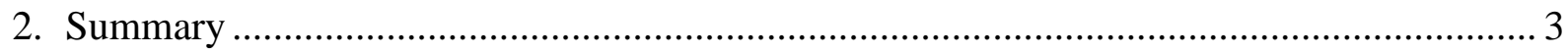

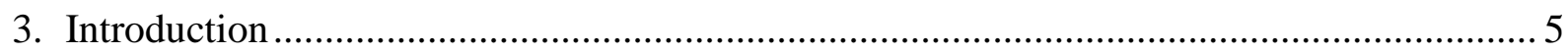

3.1. Ischemic heart disease: an epidemiological burden ................................................. 5

3.2. Ischemia/reperfusion injury: concept of the phenomenon …………………………..... 5

3.3. Classic cardioprotective methods: ischemic conditionings ............................................ 6

3.3.1. Ischemic preconditioning ............................................................................

3.3.2. Ischemic postconditioning ........................................................................... 8

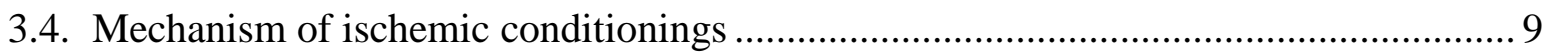

3.4.1. From triggers to end-effector …………………………….............................. 9

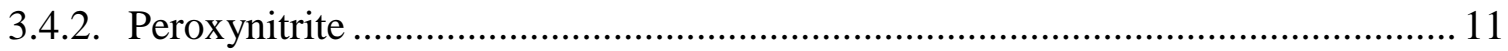

3.4.3. RISK and SAFE pathways: pro-survival signaling cascades ............................... 12

3.5. Alternative approaches: other ways to confer cardioprotection ................................... 12

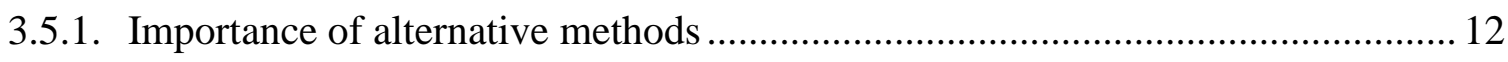

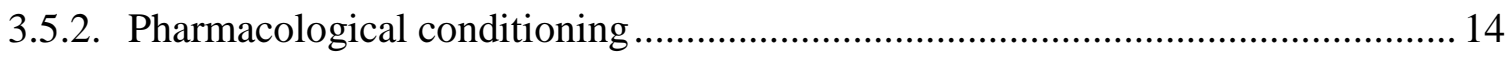

3.5.3. Non-pharmacological conditioning .................................................................... 14

4. Gaps in current knowledge: goals of the thesis............................................................... 16

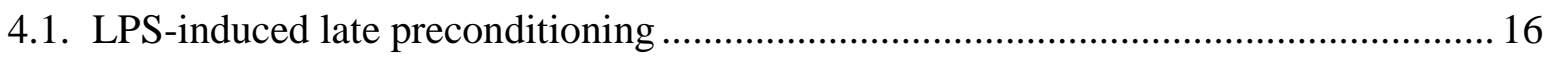

4.2. Rapid ventricular pacing-induced postconditioning................................................. 16

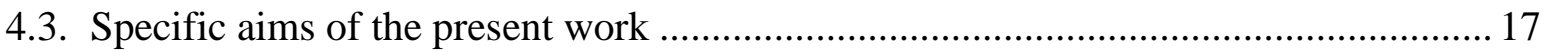

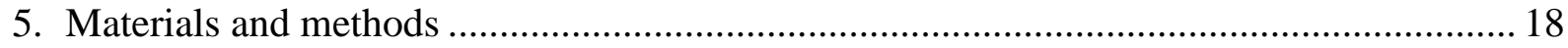

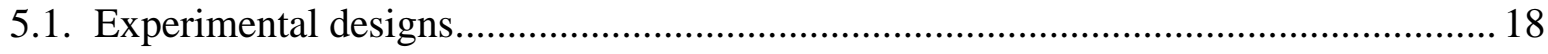

5.1.1. Verifying the late cardioprotective effect of low-dose endotoxin.......................... 18 
5.1.2. Investigating the delayed effects of low-dose endotoxin on myocardial peroxynitrite, RISK and SAFE pathways

5.1.3. Meta-analysis focusing on the relationship of the duration of reperfusion-induced ventricular tachyarrhythmias and infarct size 20

5.1.4. Testing the cardioprotective effect of rapid ventricular pacing 21

5.1.5. Assessing the myocardial peroxynitrite, RISK and SAFE pathways in rapid ventricular pacing-induced postconditioning. 22

5.2. Animals 24

5.3. Materials 24

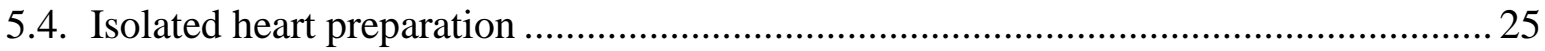

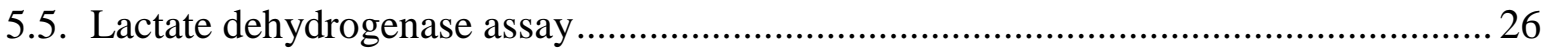

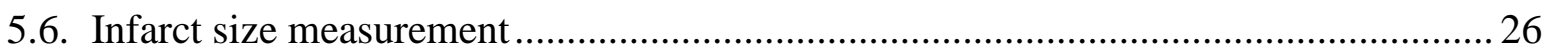

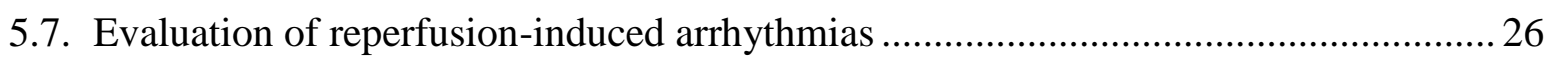

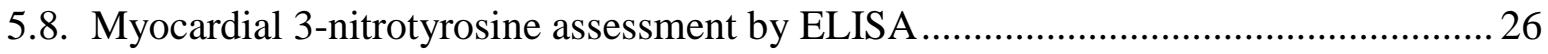

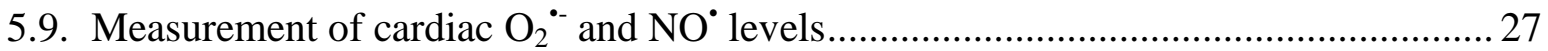

5.10.Assessment of myocardial XOR and NO synthases activities .................................. 28

5.11.Investigation of myocardial RISK and SAFE pathways by Western Blot analysis ..... 28

5.12. Statistical analysis 29

6. Results 30

6.1. Low-dose endotoxin pretreatment improves post-ischemic cardiac function and LDH release: the late cardioprotective effect is verified 30

6.2. LPS pretreatment enhances myocardial 3-nitrotyrosine formation, $\mathrm{O}_{2}{ }^{--}$and $\mathrm{NO}^{\circ}$ production, XOR and NOS activity

6.3. LPS-pretreatment results in enhanced phosphorylation of STAT3, indicating activation of SAFE pathway.

6.4. The duration of reperfusion-induced ventricular tachycardia and/or fibrillation is associated with decreased infarct size 34 
6.5. Rapid ventricular pacing exerts a cardioprotective effect: limits the infarction and reperfusion-induced arrhythmias

6.6. Peroxynitrite is likely involved in rapid ventricular pacing induced-postconditioning 37

6.7. Phosphorylation rate of ERK1/2, Akt, and STAT3 proteins were not changed in rapid ventricular pacing-induced cardioprotection

6.8. Repeated brief periods of rapid ventricular pacing increased STAT3 phosphorylation in the absence of index ischemia

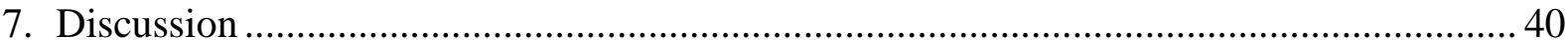

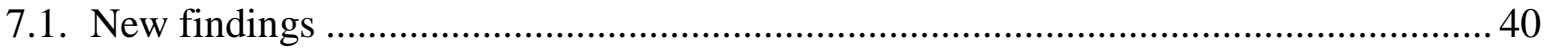

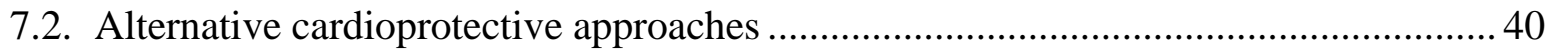

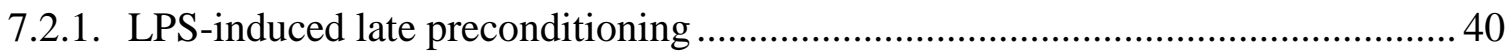

7.2.2. Rapid ventricular pacing-induced postconditioning ..................................... 41

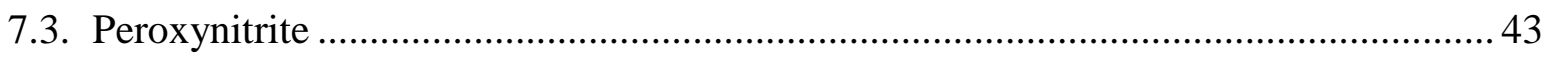

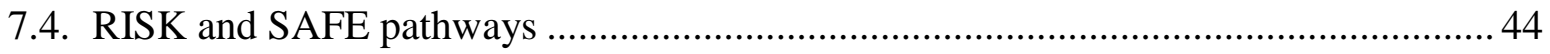

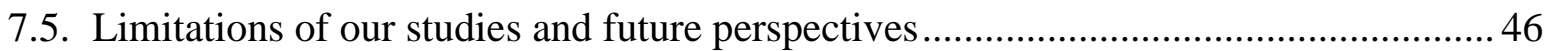

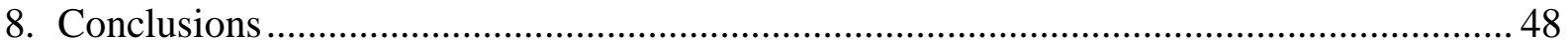

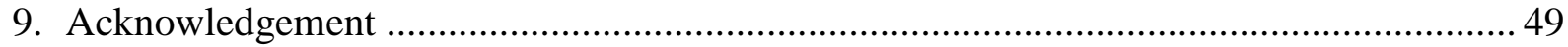

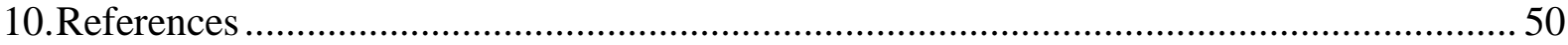

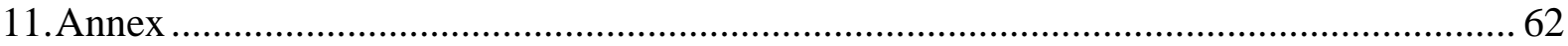




\section{List of abbreviations}

AAR: area at risk

Akt: protein kinase B

ANOVA: analysis of variance

BSA: bovine serum albumin

cGMP: cyclic guanosine monophosphate

$\pm \mathrm{d} p / \mathrm{d} t_{\max }$ : the maximum and minimum of first derivatives of LVDP

DHE: dihydroethidium

ECG: electrocardiogram

ECL: enhanced chemiluminescence

EDTA: ethylenediaminetetraacetic acid

EGTA: egtazic acid

ELISA: enzyme-linked immunosorbent assay

EPR: electron paramagnetic resonance

ERK1/2: extra-cellular signal-regulated kinase 1 and 2

GAPDH: glyceraldehyde 3-phosphate dehydrogenase

GP130: glycoprotein 130

GPCR: G protein-coupled receptor

GSK3ß: glycogen synthase kinase-3 beta

HEPES: 4-(2-hydroxyethyl)-1-piperazineethanesulfonic acid

HRP: Horseradish peroxidase

i/e/n NOS: inducible-, endothelial- and neuronal NOS

$\mathrm{I} / \mathrm{R}:$ ischemia/reperfusion

IGF: insulin-like growth factor

IL: interleukin

ip.: intraperitoneal

IPost: ischemic postconditioning

JAK: Janus kinase

$\mathrm{K}_{\mathrm{ATP}}$ : adenosine triphosphate (ATP)-sensitive potassium channel

LDH: lactate dehydrogenase 
LPS: lipopolysaccharide

LVDP: left ventricular developed pressure

LVEDP: left ventricular end-diastolic pressure

MGD: N-methyl-D-glucamine-dithiocarbamate

MMP: matrix metalloproteinase

mPTP: mitochondrial permeability transition pore

$\mathrm{NO}^{\bullet}$ : nitric oxide

NOS: nitric oxide synthase

NOX: nicotinamide adenine dinucleotide phosphate oxidase

$\mathrm{O}_{2}{ }^{-}$: superoxide

$\mathrm{ONOO}^{-}$: peroxynitrite

P70S6K: ribosomal protein S6 kinase

PI3K: phosphatidylinositol-3-kinase

PKC-PKG: protein kinase $\mathrm{C}$ and $\mathrm{G}$

PMSF: phenylmethylsulfonyl fluoride

RIPA: radioimmunoprecipitation assay

RISK: reperfusion injury salvage kinase

ROI: reactive oxygen intermediates

RTK: receptor tyrosine kinase

RVP: rapid ventricular pacing

S. typhimurium: Salmonella enterica serotype typhimurium

S.E.M.: standard error of the mean

SAFE: survivor activating factor enhancement

SDS-PAGE: sodium dodecyl sulfate-polyacrylamide gelelectrophoresis

SERCA: sarcoendoplasmic reticulum calcium transport ATPase

STAT3: signal transducer and activator of transcription 3

TNF: tumor necrosis factor

TTC: 2,3,4-triphenyl-tetrazolium-chloride

VF: ventricular fibrillation

VT: ventricular tachycardia

XOR: xanthine oxidoreductase 


\section{Summary}

Background and purpose: Ischemic heart diseases including acute myocardial infarction are the leading cause of death. Reperfusion therapy for infarction decreases mortality; however, early reperfusion itself is accompanied by additional cell death known as reperfusion injury. Ischemic pre- and postconditioning are classic strategies to attenuate ischemia/reperfusion injury, and peroxynitrite, RISK (ERK1/2, Akt) as well as SAFE (STAT3) pathways have been already implicated in their cardioprotective mechanism. Many limitations and confounding factors exist regarding classic ischemic conditionings, which indicate the necessity of alternative methods. In this thesis we focused on two distinct alternative conditioning methods, i.e. endotoxin-induced late preconditioning and rapid ventricular pacing (RVP)induced postconditioning. Administration of low-dose endotoxin (lipopolysaccharide, LPS) $24 \mathrm{~h}$ before a lethal ischemia improves post-ischemic cardiac recovery. The exact mechanism of this phenomenon is not clear. Here we aimed to test whether low-dose LPS exerts late effects on peroxynitrite formation and activation of ERK1/2, Akt and STAT3 in the heart. RVP applied before an index ischemia has anti-ischemic effects; nevertheless, the potential cardioprotective effect of rapid heart rate during the reperfusion is not known. In this work we investigated whether ventricular tachyarrhythmias (like ventricular tachycardia (VT) and/or ventricular fibrillation (VF)), developed spontaneously in response to the reperfusion, can influence infarct size, and whether RVP applied after an index ischemia, as a possible novel alternative postconditioning strategy, attenuates reperfusion injury. Peroxynitrite, RISK and SAFE pathways were also examined in the mechanism of RVP-induced postconditioning.

Experimental approaches: Male Wistar rats were used in our studies. In the first study, rats were injected with LPS (S. typhimurium; $0.5 \mathrm{mg} / \mathrm{kg}$ ip.) or saline. Twenty-four hours later, isolated working hearts were subjected to $30 \mathrm{~min}$ global ischemia and $20 \mathrm{~min}$ reperfusion, or hearts were isolated, washed out and then used for biochemical analyses. In the second study, Langendorff perfused rat hearts were subjected to $30 \mathrm{~min}$ regional ischemia and $120 \mathrm{~min}$ reperfusion with or without ischemic postconditioning $(6 \times 10 / 10$-s reperfusion/ischemia; IPost) or RVP (6x10/10-s non-pacing/rapid pacing at $600 \mathrm{bpm})$ applied at the onset of reperfusion, and the extent of infarction was determined by lactate dehydrogenase (LDH) release and standard triphenyl-tetrazolium-chloride staining. In a separate experiment, hearts 
were harvested for biochemical analyses at the $7^{\text {th }} \min$ of reperfusion. In both studies, myocardial samples from ventricles were used freshly or were rapidly freeze-clamped, powdered with a pestle and mortar in liquid nitrogen for further analyses. Peroxynitrite formation was determined indirectly by measuring 3-nitrotyrosine based on an enzyme-linked immunosorbent assay. The activation of ERK1/2, Akt and STAT3 was assessed by determining the phosphorylation rate of these proteins using Western blot analyses.

Key results: LPS-pretreatment significantly improved ischemia/reperfusion-induced deterioration of cardiac function and enhanced cardiac formation of the peroxynitrite marker 3-nitrotyrosine. Low-dose LPS also increased cardiac levels of the peroxynitrite precursor nitric oxide $\left(\mathrm{NO}^{\circ}\right)$ and superoxide. The activities of $\mathrm{Ca}^{2+}$-independent $\mathrm{NO}^{\bullet}$ synthase and xanthine oxidoreductase were increased in LPS-pretreated hearts. LPS-pretreatment resulted in significantly enhanced phosphorylation of STAT3 and non-significantly increased phosphorylation of Akt without affecting the activation of ERK1/2. Meta-analysis of our previous studies revealed an association between longer reperfusion-induced ventricular tachycardia/fibrillation with decreased infarct size. In the present experiments testing whether RVP at the onset of reperfusion is cardioprotective, we found that both IPost and RVP significantly decreased infarct size; however, only RVP attenuated the LDH release and the incidence of reperfusion-induced ventricular tachycardia. Both postconditioning methods increased formation of cardiac 3-nitrotyrosine and superoxide, and non-significantly enhanced Akt phosphorylation at the beginning of reperfusion without affecting ERK1/2 and STAT3. Application of brief ischemia/reperfusion cycles or RVP without preceding index ischemia also facilitated peroxynitrite formation; nevertheless, only brief RVP increased STAT3 phosphorylation.

Conclusions: LPS-pretreatment $24 \mathrm{~h}$ later enhances cardiac peroxynitrite formation and activates STAT3, which may contribute to LPS-induced late preconditioning. Application of short periods of RVP at the onset of reperfusion is cardioprotective similarly to IPost, and thus may serve as an alternative postconditioning method. RVP increases peroxynitrite formation without activating RISK or SAFE. Taken together, peroxynitrite may be somehow involved in both alternative cardioprotective approaches; nevertheless, the role of RISK and SAFE pathways seems to be not clear and partly different in these alternative conditionings. 


\section{Introduction}

\subsection{Ischemic heart disease: an epidemiological burden}

Ischemic heart disease is a group of entities characterized by restriction in blood supply to the heart, leading to functional and/or structural cardiac alterations. The clinical presentations of the disease are asymptomatic silent ischemia, stable angina, unstable angina, myocardial infarction and sudden cardiac death. Ischemic heart diseases were the leading cause of mortality in 2015 with an estimated 8.9 million deaths worldwide (Wang et al., 2016), indicating an epidemiological burden [Table 1].

Table 1. All-cause mortality worldwide in 2015 , both sexes, all-ages

\begin{tabular}{|lcr|}
\hline & CAUSE OF MORTALITY & DEATHS \\
\hline 1. & Ischemic heart diseases & $8,916,964$ \\
2. & Hemorrhagic stroke & $3,348,155$ \\
3. & Chronic obstructive pulmonary diseases & $3,188,326$ \\
4. & Ischemic stroke & $2,977,980$ \\
5. & Lower respiratory infection & $2,736,714$ \\
\hline
\end{tabular}

Although the mortality of ischemic heart diseases has declined in developed societies over the last years, they are still a major cause of death and disability (Mozaffarian et al., 2016; Townsend et al., 2016). The Hungarian Central Statistical Office has shown that 32,825 people died from ischemic heart diseases in Hungary in 2015 (HCSO, 2015). Regarding the number of disease-specific mortality, acute myocardial infarction is one of the major emergency manifestation of ischemic heart diseases, when the heart muscle is irreversibly damaged secondary to a prolonged ischemia resulting in myocardial necrosis.

\subsection{Ischemia/reperfusion injury: concept of the phenomenon}

Prolonged myocardial ischemia usually occurs when a coronary artery is suddenly occluded as a consequence of atherosclerotic plaque rupture with thrombus formation, thereby restricting blood supply to the myocardium. As a result of hypoxia and deprivation of nutrients, ischemia leads to time-dependent cell death (i.e. ischemic injury) (Reimer et al., 1977) [Figure 1]. Thus it is clinically important to restore blood supply as early as possible in order to prevent progressive damage to the myocardium. The procedure that allows rapid 
return of blood flow to the ischemic myocardium is termed reperfusion therapy, which decreases infarct development and mortality of acute myocardial infarction (Ibanez et al., 2017). However, early reperfusion period itself is accompanied by deleterious events such as life-threatening arrhythmias, no-reflow phenomenon, myocardial stunning and additional cell death as well, which is called reperfusion injury (Yellon et al., 2007) [Figure 1]. Therapeutic strategies attenuating ischemia/reperfusion injury has a potential to improve clinical outcomes.

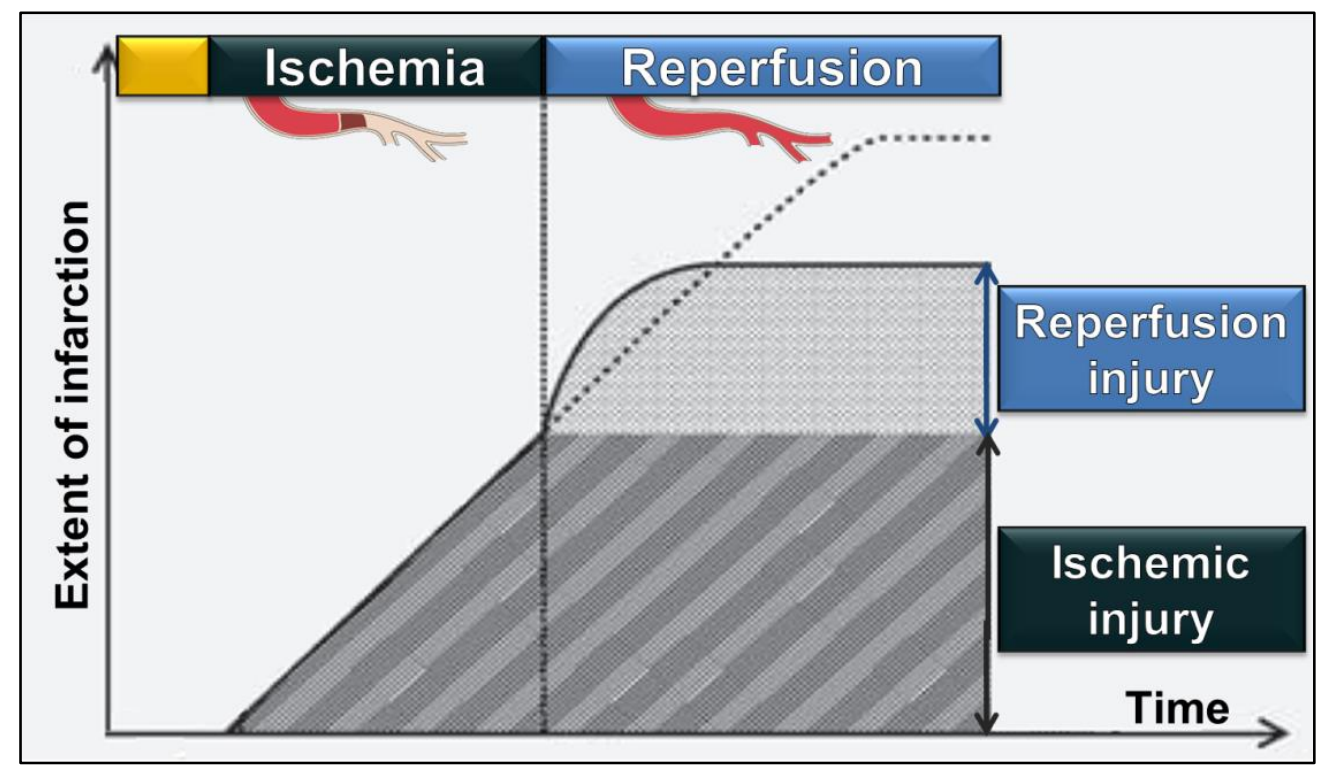

Figure 1. Phenomenon of ischemia/reperfusion injury Adapted from Thibault et al., 2007.

\subsection{Classic cardioprotective methods: ischemic conditionings}

Ischemic conditionings are strategies for protecting the heart against the detrimental effects of ischemia/reperfusion injury, by means of application of brief non-harmful ischemia/reperfusion cycles to elicit endogenous cardioprotective mechanisms [Figure 2] (Hausenloy et al., 2016).

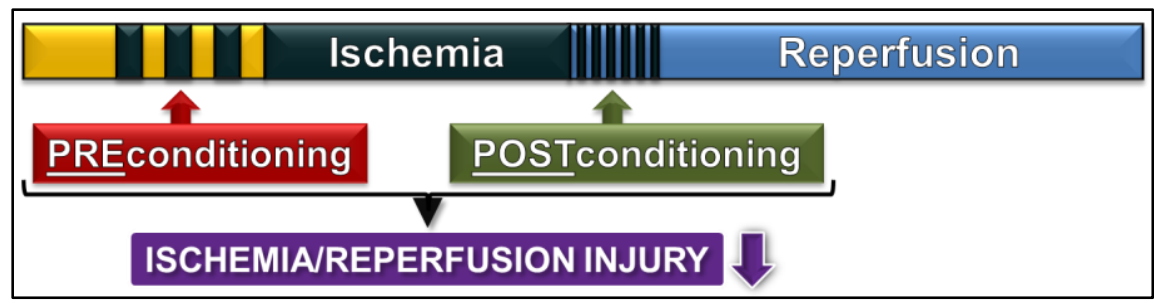

Figure 2. Ischemic conditioning strategies 
When the conditioning method is applied before the prolonged lethal ischemia, it is called ischemic preconditioning [Figure 2]. The strategy used after the sustained ischemia is known as ischemic postconditioning [Figure 2]. These approaches represent the classic cardioprotective conditionings.

\subsubsection{Ischemic preconditioning}

In 1986, Murry and colleagues described first the phenomenon of ischemic preconditioning (Murry et al., 1986). In an open-chest canine model, dogs were subjected to four periods of $5 \mathrm{~min}$ coronary artery occlusion, each separated by 5 min reperfusion, followed by 40-min prolonged ischemia. The preconditioned group had a remarkably smaller adenosine triphosphate depletion and infarct size compared to the control group, indicating that brief episodes of ischemia/reperfusion somehow protect the heart against a subsequent lethal ischemia. Since then the beneficial effect of ischemic preconditioning was also confirmed in many other laboratory species without collateral arteries e.g. in pigs (Schott et al., 1990), rats (Liu et al., 1992), rabbits (Goto et al., 1995) and mice (Miller et al., 1999) as well, proving that the phenomenon is independent of species and presence of coronary collaterals. Beside the effectiveness of infarct size reduction, ischemic preconditioning reduces reperfusion-induced arrhythmias (Shiki et al., 1987) and results in better postischemic functional recovery (Cave et al., 1992). The cardioprotective effect of preconditioning is biphasic with an early phase (lasts for hours) and a late phase (starts $12 \mathrm{~h}$ after preconditioning stimuli and lasts for $\sim 72 \mathrm{~h}$ ) (Yellon et al., 2003). The latter lasts longer and protects against myocardial stunning as well, which makes the late phase of preconditioning clinically more relevant (Stein et al., 2004).

Although clinical application of ischemic preconditioning is limited in the setting of acute myocardial infarction, this cardioprotective strategy can be applied in scheduled medical procedures accompanied by ischemia/reperfusion injury to the heart. In 1993, a group of investigators conducted a study on patients undergoing coronary artery bypass graft surgery (Yellon et al., 1993). They performed a series of aortic clamping and declamping before the surgery to induce intermittent ischemia and reperfusion, respectively. As the end-point of the study, they found preserved myocardial adenosine triphosphate levels in biopsy specimens, indicating cardioprotection. The beneficial impact of ischemic preconditioning on myocardial 
damage was then confirmed in subsequent clinical studies (Jenkins et al., 1997; Laurikka et al., 2002; Ji et al., 2007)

\subsubsection{Ischemic postconditioning}

A research group reported in 2003, that the heart could be protected against ischemia/reperfusion injury by interrupting reperfusion with several brief periods of ischemia (Zhao et al., 2003). They found that after a prolonged ischemia three cycles of 30-s ischemia and 30-s reperfusion at the onset of reperfusion can reduce infarct size in anesthetized openchest dogs. On the analogy of ischemic preconditioning, this phenomenon was termed ischemic postconditioning and was described in various ex vivo and in vivo animal models (Iliodromitis et al., 2006; Philipp et al., 2006; Xi et al., 2008; Penna et al., 2009). Other studies showed that ischemic postconditioning effectively decreases reperfusion-induced ventricular arrhythmias (Kloner et al., 2006) and post-infarct myocardial function (Pinheiro et al., 2009). There is consensus that postconditioning should be applied within the first minute of reperfusion to elicit cardioprotection, later the beneficial effect will disappear (Ovize et al., 2010).

Compared to ischemic preconditioning, postconditioning may be clinically more applicable in the treatment of acute myocardial infarction during the coronary intervention. The experimental procedure was translated into clinical practice in 2005 (Staat et al., 2005). Patients with ST-segment elevation myocardial infarction underwent revascularization by direct stenting. Ischemic postconditioning was performed by inflating and deflating the angioplasty balloon in four cycles after stent implantation. The approach significantly reduced the creatine kinase release which correlates with the extent of myocardial infarction and investigators confirmed the decreased infarct size by single-photon emission computed tomography imaging method. After 1 year, as a result of smaller infarct size, the contractile function of the heart was improved by ischemic postconditioning. Over the last years, several clinical trials have reported the beneficial effect of ischemic postconditioning on infarct size (Darling et al., 2007; Yang et al., 2007; Laskey et al., 2008; Thibault et al., 2008), although the largest study showed inefficiency on patients with ST-segment elevation myocardial infarction (Hahn et al., 2013). 


\subsection{Mechanism of ischemic conditionings}

\subsubsection{From triggers to end-effector}

Both ischemic conditioning approaches may partly share common mechanisms: promote formation of trigger molecules which act on receptor dependent or independent pathways to activate a final end-effector, thereby exerting cardioprotection (Hausenloy et al., 2016) [Figure 3]. Although the exact mechanism is not entirely elucidated, some participating molecules have been identified.
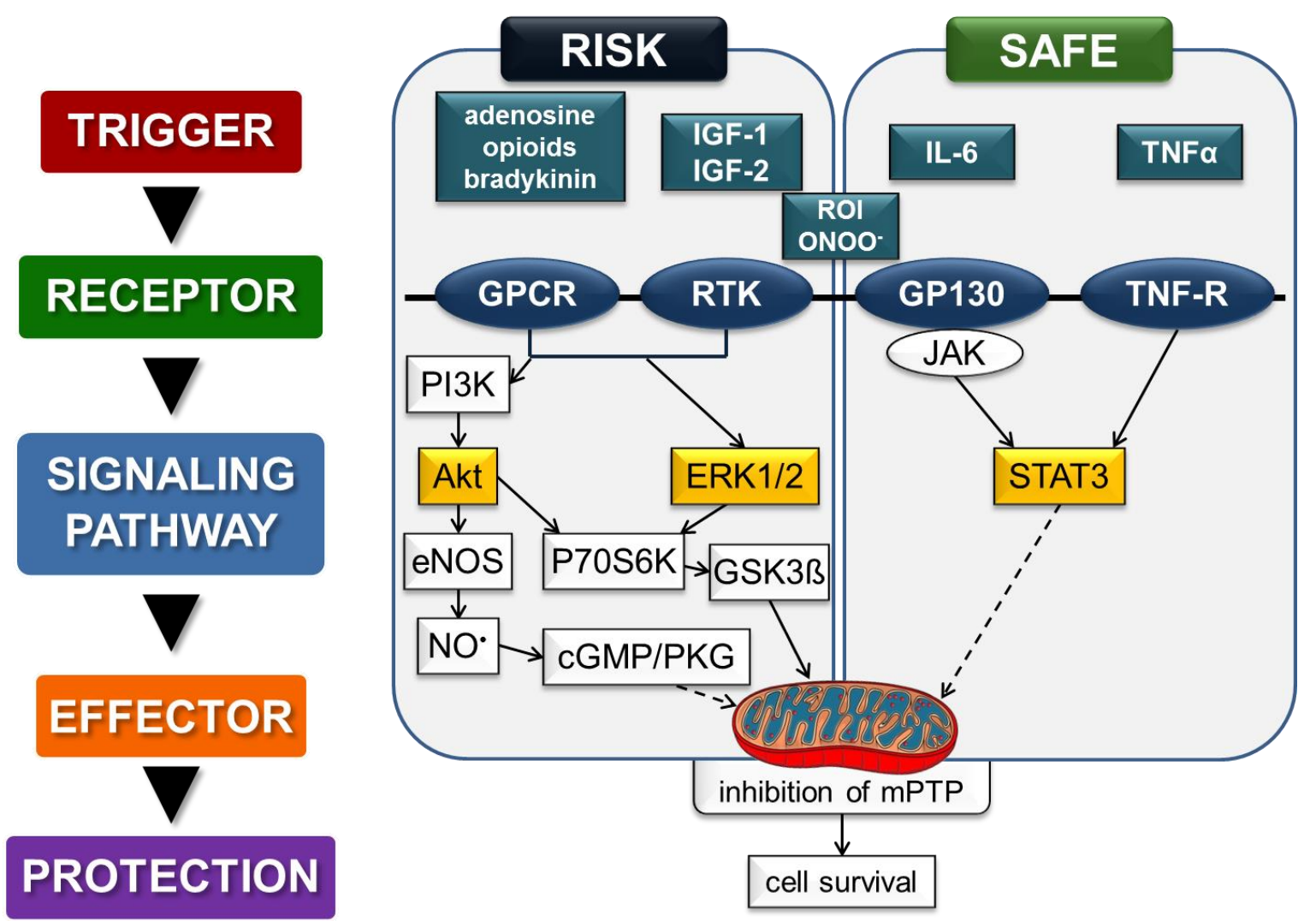

Figure 3. Mechanism of cardioprotection: from triggers to end-effector

Akt: protein kinase B, cGMP: cyclic guanosine monophosphate, eNOS: endothelial nitric oxide synthase, ERK1/2: extracellular signal-regulated kinase 1 and 2, GP130: glycoprotein 130, GPCR: G protein-coupled receptor, GSK3ß: glycogen synthase kinase-3 beta, IGF: insulin-like growth factor, IL: interleukin, JAK: Janus kinase, mPTP: mitochondrial permeability transition pore, $\mathrm{NO}^{\circ}$ : nitric oxide, $\mathrm{ONOO}^{-}$: peroxynitrite, P70S6K: ribosomal protein S6 kinase, PI3K: phosphatidylinositol-3-kinase, PKG: cGMP-dependent protein kinase, RISK: reperfusion injury salvage kinase, ROI: reactive oxygen intermediates, RTK: receptor tyrosine kinase, SAFE: survivor activating factor enhancement, STAT3: signal transducer and activator of transcription 3, TNF $\alpha$ : tumor necrosis factor alpha, TNF-R: TNF receptor 
Adenosine, opioid peptides and bradykinin are thought to be the conventional triggers of ischemic conditionings (Gross et al., 2006). The level of these metabolites increases in response to ischemia, so it is plausible that their release is enhanced during the brief ischemia/reperfusion cycles of preconditioning and leads to cardioprotection. On the other hand, postconditioning delays the wash out of these cardioprotective metabolites accumulated in sustained ischemia, thereby protecting myocardium. The conventional triggers act on corresponding cell-surface receptors (e.g. adenosine 1, delta opioid or bradykinin 2) and their inhibition interfere with the efficacy of conditioning strategies. Over the last decade, reactive oxygen intermediates (Tsutsumi et al., 2007) and peroxynitrite (Altug et al., 2000; Li et al., 2013) have emerged as non-conventional triggers of ischemic conditionings and along with conventional trigger factors recruit pro-survival signaling pathways.

Several protein kinases are implicated in the mediation of cardioprotective effect. The following cascades have already been identified: (1) reperfusion injury salvage kinase(RISK), (2) survivor activating factor enhancement- (SAFE) and (3) cyclic guanosine monophosphate (cGMP)-protein kinase G-protein kinase C (cGMP-PKG-PKC) pathways (Perrelli et al., 2011). These pathways basically are activated during reperfusion in order to promote cell survival. Ischemic conditionings facilitate the activation of these pathways in a receptor dependent (e.g. adenosine) or independent way (e.g. peroxynitrite).

The different types of trigger molecules via signaling pathways are suggested to converge on a final end-effector of cardioprotection (Hausenloy et al., 2016). Mitochondria are the proposed end-effectors. These organelles play an important role in energy- and calcium homeostasis, which are undoubtedly the corner-stones of cell survival (Perrelli et al., 2011). Mitochondrial permeability transition pore $(\mathrm{mPTP})$ is a molecule complex which opens during reperfusion. The opening of the pore disrupts the mitochondrial membrane potential, electron transport chain and oxidative phosphorylation, which eventually lead to severe energy disturbance. These deleterious molecular events contribute to reperfusion injury. Ischemic conditionings inhibit the opening of mPTP (Hausenloy et al., 2009), prevent the harmful molecular events and preserve energy homeostasis. 


\subsubsection{Peroxynitrite}

Peroxynitrite $\left(\mathrm{ONOO}^{-}\right)$arises from the non-enzymatic reaction of superoxide $\left(\mathrm{O}_{2}{ }^{-}\right)$with nitric oxide $\left(\mathrm{NO}^{\circ}\right)$ and the production of peroxynitrite is depending on the concentration of precursors [Figure 4]. Xanthine oxidoreductase (XOR), nicotinamide adenine dinucleotide phosphate oxidases and nitric oxide synthases (NOS) are the primary sources of $\mathrm{O}_{2}{ }^{-\cdots}$ and $\mathrm{NO}^{\circ}$, respectively. It is widely accepted that enhanced peroxynitrite formation contributes to the pathophysiology of several cardiovascular diseases (Pacher et al., 2007). Yasmin et al. reported in 1997 that the level of peroxynitrite increases during reperfusion after a long ischemia, which contributes to reperfusion injury in isolated rat hearts (Yasmin et al., 1997). Further studies also confirmed that enhanced peroxynitrite generation plays a role in the pathophysiology of numerous cardiovascular diseases by inducing oxidative- and nitrosative stress (Pacher et al., 2007). However, evidence suggests that low level of peroxynitrite has an important role in physiological regulation of certain processes such as relaxation of coronary arteries (Liu et al., 1994) or inhibition of platelet aggregation (Ku et al., 1995). In 1997, Lefer demonstrated that peroxynitrite inhibits leukocyte-endothelial cell interaction, which improves the function of post-ischemic myocardium (Lefer et al., 1997). However, increasing evidence suggests that peroxynitrite may be involved in preconditioning (Altug et al., 2000) and postconditioning (Kupai et al., 2009; Li et al., 2013) as well.

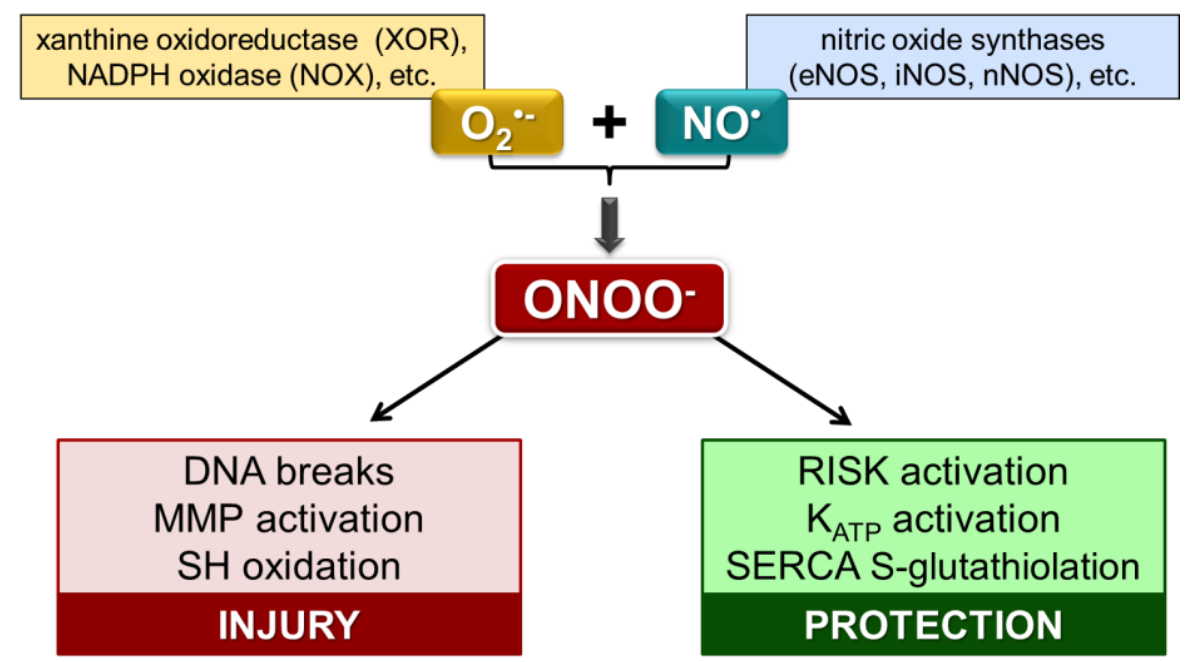

Figure 4. Peroxynitrite: the double-edged sword

DNA: deoxyribonucleic acid, e/i/nNOS: endothelial-, inducible- and neural nitric oxide synthase, $\mathrm{K}_{\mathrm{ATP}}$ : adenosine triphosphate (ATP)-sensitive potassium channel, MMP: matrix metalloproteinase, NO: nitric oxide, NOX: nicotinamide adenine dinucleotide phosphate (NADPH)-oxidase, $\mathrm{O}_{2}{ }^{-}$: superoxide, $\mathrm{ONOO}^{-}$: peroxynitrite, RISK: reperfusion injury salvage kinase, SERCA: sarcoendoplasmic reticulum calcium transport ATPase, SH: sulfhydryl, XOR: xanthine oxidoreductase 


\subsubsection{RISK and SAFE pathways: pro-survival signaling cascades}

RISK and SAFE pathways represent pro-survival kinase cascades [Figure 3] activated at the time of reperfusion in response to ischemia/reperfusion, and elicited by ischemic conditioning strategies for cell survival.

In 2002, Yellon and colleagues have concluded that p44/p42 mitogen-activated protein kinases also known as extra-cellular signal-regulated kinase 1 and 2 (ERK1/2) may play a role in urocortin-induced protection against reperfusion injury, and the heart may possess reperfusion injury salvage kinases (Schulman et al., 2002). Later, they termed ERK1/2 and phosphatidylinositol-3-kinase (PI3K)-protein kinase B (Akt) as the RISK pathway (Hausenloy et al., 2004) [Figure 3]. These kinases are activated by a wide variety of molecules (e.g. adenosine, bradykinin, insulin like growth factors) through the activation of G-protein-coupled receptors and receptor tyrosine kinase. RISK pathway has been implicated in various pro-survival cellular processes by phosphorylating diverse downstream targets (e.g. caspase 3, BAX, endothelial NOS, glycogen synthase kinase-3, p53), resulting in inhibition of apoptosis, preventing the opening of $\mathrm{mPTP}$ and enhancing expression of genes associated with cellular survival (Hausenloy et al., 2004).

A RISK-independent alternative cardioprotective pathway was postulated by Lecour and coworkers (Lecour et al., 2005) and they have called it as the SAFE pathway, which involves the Janus kinase (JAK) and signal transducer and activator of transcription 3 (STAT3) [Figure 3]. JAK is associated with membrane receptors and activated when ligands (like tumor necrosis factor alpha (TNF $\alpha$ ) or interleukin 6) bind to the membrane receptor (Lecour, 2009b). Subsequently, STAT3 is phosphorylated and translocated to the nucleus, resulting in alteration of stress-responsive gene expression involved in cardioprotection (Lecour, 2009a).

\subsection{Alternative approaches: other ways to confer cardioprotection}

\subsubsection{Importance of alternative methods}

Ischemic pre- and postconditioning seems to be effective cardioprotective approaches; nevertheless, there are many limitations and confounding factors which indicated and indicate nowadays the necessity of developing alternative methods of classic ischemic conditionings.

First of all, ischemia/reperfusion maneuvers can be solely applied in the heart by invasive procedures, resulting in direct mechanical stress to tissues. Moreover it is not predictable 
when the acute myocardial infarction happens, which limits the usefulness of ischemic preconditioning in setting of acute ischemia/reperfusion injury.

Second, although ischemic postconditioning has a great potential in clinical application, it seems to be less robust and ambiguous in cardioprotection compared to ischemic preconditioning. A large number of controversial results are available in the literature about the efficacy of ischemic postconditioning (Skyschally et al., 2009b). There are many possible explanations for these controversial results. The beneficial outcome of postconditioning depends on several factors: (1) species, strain, gender, age of research animal; (2) experimental model and set up; (3) the duration of index ischemia before reperfusion; (4) number and duration of brief ischemia/reperfusion cycles; (5) temperature (Skyschally et al., 2009b). Beneficial effect of ischemic postconditioning is primarily based on the intermittent coronary flow which vastly depends on the postconditioning maneuver (that is the application of brief ischemia/reperfusion cycles). In small animal models, it is technically difficult to carry out the maneuver in a standard way.

Third, many clinical trials failed to prove the efficacy of ischemic conditioning approaches. Numerous explanations exist why the translation of experimental conditionings into clinical setting is limited. According to a widely accepted concept in the literature (Ferdinandy et al., 2007), the main cause of limited translation is that the preclinical experiments are carried out using healthy, young and male animals. In the clinical practice, ischemic heart diseases occur typically in patients of both genders who are aged and have several comorbidities like hyperlipidemia, diabetes mellitus or hypertension. A number of evidence suggests that these comorbidities interfere with endogenous myocardial adaptation elicited by ischemic conditionings. Therefore, it is currently a new research field that focuses on the revealing of underlying mechanisms of interference between comorbidities and ischemic conditionings. These studies may identify potential target molecules to restore the endogenous adaptive mechanisms of the heart.

The above detailed factors contributed to develop alternative approaches of ischemic conditionings. For instance, both conditioning methods can be elicited by a wide variety of pharmacological (e.g. antioxidants, cyclosporine, endotoxin) and non-pharmacological (e.g. heat stress, exercise, rapid ventricular pacing) stimuli as well (Bolli, 2000; Baxter et al., 2001) to confer cardioprotection. 


\subsubsection{Pharmacological conditioning}

The intensive research into the revealing of underlying molecular mechanisms of ischemia/reperfusion injury and cardioprotection results in investigating pharmacological agents which mimic the cardioprotective effect of ischemic conditionings. These pharmacons inhibit the cellular events that lead to ischemia/reperfusion injury and/or can activate mechanisms playing a role in ischemic conditionings.

Numerous agents (e.g. antioxidants, $\mathrm{Na}^{+}-\mathrm{H}^{+}$exchanger inhibitors, anti-inflammatory drugs) have been tested to reduce reperfusion injury by targeting harmful cellular events (Yellon et al., 2007). In addition, many naturally occurring ligands (for instance adenosine, bradykinin, opioids) display cardioprotective properties when administered exogenously in the setting of ischemia/reperfusion (Gross et al., 2006). Among these agents, atrial natriuretic peptide and cyclosporine have yielded promising results in both animal and clinical studies (Ovize et al., 2010). Cyclosporine seems to be the most effective drug, which inhibits the opening of mitochondrial permeability transition pore (a proposed essential step in reperfusion injury) and ameliorate energy disturbance during reperfusion by improving mitochondrial respiration function (Piot et al., 2008).

Another well-documented cardioprotective drug is the gram-negative bacterial lipopolysaccharide (LPS) endotoxin. Specifically, administration of low-dose endotoxin $24 \mathrm{~h}$ before a test ischemia/reperfusion has been shown to improve post-ischemic cardiac functional recovery and creatine kinase leak as well (Brown et al., 1989; Meldrum et al., 1996). LPS seems to increase endogenous antioxidant capacity of the heart, thereby blunting harmful oxidative stress during ischemia/reperfusion (Bensard et al., 1990).

\subsubsection{Non-pharmacological conditioning}

It is well established that beside the pharmacological approaches many other ways (e.g. exercise, heat, rapid ventricular pacing, etc.) exit to recruit endogenous adaptive mechanisms of the myocardium and improve tolerance to ischemia/reperfusion.

Exercise-induced cardioprotection is an old and extensively studied phenomenon in animals: repeated bouts of exercise before myocardial ischemia elicit reduction in infarct size, and the protection seems to be biphasic similarly to ischemic preconditioning (Frasier et al., 2011). In accordance with animal studies, human epidemiologic data shows that regular 
exercise protects against ischemia and its consequences in coronary heart diseases (Morris et al., 1980).

Sublethal whole-body thermal stress (hyperthermia) can attenuate myocardial ischemia/reperfusion injury and deterioration of ventricular function (Currie et al., 1988). Later it was reported that local heating of the heart also confers myocardial salvage (Gowda et $a l ., 1998)$. Heat shock proteins have been implicated as mediators of the protection (Marber $e t$ al., 1993; Kingma, 1999).

Heart rate is known to play a role in the development of ischemia/reperfusion injury (Bernier et al., 1989), and it was shown that induction of either slow- or rapid heart rate before ischemia limits myocardial injury (Tosaki et al., 1988; Hearse et al., 1999). Moreover, we have shown previously that short periods of rapid ventricular pacing applied before an index ischemia has anti-ischemic effects (pacing-induced preconditioning) (Ferdinandy et al., 1997a; Ferdinandy et al., 1997b; Ferdinandy et al., 1998). 


\section{Gaps in current knowledge: goals of the thesis}

Developing and testing alternative conditioning approaches is indispensable to elucidate and understand cardioprotection. In order to improve our knowledge, in this thesis we focused on two distinct alternative methods of ischemic pre- and postconditioning, i.e. LPS-induced late preconditioning and rapid ventricular pacing-induced postconditioning. Regarding these approaches many knowledge gaps exist in the literature, what we aimed to address.

\subsection{LPS-induced late preconditioning}

The exact mechanism of endotoxin-induced late preconditioning is not entirely clear. NO${ }^{\circ}$ has been implicated as a mediator, and inducible NO ${ }^{\circ}$ synthase (iNOS) has been identified as a major source of $\mathrm{NO}^{*}$ in endotoxin-induced late preconditioning in the heart (Wang et al., 2002; Portnychenko et al., 2005; Wang et al., 2011). Beside NO, indirect evidence suggests that $\mathrm{O}_{2}{ }^{\circ-}$ may also be involved in endotoxin-induced late cardioprotection (Brown et al., 1989; Maulik et al., 1995). Increasing evidence suggests that enhanced formation of cardiac peroxynitrite plays a role in early (Altug et al., 2000; Csonka et al., 2001) and late phase of ischemia-induced delayed preconditioning as well (Tang et al., 2002). However, data is still lacking regarding the delayed effect of cardioprotective low-dose LPS on peroxynitrite formation in the heart.

Cardioprotective signaling pathways are barely investigated in late preconditioning elicited by LPS. The well-known RISK and SAFE pathways have been implicated in the mechanism of ischemic and certain types of pharmacological late preconditioning (Bolli, 2000; Das et al., 2008). In LPS-induced late preconditioning the activation of Akt, a protein kinase of RISK pathway was shown to play a role (Ha et al., 2008); nevertheless, potential implication of ERK1/2, another RISK kinases, and STAT3, the key member of SAFE, has not yet been tested.

\subsection{Rapid ventricular pacing-induced postconditioning}

As we described above, the cardioprotective outcome of ischemic postconditioning depends on several factors (for instance, failure to achieve complete reperfusion during application of brief ischemia/reperfusion cycles, the algorithm of postconditioning maneuver or presence of comorbidities), which indicates the necessity to develop new alternative 
approaches (Skyschally et al., 2009b). Heart rate is suggested to influence the extent of ischemia/reperfusion injury (Bernier et al., 1989), and our group has introduced the preconditioning effect of short periods of rapid ventricular pacing applied before a sustained ischemia (Ferdinandy et al., 1997a). Nevertheless, it is not known whether the ventricular tachyarrhythmias (like ventricular tachycardia (VT) and/or ventricular fibrillation (VF)), developed spontaneously in response to the reperfusion, can influence the final infarct size. Furthermore, the potential cardioprotective effect of short periods of rapid ventricular pacing performed at the early phase of reperfusion has not been investigated so far as a possible novel alternative postconditioning strategy.

The exact molecular mechanism of myocardial postconditioning is not entirely clear. Increasing evidence suggests that enhanced formation of cardiac peroxynitrite (Kupai et al., 2009; Li et al., 2013), RISK and SAFE pathways (Perrelli et al., 2011) may be involved in cardioprotection afforded by ischemic postconditioning. The effects of short periods of rapid ventricular pacing on myocardial peroxynitrite, and possible downstream signaling targets are not known.

\subsection{Specific aims of the present work}

In order to fulfil the above mentioned gaps in the current knowledge, the two proposed alternative methods were tested and the following specific questions were addressed:

1. Has the low-dose cardioprotective LPS any delayed effect on myocardial peroxynitrite formation in endotoxin-induced late preconditioning?

2. How does the low-dose LPS treatment affect the cardiac RISK and SAFE pathways in the late phase of endotoxin-induced preconditioning?

3. Is there an association between the duration of reperfusion-induced ventricular tachyarrhythmias (VT, VF, or VT+VF) and infarct size?

4. Could the short periods of rapid ventricular pacing performed at the early phase of reperfusion attenuate reperfusion injury and induce postconditioning?

5. Is peroxynitrite potentially involved in the rapid ventricular pacing-induced postconditioning?

6. What is the effect of rapid ventricular pacing-induced postconditioning on the possible myocardial downstream targets, RISK and SAFE pathways? 


\section{Materials and methods}

\subsection{Experimental designs}

In this work different experimental designs were set-up to address our aims. Technical details of the methods are indicated in later subsections.

\subsubsection{Verifying the late cardioprotective effect of low-dose endotoxin}

Male Wistar rats were treated intraperitoneally with saline or low-dose $(0.5 \mathrm{mg} / \mathrm{kg}) \mathrm{LPS}$ from Salmonella enterica serotype typhimurium ( $n=6-7$ in both groups). Twenty four hours after LPS treatment, hearts were isolated and perfused according to Langendorff for $5 \mathrm{~min}$ [Figure 5]. Then the perfusion system was switched to working mode according to Neely with recirculating buffer (Csont et al., 2002; Csont et al., 2003). Hearts were subjected to $10 \mathrm{~min}$ equilibration period followed by $30 \mathrm{~min}$ normothermic global ischemia and $20 \mathrm{~min}$ reperfusion. Before ischemia and at the end of reperfusion cardiac functional parameters including heart rate, coronary flow, aortic flow, left ventricular end-diastolic pressure were measured, left ventricular developed pressure and the maximum and minimum of its first derivatives $\left( \pm \mathrm{d} p / \mathrm{d} t_{\max }\right)$. To estimate the severity of cellular damage in the heart, the activity of lactate dehydrogenase was measured from coronary effluents.

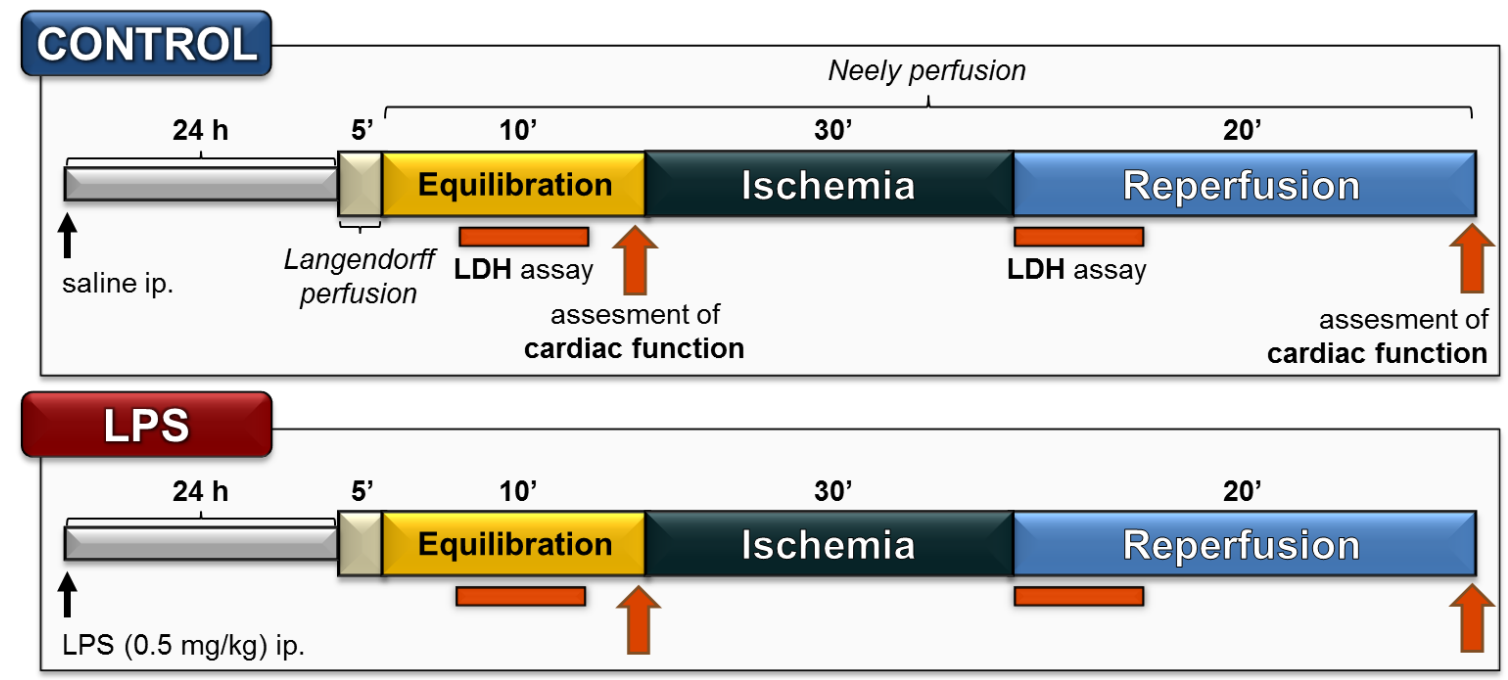

Figure 5. Protocol for verifying the late cardioprotective effect of low-dose endotoxin After intraperitoneal (ip.) saline injection or lipopolysaccharide (LPS) treatment, isolated working rat hearts were subjected to ischemia/reperfusion ( $n=6-7$ in both groups). Lactate dehydrogenase (LDH) activity from coronary effluent, and cardiac function were assessed. Langendorff or Neely perfusion represents non-working or working mode, respectively. 


\subsubsection{Investigating the delayed effects of low-dose endotoxin on myocardial peroxynitrite, RISK and SAFE pathways}

In separate experiments [Figure 6], $24 \mathrm{~h}$ after the intraperitoneal injection of saline or $0.5 \mathrm{mg} / \mathrm{kg}$ LPS, hearts were subjected to $5 \mathrm{~min}$ Langendorff perfusion to wash out blood $(n=7-$ 12 in both groups). Then the hearts were harvested. After removing of atria, ventricles were used freshly or were rapidly freeze-clamped, powdered with a pestle and mortar in liquid nitrogen, and stored in cryovials at $-80{ }^{\circ} \mathrm{C}$ until further analysis.

To assess the delayed effect of cardioprotective LPS on peroxynitrite formation, the level of cardiac 3-nitrotyrosine, a well-known maker of peroxynitrite was measured by enzymelinked immunosorbent assay (ELISA). The precursors of peroxynitrite, $\mathrm{O}_{2}{ }^{--}$and $\mathrm{NO}^{\circ}$ were also evaluated by lucigenin-enhanced chemiluminescence (ECL) assay and spin trapping followed by electron paramagnetic resonance (EPR) spectroscopy, respectively. To reveal the possible source of cardiac $\mathrm{O}_{2}{ }^{--}$and $\mathrm{NO}^{\circ}$ induced by low-dose LPS, activity of XOR and NOS were measured. The activation of ERK1/2, Akt and STAT3 was assessed by determining the phosphorylation rate of these proteins on Western blot analyses.

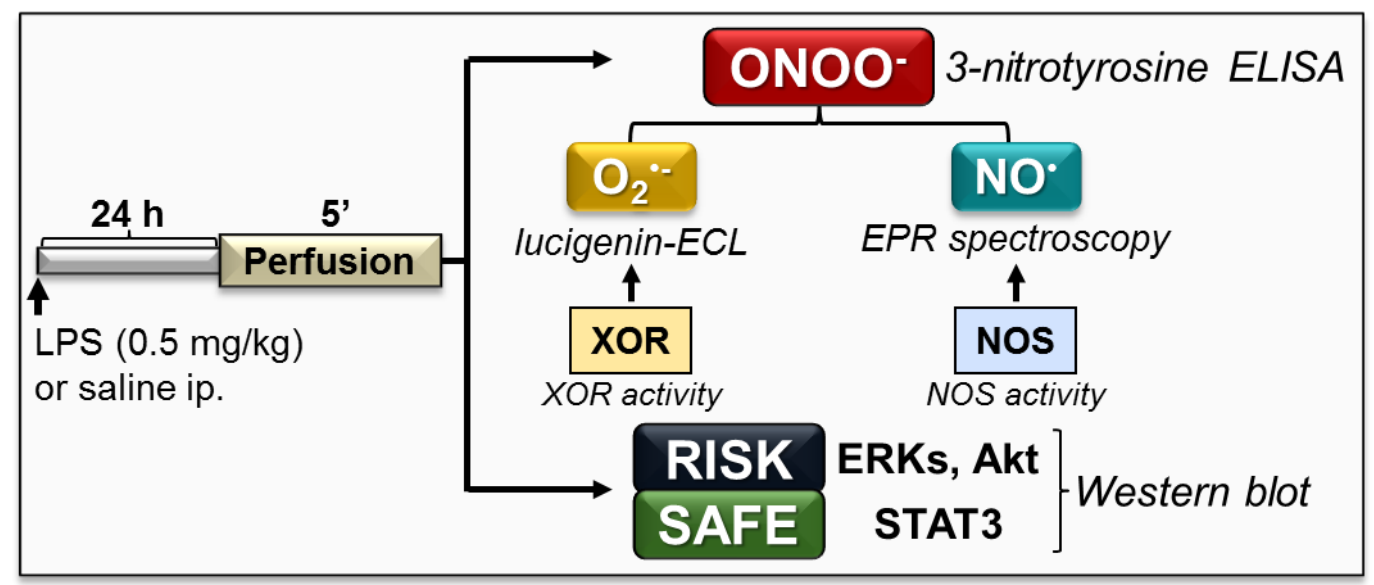

Figure 6. Experimental design for investigating the delayed effects of low-dose endotoxin on myocardial peroxynitrite, RISK and SAFE pathways

After intraperitoneal (ip.) lipopolysaccharide (LPS) treatment, isolated rat hearts were harvested for biochemical analyses ( $n=7-12$ in both groups). Akt: protein kinase B, ECL: enhanced chemiluminescence, ELISA: enzyme-linked immunosorbent assay, EPR: electron paramagnetic resonance, ERKs: extra-cellular signal-regulated kinases, NO: nitric oxide, NOS: nitric oxide synthases, $\mathrm{O}_{2}{ }^{-}$: superoxide, $\mathrm{ONOO}^{-}$: peroxynitrite, RISK: reperfusion injury salvage kinase, SAFE: survivor activating factor enhancement, STAT3: signal transducer and activator of transcription 3, XOR: xanthine oxidoreductase 


\subsubsection{Meta-analysis focusing on the relationship of the duration of reperfusion-induced ventricular tachyarrhythmias and infarct size}

In order to address the question whether there is an association between the duration of reperfusion-induced ventricular tachyarrhythmias and infarct size, a meta-analysis was performed. Electrocardiograms (ECG) and infarct size data were analyzed from our six previous studies done in our laboratory on isolated rat hearts subjected to 30 min regional ischemia and $120 \mathrm{~min}$ reperfusion [Figure 7]. Reperfusion-induced arrhythmias were analyzed in the first $10 \mathrm{~min}$ of reperfusion. Hearts presenting sustained (>10 min) tachyarrhythmia were excluded $(n=14)$. Three separate evaluations were done based on total duration of VT, VF, or VT+VF, respectively. Infarct size data were presented on the basis of duration (shorter or longer than $60 \mathrm{~s}$ ) of VT, VF, or VT+VF. Infarct size data exceeding mean \pm two standard deviations were excluded from the analysis $(n=6)$.

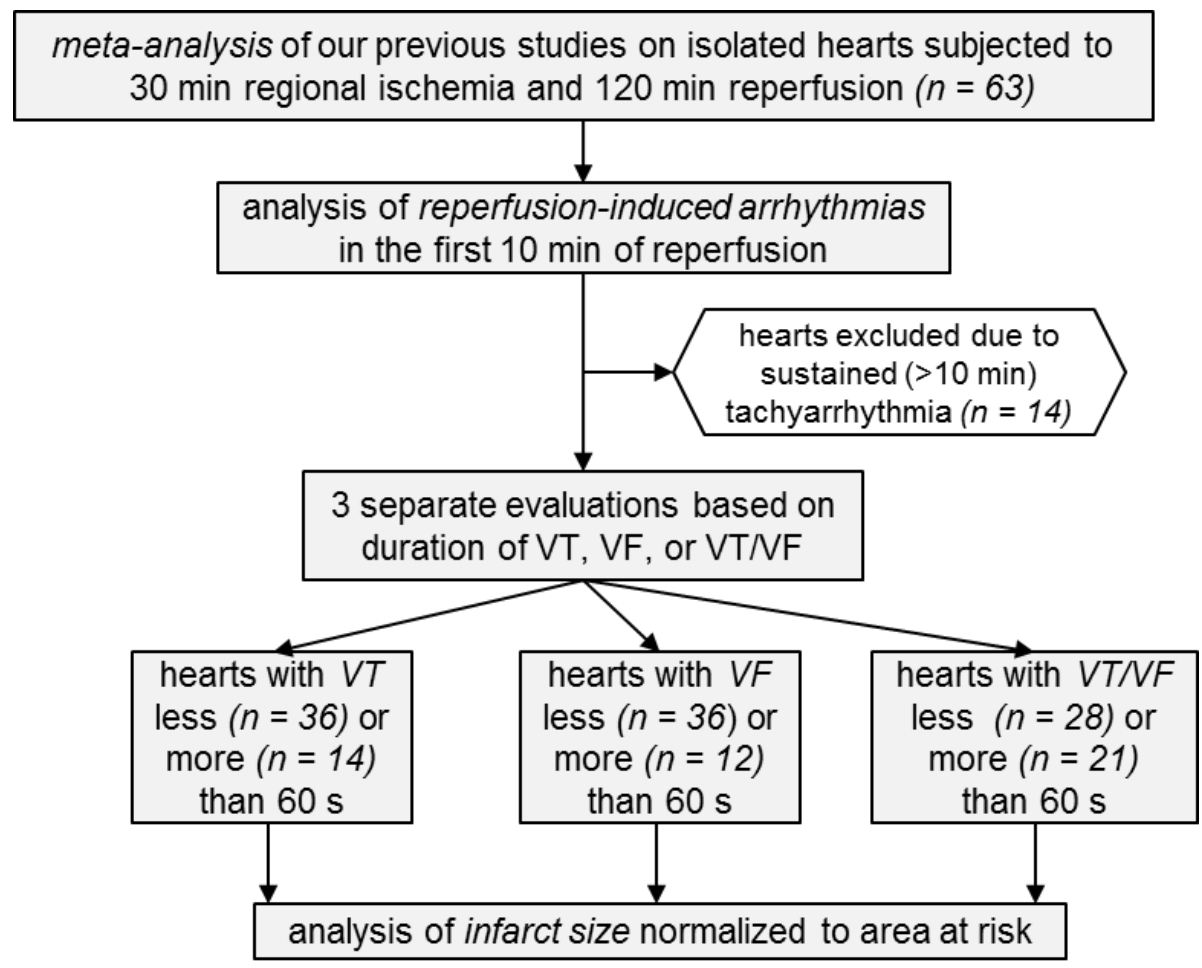

Figure 7. The algorithm of meta-analysis focusing on the relationship of the duration of reperfusioninduced ventricular tachyarrhythmias and infarct size

Flow chart of the meta-analysis indicates that reperfusion-induced tachyarrhythmias and infarct size data from our previous studies (on isolated rat hearts subjected to $30 \mathrm{~min}$ regional ischemia and $120 \mathrm{~min}$ reperfusion) were analyzed in three separate ways considering the duration of either ventricular tachycardia (VT), ventricular fibrillation (VF) or both in the first $10 \mathrm{~min}$ of reperfusion. 


\subsubsection{Testing the cardioprotective effect of rapid ventricular pacing}

To examine whether rapid ventricular pacing applied at the onset of reperfusion induces cardioprotection, isolated hearts were perfused as shown on Figure 8. Three experimental groups were designed: (1) ischemia/reperfusion control, (2) ischemic postconditioning, (3) and rapid ventricular pacing groups. The ischemia/reperfusion control group was subjected to $15 \mathrm{~min}$ equilibration period, followed by $30 \mathrm{~min}$ regional index ischemia and $120 \mathrm{~min}$ reperfusion. Ischemic postconditioning was induced by six consecutive cycles of $10 \mathrm{~s}$ reperfusion and $10 \mathrm{~s}$ no-flow global ischemia at the onset of reperfusion. In the rapid ventricular pacing group the spontaneous rhythm of hearts was replaced by 10 -s pacing period $(600 \mathrm{bpm} ; 10 \mathrm{~Hz})$ in 6 alternating cycles during the first $2 \mathrm{~min}$ of reperfusion. The extent of myocardial injury was assessed by post-ishemic LDH release ( $n=5$ in each group), and infarct size was determined by standard 2,3,4-triphenyl-tetrazolium-chloride (TTC) staining at the end of reperfusion ( $n=12$ in each group). To assess reperfusion-induced tachyarrhythmias (VT and VF), ECG was recorded during entire perfsuion protocol ( $n=11-14$ in each group).

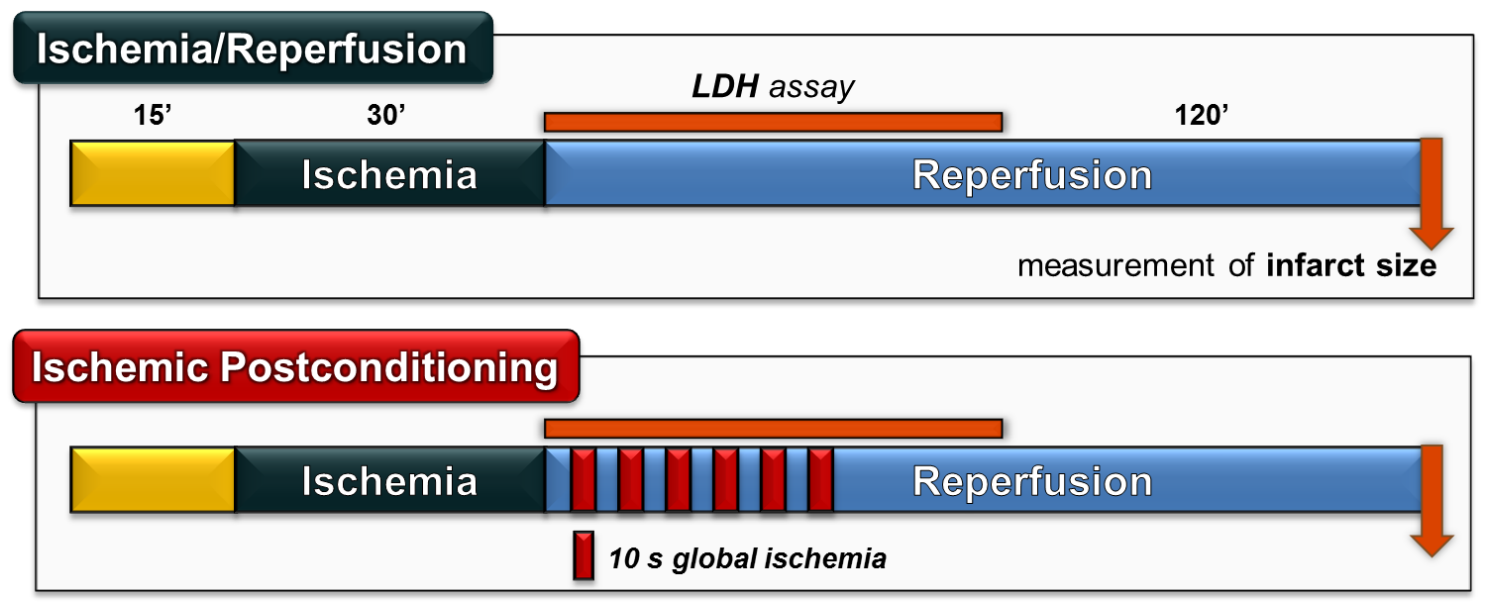

\section{Rapid Ventricular Pacing}

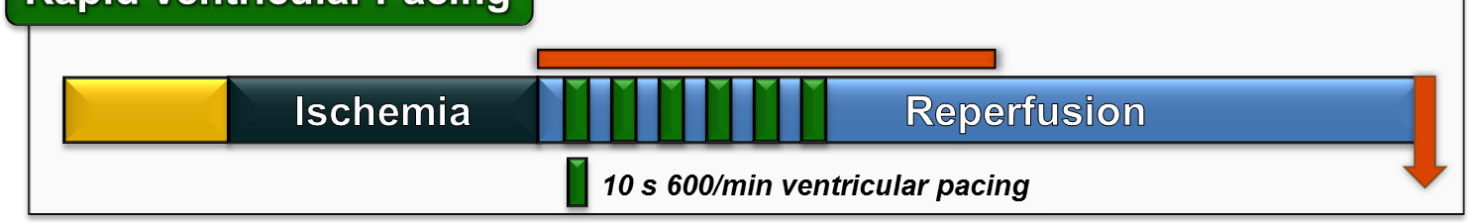

Figure 8. Experimental protocol for testing the cardioprotective effect of rapid ventricular pacing Langendorff perfused rat hearts were subjected to $30 \mathrm{~min}$ regional ischemia and $120 \mathrm{~min}$ reperfusion with or without ischemic postconditioning (6x10/10-s reperfusion/ischemia) or rapid ventricular pacing (6x10/10-s non-pacing/rapid pacing at $600 \mathrm{bpm})$ during the first $2 \mathrm{~min}$ of reperfusion. Lactate dehydrogenase (LDH) activity from coronary effluent $(n=5$ in each group), and infarct size were assessed ( $n=12$ in each group). 


\subsubsection{Assessing the myocardial peroxynitrite, RISK and SAFE pathways in rapid ventricular pacing-induced postconditioning}

Hearts were subjected to $15 \mathrm{~min}$ equilibration period, followed by $30 \mathrm{~min}$ regional ischemia and 7 min reperfusion with or without ischemic postconditioning or rapid ventricular pacing [Figure 9]. At the end of reperfusion myocardial samples were taken from the ischemic zone of the left ventricle. Sampling was done by an oblique cut from the origin of the left anterior descending coronary artery toward the right side of the apical area that involves the majority of the anterior wall of the left ventricle as well as the apex of the heart. Samples were rapidly freeze-clamped, powdered with a pestle and mortar in liquid nitrogen, and stored in cryovials at $-80{ }^{\circ} \mathrm{C}$ until further biochemical analyses. Tissue sections were sampled for in situ detection of $\mathrm{O}_{2}^{--}$anion in separate experiments ( $n=3$ in each group) using the same perfusion protocol [Figure 9].

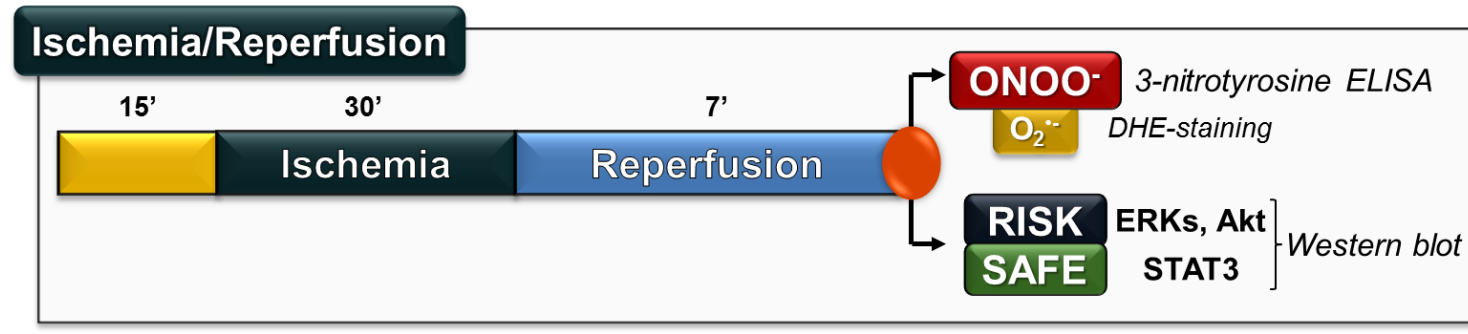

\section{Ischemic Postconditioning}

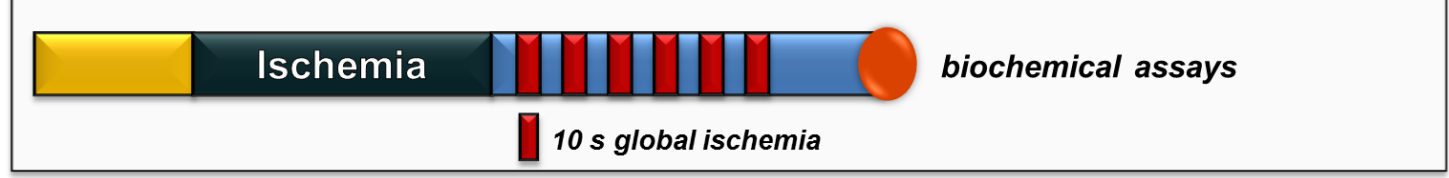

\section{Rapid Ventricular Pacing}

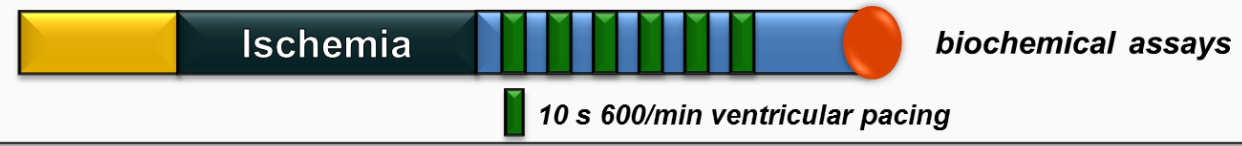

Figure 9. Experimental design for assessing the myocardial peroxynitrite, RISK and SAFE pathways in rapid ventricular pacing-induced postconditioning

Isolated rat hearts subjected to ischemia/reperfusion with or without postconditioning were harvested for biochemical analyses. The peroxynitrite $\left(\mathrm{ONOO}^{-}\right)$marker, 3-nitrotyrosine was quantified by enzyme-linked immunosorbent assay (ELISA; $n=5$ in each group). Superoxide $\left(\mathrm{O}_{2}{ }^{-}\right)$was detected by dihydroethidium (DHE) staining ( $n=3$ in each group). Activation of reperfusion injury salvage kinase- (RISK) and survivor activating factor enhancement- (SAFE) pathway was assessed by western blot ( $n=5$ in each group). Akt: protein kinase B, ERKs: extra-cellular signal-regulated kinases, STAT3: signal transducer and activator of transcription 3 
The peroxynitrite marker, cardiac 3-nitrotyrosine was determined by ELISA ( $n=5$ in each group) [Figure 9]. Myocardial $\mathrm{O}_{2}{ }^{--}$, a precursor of peroxynitrite, was also measured by in situ detection based on dihydroethidium staining. Furthermore, activation of RISK and SAFE pathways as possible downstream targets of rapid ventricular pacing-induced postconditioning were also investigated on Western blots ( $n=5$ in each group).

To further investigate the possible effect of both ischemic postconditioning and rapid ventricular pacing protocols (i.e. application of brief ischemia/reperfusion or rapid ventricular pacing) on myocardial peroxynitrite, RISK and SAFE pathways, the cardioprotective protocols were examined in the absence of preceding index ischemia. In this set of experiments, the time course of perfusion protocol was adjusted to the previous setup without index ischemia [Figure 10].

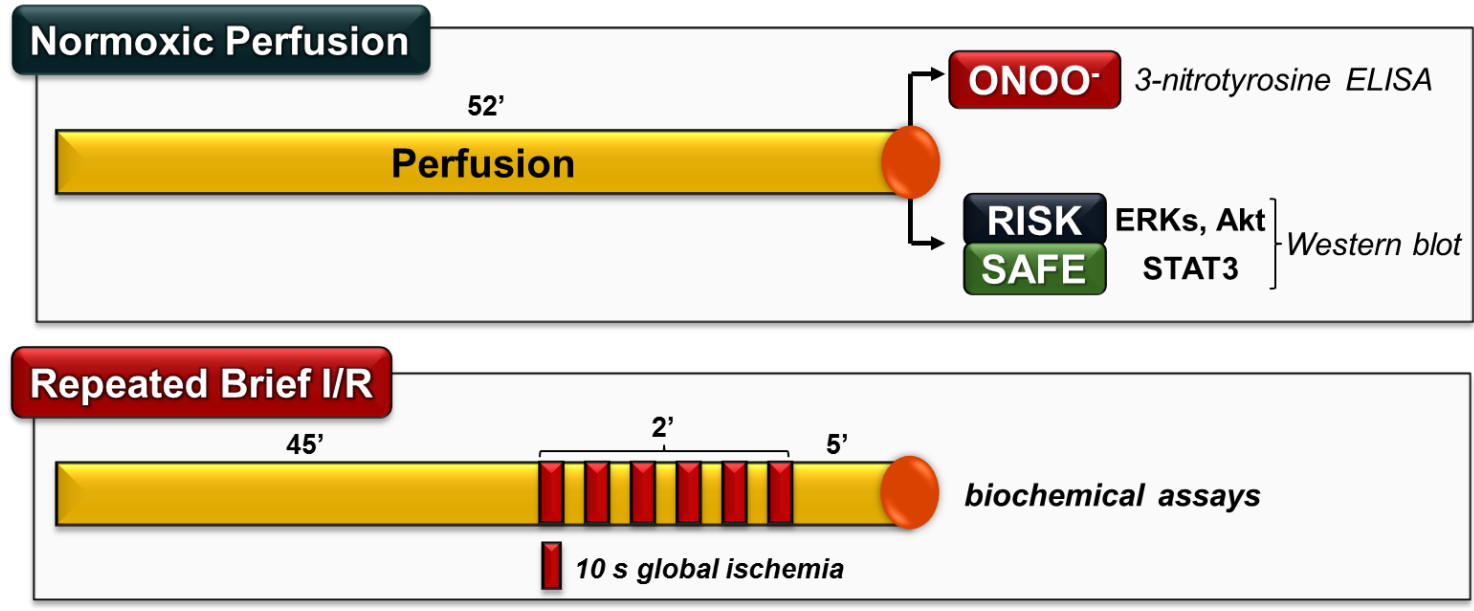

\section{Repeated Brief RVP}

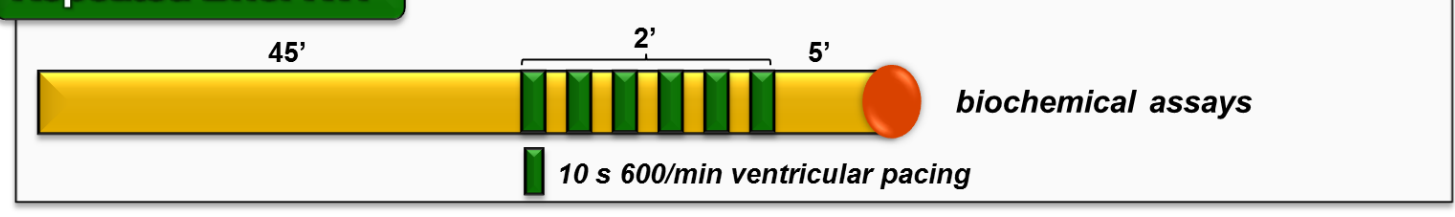

Figure 10. Protocol for assessing the myocardial peroxynitrite, RISK and SAFE pathways in rapid ventricular pacing-induced postconditioning in the absence of preceding index ischemia Isolated rat hearts subjected to normoxic perfusion with or without postconditioning maneuver - brief cycles of ischemia/reperfusion (I/R) or rapid ventricular pacing (RVP) - were harvested for biochemical analyses $(n=7-8$ in each group). The peroxynitrite ( $\left.\mathrm{ONOO}^{-}\right)$marker 3-nitrotyrosine was quantified by enzyme-linked immunosorbent assay (ELISA). Activation of reperfusion injury salvage kinase- (RISK) and survivor activating factor enhancement- (SAFE) pathway was assessed by western blot ( $n=5$ in each group). Akt: protein kinase B, ERKs: extra-cellular signal-regulated kinases, STAT3: signal transducer and activator of transcription 3 
In the normoxic perfusion group $(n=8)$ hearts were perfused for $52 \mathrm{~min}$. In the repeated brief ischemia/reperfusion group $(n=7)$ hearts were subjected to 45 min perfusion followed by $6 \times 10 / 10$-s cycles of no-flow global ischemia/reperfusion and 5 min reperfusion. In the repeated brief rapid ventricular pacing group $(n=8)$, the spontaneous rhythm of the hearts was replaced by 10 -s pacing period $(600 \mathrm{bpm} ; 10 \mathrm{~Hz})$ in 6 alternating cycles after $45 \mathrm{~min}$ perfusion. At the end of perfusion, cardiac free 3-nitrotyrosine level ( $n=7-8$ in each group) and the activation of RISK as well as SAFE pathway was determined ( $n=5$ in each group).

\subsection{Animals}

Male Wistar rats $(250-400 \mathrm{~g})$ were used in our experiments. The studies conformed to the 'Guide for the care and use of laboratory animals' published by the US National Institutes of Health (NIH publication No. 85-23, revised 1996) and was approved by local ethics committees. The animals were kept at 12/12-hour light/dark cycle and had free access to standard laboratory chow and drinking water.

\subsection{Materials}

Bovine serum albumin (BSA), LPS from Salmonella enterica serotype typhimurium (\#L7261), 4-(2-hydroxyethyl)-1-piperazineethanesulfonic acid (HEPES), dithiothreitol, trypsin inhibitor, leupeptin, aprotinin, phenylmethylsulfonyl fluoride (PMSF), lucigenin, L$\left[{ }^{14} \mathrm{C}\right]$ arginine, egtazic acid (EGTA), $N^{\mathrm{G}}$-monomethyl-L-arginine, L-citrulline, pterin, dihydroethidium and methylene blue, protease inhibitor cocktail (\#8340) were purchased from Sigma Aldrich (Saint Louis, MO, USA). Sucrose, disodium ethylenediaminetetraacetic dihydrate $\left(\mathrm{Na}_{2}\right.$ EDTA) and $\mathrm{FeSO}_{4} \times 7 \mathrm{H}_{2} \mathrm{O}$ were from Reanal (Budapest, Hungary). N-methylD-glucamine-dithiocarbamate (MGD) was synthetized by Fülöp F (Department of Pharmaceutical Chemistry, Faculty of Pharmacy, Szeged, Hungary). BCA Protein Assay Kit was from Pierce (Rockford, IL, USA). Tissue-Tek O.C.T. compound was from Sakura Finetek (Zoeterwoude, Netherlands). Saline was from TEVA (Petah Tikva, Israel). LDH-P kit was purchased from Diagnosticum (Budapest, Hungary). Peroxynitrite marker 3-nitrotyrosine ELISA was from Cayman Chemical (Ann Arbor, MI, USA). Western blotting reagents for sodium dodecyl sulfate-polyacrylamide gelelectrophoresis (SDS-PAGE) were from Bio-Rad (Hercules, California, USA). Radioimmunoprecipitation assay (RIPA) buffer and primary antibodies were purchased from Cell Signaling Technology (Danvers, MA, USA): anti- 
phospho(Tyr705)-STAT3 (\#9145), anti-phospho(Ser473)-Akt (\#9271), antiphospho(Thr202/204)-ERK1/2 (\#9101), anti-total STAT3 (\#4904), anti-total Akt (\#9272), anti-total ERK (\#9102), anti-glyceraldehyde 3-phosphate dehydrogenase (GAPDH, \#2118). Horseradish peroxidase (HRP)-conjugated secondary antibody was from Dako Corporation (Santa Barbara, CA, USA). Western blotting Detection Reagent was from Pierce (Rockford, IL, USA).

\subsection{Isolated heart preparation}

Isolated heart preparation was carried out as described in our previous studies with slight modifications (Ferdinandy et al., 1997a; Kocsis et al., 2012; Varga et al., 2014). Rats were anesthetized with diethyl ether, an anesthetic not known to interfere with cardioprotection. Inhalation anesthesia was induced in a glass desiccator containing cellulose wadding soaked in diethyl ether. During isolation of the heart, rats were removed from the chamber and a beaker containing wadding soaked in ether was held near the muzzle of rats in order to maintain anesthesia. Rats were given $500 \mathrm{U} / \mathrm{kg}$ heparin intravenously. Hearts were then isolated and perfused according to Langendorff at $37{ }^{\circ} \mathrm{C}$ with Krebs-Henseleit buffer containing $\mathrm{NaCl} 118 \mathrm{mM}, \mathrm{NaHCO}_{3} 25 \mathrm{mM}, \mathrm{KCl} 4.3 \mathrm{mM}, \mathrm{CaCl}_{2} 2.4$ or $1.4 \mathrm{mM}, \mathrm{KH}_{2} \mathrm{PO}_{4}$ $1.2 \mathrm{mM}, \mathrm{MgSO}_{4} 1.2 \mathrm{mM}$, glucose $11 \mathrm{mM}$, gassed with $95 \% \mathrm{O}_{2}$ and $5 \% \mathrm{CO}_{2}$. Hydrostatic perfusion pressure was kept constant at $100 \mathrm{cmH}_{2} \mathrm{O}(9.8 \mathrm{kPa})$ throughout the experiments. In recirculating working mode according to Neely, preload and afterload were kept constant at $1.7 \mathrm{kPa}$ and $9.8 \mathrm{kPa}$, respectively throughout the experiments. Coronary flow was measured by collecting coronary effluent for a period of time and was expressed as $\mathrm{mL} / \mathrm{min}$.

No-flow global ischemia was performed by turning off the perfusion cannula. To induce regional index ischemia, a 3-0 silk suture was placed around the left anterior descending coronary artery close to its origin and the snare was tightened by applying a $100 \mathrm{~g}$ hanging weight. The presence of ischemia was verified by monitoring coronary flow.

Rapid ventricular pacing $(600 \mathrm{bpm} ; 10 \mathrm{~Hz})$ was performed by an electric stimulator (Experimetria, Budapest, Hungary) with double threshold square, $1 \mathrm{~V}, 1 \mathrm{~mA}$ and 5-ms impulses conducted by electrodes attached directly to the surface of the right ventricle close to the apex and to the aortic cannula as described previously (Ferdinandy et al., 1997a; Ferdinandy et al., 1997b; Ferdinandy et al., 1998). 
Heart rates were monitored (Isosys, Experimetria Inc., Budapest, Hungary) by recording epicardial ECG throughout the whole duration of perfusion.

\subsection{Lactate dehydrogenase assay}

To assess the severity of cellular damage in the myocardium, the activity of LDH enzyme from coronary effluents (collected for $5 \mathrm{~min}$ ) was measured using a LDH-P kit. The enzyme activity $(\mathrm{U} / \mathrm{mL})$ measured in an effluent was multiplied with the corresponding coronary flow ( $\mathrm{mL} / \mathrm{min}$ ) to give $\mathrm{LDH}$ release expressed as $\mathrm{U} / \mathrm{min}$.

\subsection{Infarct size measurement}

In order to determine infarct size in ischemic postconditioning and rapid ventricular pacing groups, the left anterior descending coronary artery was reoccluded at the end of reperfusion and hearts were stained with $0.1 \%$ Evans-blue to determine area at risk (Csonka et al., 2010). Hearts were then frozen at $-20^{\circ} \mathrm{C}$ and cut into approximately 2-mm thick slices. Each slice was incubated at $37^{\circ} \mathrm{C}$ for $10 \mathrm{~min}$ in $1 \%$ TTC solution dissolved in phosphate buffer ( $\mathrm{pH}$ 7.4). TTC differentiated red, viable heart tissues from non-viable, white tissues within the area at risk. Slices were then fixed in $10 \%$ formaldehyde and scanned. Finally, infarct size was determined by planimetry (InfarctSize ${ }^{\mathrm{TM}}$ 2.4.b, Pharmahungary Group, Szeged, Hungary) and normalized to area at risk.

\subsection{Evaluation of reperfusion-induced arrhythmias}

To assess reperfusion-induced arrhythmias, epicardial ECGs were recorded (Isosys, Experimetria Inc., Budapest, Hungary) and analysis was carried out according to the original Lambeth conventions (Walker et al., 1988), focusing on the duration or incidence of ventricular tachyarrhythmias (VT and VF).

\subsection{Myocardial 3-nitrotyrosine assessment by ELISA}

To estimate cardiac peroxynitrite formation, free 3-nitrotyrosine, a well-known marker of peroxynitrite was measured by ELISA as described (Csont et al., 2002).

Heart samples were homogenized in a buffer containing HEPES $(10 \mathrm{mM})$, sucrose $(0.32 \mathrm{M}), \mathrm{Na}_{2}$ EDTA $(0.1 \mathrm{mM})$, dithiothreitol $(1.0 \mathrm{mM})$, trypsin inhibitor $(10 \mathrm{mg} / \mathrm{mL})$, 
leupeptin $(10 \mathrm{mg} / \mathrm{mL})$, aprotinin $(2 \mathrm{mg} / \mathrm{mL})$, and PMSF $(125 \mu \mathrm{g} / \mathrm{mL})$ at $\mathrm{pH} 7.4$. The crude homogenates were centrifuged at $10,000 \times g$ for $10 \mathrm{~min}$ at $4{ }^{\circ} \mathrm{C}$, and supernatants were then used for 3-nitrotyrosine quantification.

According to the manufacturer's instructions, supernatants from the heart homogenates were incubated overnight at $4{ }^{\circ} \mathrm{C}$ with nitrotyrosine acetylcholinesterase tracer and antinitrotyrosine rabbit IgG in microplates precoated with mouse anti-rabbit IgG. Ellman's reagent was then used for development. Free nitrotyrosine content was normalized to protein content of cardiac homogenates and expressed as ng/mg protein.

\subsection{Measurement of cardiac $\mathrm{O}_{2}{ }^{--}$and $\mathrm{NO}^{\circ}$ levels}

Since peroxynitrite is formed as a result of the reaction of $\mathrm{O}_{2}{ }^{--}$and $\mathrm{NO}^{\circ}$, the cardiac level of these intermediates were also measured.

Cardiac $\mathrm{O}_{2}{ }^{*-}$ production was assessed either by lucigenin-ECL or by in situ detection. For chemiluminescence determination the apex of the heart was cut into small pieces, placed in Krebs-Henseleit buffer containing $10 \mu \mathrm{mol} / \mathrm{L}$ lucigenin and $10 \mathrm{mmol} / \mathrm{L}$ HEPES-NaOH $(1 \mathrm{~mL}$, pH 7.4), then luminescence was measured using a liquid scintillation counter (Tri-Carb 2100TR, Packard Instrument Company, Meriden, CT, USA) with in the presence or absence of the superoxide scavenger nitro blue tetrazolium $(200 \mu \mathrm{mol} / \mathrm{L})(\mathrm{Csont}$ et al., 2002; Csont et al., 2007). Cardiac $\mathrm{O}_{2}{ }^{\circ-}$ production was expressed as counts per $\mathrm{min} / \mathrm{mg}$ wet tissue weight.

The fluorescent dihydroethidium staining was performed to evaluate in situ intracellular production of $\mathrm{O}_{2}{ }^{--}$(Varga et al., 2013). Approximately 3-mm thick transverse slices were cut from the middle of the ventricles, embedded in Tissue-Tek O.C.T. compound, carefully frozen in isopentane precooled in liquid nitrogen, and stored at $-80{ }^{\circ} \mathrm{C}$ until sectioning with a microtome. Unfixed frozen heart sections $(30 \mu \mathrm{m})$ were placed on glass slides and incubated in $10^{-6} \mathrm{~mol} / \mathrm{L}$ dihydroethidium in phosphate-buffered saline $(\mathrm{pH} 7.4)$ at $37^{\circ} \mathrm{C}$ for $30 \mathrm{~min}$ in a dark humidified container. Fluorescence was then detected by a fluorescent microscope (Nikon, Japan) with a $590 \mathrm{~nm}$ long-pass filter. Images of the hearts were collected digitally $(n=20$ in each heart), integrated density were evaluated by ImageJ $1.44 p$ software and expressed in arbitrary unit.

The level of $\mathrm{NO}^{\circ}$ in ventricular tissue was measured by spin trapping followed by EPR spectroscopy as described (Csonka et al., 1999; Csont et al., 1999). Hearts were loaded with the 
freshly prepared $\mathrm{NO}^{\circ}$-specific spin trap $\mathrm{Fe}^{2+}(\mathrm{MGD})_{2}$. The spin trap $(175 \mathrm{mg}$ MGD and $50 \mathrm{mg}$ $\mathrm{FeSO}_{4}$ dissolved in $6 \mathrm{~mL}$ distilled water and $\mathrm{pH}$ set to 7.4) was infused for 5 min into the aorta during Langendorff perfusion at a rate of $1 \mathrm{~mL} / \mathrm{min}$. At the end of the infusion of $\mathrm{Fe}^{2+}(\mathrm{MGD})_{2}$, myocardial tissue samples were collected, minced, and pushed into the bottom of quartz EPR tubes and frozen carefully in liquid nitrogen. EPR spectra of $\mathrm{NO}^{\circ}-\mathrm{Fe}^{2+}-(\mathrm{MGD})_{2}$ adducts were recorded with an EPR spectrometer (model ECS106, Bruker; Rheinstetten, Germany) and analyzed for $\mathrm{NO}^{\bullet}$ signal intensity as described (Csont et al., 1998; Csonka et al., 2015).

\subsection{Assessment of myocardial XOR and NO synthases activities}

Powdered frozen ventricular tissue was homogenized in 4 volumes of ice-cold homogenization buffer (composition is same as described above for peroxynitrite measurement) with an Ultra-Turrex disperser using three 20-s strokes. The homogenate was centrifuged $(1000 \times \mathrm{g}$ for $10 \mathrm{~min})$ at $4{ }^{\circ} \mathrm{C}$ and the supernatant was kept on ice for immediate assays of enzyme activities.

Since XOR is a major source of $\mathrm{O}_{2}{ }^{--}$in the rat heart (Downey et al., 1988), the activity of XOR was determined in supernatants. A fluorometric kinetic assay was performed by measuring the conversion of pterine to isoxanthopterine in the presence as well as in the absence of the electron acceptor methylene blue (Beckman et al., 1989; Csont et al., 2002).

To determine enzymatic NO production in the hearts, $\mathrm{Ca}^{2+}$-dependent and -independent NOS activities were assessed. The conversion of $\mathrm{L}-\left[{ }^{14} \mathrm{C}\right]$ arginine to $\mathrm{L}-\left[{ }^{14} \mathrm{C}\right]$ citrulline was measured in supernatants with or without EGTA $(1 \mathrm{mM})$ or EGTA plus $N^{\mathrm{G}}$-monomethyl-Larginine $(1 \mathrm{mM})$ to estimate $\mathrm{Ca}^{2+}$-dependent and -independent NOS activities, respectively (Csont et al., 2002; Csont et al., 2007). NOS activities were expressed in pmol/min/mg protein.

\subsection{Investigation of myocardial RISK and SAFE pathways by Western Blot analysis}

In order to assess the activation of RISK and SAFE pathways, the phosphorylation rate of ERK1/2, Akt and STAT3 proteins was determined by standard Western blot techniques (Kocsis et al., 2008; Fekete et al., 2013). Tissue samples were homogenized with an ultrasonicator (UP100H Hielscher, Teltow, Germany) in RIPA buffer (50 mM Tris-HCl $\mathrm{pH} 8.0,150 \mathrm{mM} \mathrm{NaCl}, 0.5 \%$ sodium deoxycholate, $5 \mathrm{mM}$ EDTA, $0.1 \%$ SDS, $1 \% \mathrm{NP}-40$ ) 
supplemented with protease inhibitor cocktail, PMSF, $\mathrm{NaF}$ and $\mathrm{Na}_{3} \mathrm{VO}_{4}$. The crude homogenates were centrifuged at $10,000 \times \mathrm{x}$ or $15,000 \mathrm{x} g$ for 10 or $30 \mathrm{~min}$ at $4{ }^{\circ} \mathrm{C}$. After quantification of protein concentrations of the supernatants using BCA Protein Assay Kit, 20 or $25 \mu \mathrm{g}$ reduced and denatured protein was loaded on polyacrylamide gels and SDS-PAGE $(10 \%$ gel, $90 \mathrm{~V}, 1.5 \mathrm{~h})$ was performed followed by transfer of proteins onto nitrocellulose membrane (20\% methanol, $35 \mathrm{~V}, 2 \mathrm{~h}$ ). Membranes were blocked for $1 \mathrm{~h}$ in $5 \% \mathrm{w} / \mathrm{v}$ BSA at room temperature and then incubated with primary antibodies against phospho(Thr202/Tyr204)-ERK1/ERK2 1:2,000, ERK1/ERK2 1:1,000, phospho(Ser473)-Akt 1:500, Akt 1:2,000, phospho(Tyr705)-STAT3 1:1,000-2,000, STAT3 1:2,000 (overnight, $\left.4{ }^{\circ} \mathrm{C}, 5 \% \mathrm{BSA}\right)$ or GAPDH 1:10,000 (1 h, room temperature, $1 \%$ milk). After incubation with HRP-conjugated secondary antibody 1:5,000 (1:20,000 for GAPDH) (1 h, room temperature, $1 \%$ milk), membranes were developed using enhanced chemiluminescence kit.

\subsection{Statistical analysis}

Data were expressed as mean \pm standard error of the mean (S.E.M.) and analyzed by use of Student's unpaired $t$-test, one-way analysis of variance (ANOVA), two-way ANOVA or Fisher's exact test as appropriate. If a difference was established in ANOVA, Fisher's Least Significant Difference post hoc test was applied. Differences were considered significant at $p<0.05$. 


\section{Results}

\subsection{Low-dose endotoxin pretreatment improves post-ischemic cardiac function and}

\section{LDH release: the late cardioprotective effect is verified}

Cardiac performance was measured in isolated hearts subjected to global ischemia $24 \mathrm{~h}$ after in vivo LPS (S. typhimurium; $0.5 \mathrm{mg} / \mathrm{kg}$ ip.) or saline injection, in order to verify the late cardioprotective effect of low-dose endotoxin. There was no difference in animal weight (307 \pm 5 g vs. $301 \pm 5 \mathrm{~g})$ and heart wet weight (928 \pm 25 vs. $927 \pm 28 \mathrm{mg})$ between the control and LPS-pretreated groups. Cardiac function was deteriorated in both experimental groups during reperfusion after global ischemia [Figure 11].
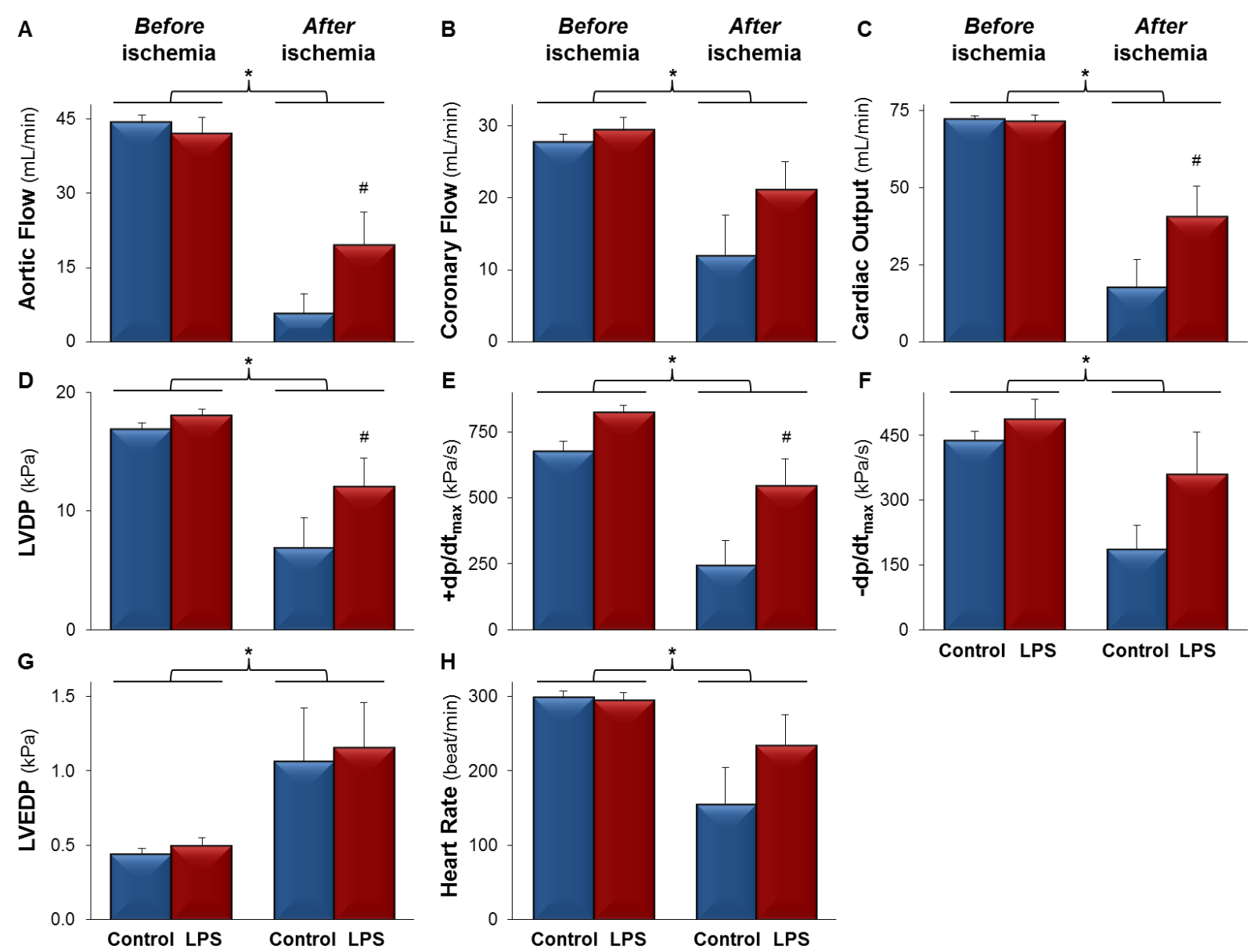

Figure 11. LPS-pretreatment improves post-ischemic cardiac function

Isolated rat hearts were subjected to $10 \mathrm{~min}$ equilibration period, $30 \mathrm{~min}$ normothermic global ischemia followed by $20 \mathrm{~min}$ reperfusion, $24 \mathrm{~h}$ after in vivo $0.5 \mathrm{mg} / \mathrm{kg}$ lipopolysaccharide (LPS) treatment. Values are expressed as mean \pm S.E.M $(n=6-7$ in both groups). ${ }^{*} p<0.05$ vs. Before ischemia, ${ }^{\#} p<0.05$ vs. Control, two-way ANOVA. LVDP: left ventricular developed pressure, $\pm \mathrm{d} p / \mathrm{d} t_{\max }:$ maximum of first derivatives of LVDP, LVEDP: left ventricular end-diastolic pressure. 
The post-ischemic aortic flow, coronary flow, cardiac output, left ventricular developed pressure, $\pm \mathrm{d} p / \mathrm{d} t_{\max }$ and heart rate were decreased [Figure $\left.11 \mathrm{~A}-\mathrm{F}, \mathrm{H}\right]$, while left ventricular end-diastolic pressure was increased [Figure 11G] compared to the pre-ischemic values. However, post-ischemic decline of aortic flow, cardiac output, left ventricular developed pressure, and $+\mathrm{d} p / \mathrm{d} t_{\max }$ was significantly improved by LPS-pretreatment [Figure $11 \mathrm{~A}, \mathrm{C}$, $\mathrm{D}, \mathrm{E}]$. Coronary flow, $-\mathrm{d} p / \mathrm{d} t_{\max }$, left ventricular end-diastolic pressure and heart rate were not affected significantly by low-dose LPS-pretreatment after the ischemia [Figure 11B, F, G, H].

At the beginning of reperfusion after a global ischemia LDH release was markedly increased in the control group [Figure 12]. In contrast, low-dose LPS pretreatment prevented the post-ischemic LDH release [Figure 12].

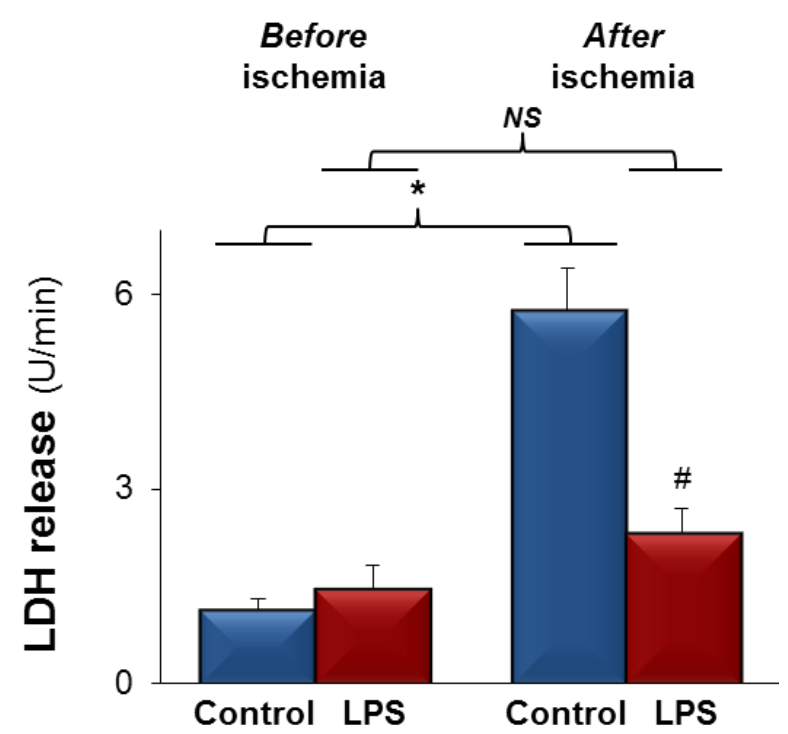

Figure 12. LPS-pretreatment attenuates post-ischemic LDH release

Figure shows lactate dehydrogenase (LDH) activity in coronary effluents. Isolated rat hearts were subjected to $10 \mathrm{~min}$ equilibration period, $30 \mathrm{~min}$ normothermic global ischemia followed by $20 \mathrm{~min}$ reperfusion, $24 \mathrm{~h}$ after in vivo $0.5 \mathrm{mg} / \mathrm{kg}$ lipopolysaccharide (LPS) treatment. Values are expressed as mean \pm S.E.M $(n=3-4$ in both groups). * $p<0.05$ vs. Before ischemia, ${ }^{\#} p<0.05$ vs. Control, two-way ANOVA, NS: not significant

\subsection{LPS pretreatment enhances myocardial 3-nitrotyrosine formation, $\mathrm{O}_{2}{ }^{--}$and $\mathrm{NO}^{\circ}$ production, XOR and NOS activity}

To assess the delayed effect of cardioprotective LPS on myocardial peroxynitrite formation, the level of cardiac free 3-nitrotyrosine, a marker of peroxynitrite was measured. Low dose of LPS significantly enhanced the formation of myocardial 3-nitrotyrosine $24 \mathrm{~h}$ after the in vivo administration [Figure 13]. 


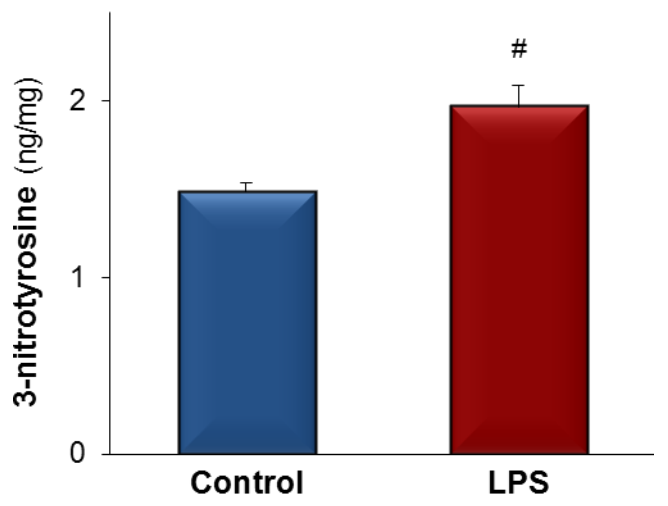

Figure 13. LPS-pretreatment enhances cardiac 3-nitrotyrosine formation

Figure shows the level of a peroxynitrite marker. Analysis was performed $24 \mathrm{~h}$ after in vivo $0.5 \mathrm{mg} / \mathrm{kg}$ lipopolysaccharide (LPS) treatment. Values are expressed as mean \pm S.E.M $\left(n=7-9\right.$ in both groups). ${ }^{\#} p<0.05$ vs. Control, unpaired $t$-test.

In order to elucidate the source of enhanced cardiac peroxynitrite formation induced by low-dose LPS, $\mathrm{O}_{2}{ }^{--}$and $\mathrm{NO}^{\circ}$ the precursors of peroxynitrite were measured. The cardiac levels of both $\mathrm{O}_{2}{ }^{-}$(measured by lucigenin-ECL) [Figure 14A] and $\mathrm{NO}^{\circ}$ (detected by EPR) [Figure 14B] were significantly increased in LPS-pretreated hearts.

A

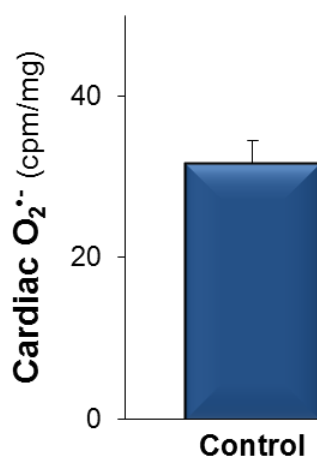

B

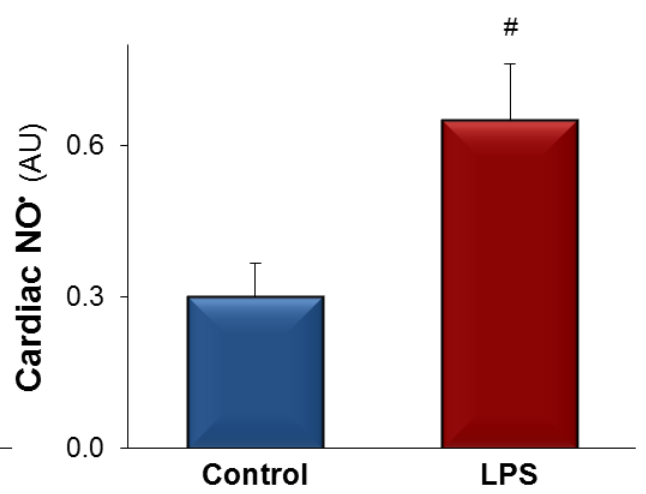

Figure 14. LPS-pretreatment increases the level of cardiac superoxide $\left(\mathrm{O}_{2}{ }^{\circ}\right)$ and nitric oxide $\left(\mathrm{NO}^{\circ}\right)$ Assays were performed $24 \mathrm{~h}$ after in vivo $0.5 \mathrm{mg} / \mathrm{kg}$ lipopolysaccharide (LPS) treatment. Values are expressed as mean \pm S.E.M $\left(n=7-12\right.$ in both groups). ${ }^{\#} p<0.05$ vs. Control, unpaired $t$-test. AU: arbitrary unit

To reveal the possible source of increased $\mathrm{O}_{2}{ }^{--}$and $\mathrm{NO}^{\circ}$ levels induced by low-dose LPS, activity of XOR and NOS enzymes were measured. The activity of XOR [Figure 15A] and $\mathrm{Ca}^{2+}$-independent-NOS was significantly enhanced in LPS-pretreated hearts without affecting the $\mathrm{Ca}^{2+}$-dependent-NOS activity [Figure 15B]. 
A

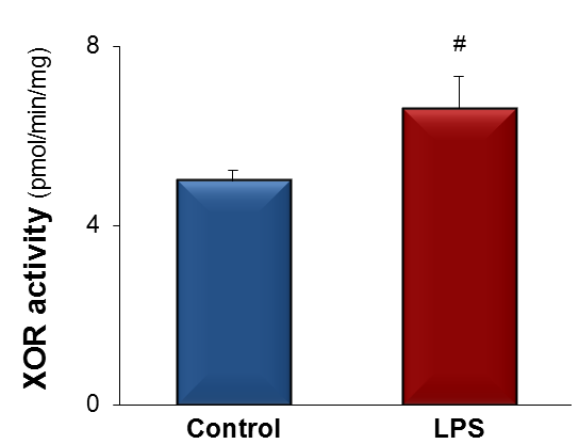

B

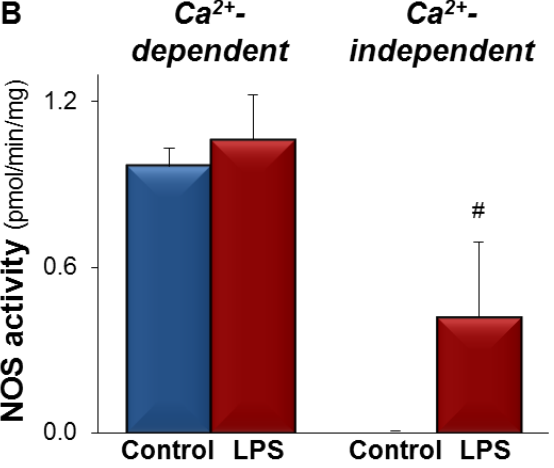

Figure 15. Cardiac xanthine oxidoreductase (XOR) and $\mathrm{NO}^{\circ}$ synthases (NOS) enzymes may contribute to elevated $\mathrm{O}_{2}{ }^{-}$and $\mathrm{NO}^{\circ}$ production induced by LPS

Assays were performed $24 \mathrm{~h}$ after in vivo $0.5 \mathrm{mg} / \mathrm{kg}$ low-dose lipopolysaccharide (LPS) treatment. Values are expressed as mean \pm S.E.M $\left(n=7-12\right.$ in both groups). ${ }^{\#} p<0.05$ vs. Control, unpaired $t$-test.

\subsection{LPS-pretreatment results in enhanced phosphorylation of STAT3, indicating activation of SAFE pathway}

In order to elucidate the possible downstream targets of low-dose LPS, the activations of ERK1/2, Akt and STAT3 (members of RISK and SAFE pathways) were investigated $24 \mathrm{~h}$ after LPS-pretreatment. Low-dose LPS significantly enhanced cardiac STAT3 phosphorylation and non-significantly increased Akt phosphorylation without affecting phosphorylation of ERK1/2 [Figure 16]. Total STAT3 (both phosphorylated and nonphosphorylated forms) was increased by approximately $20 \%$ due to LPS-pretreatment ( $p=$ 0.044) [Figure 16].

A

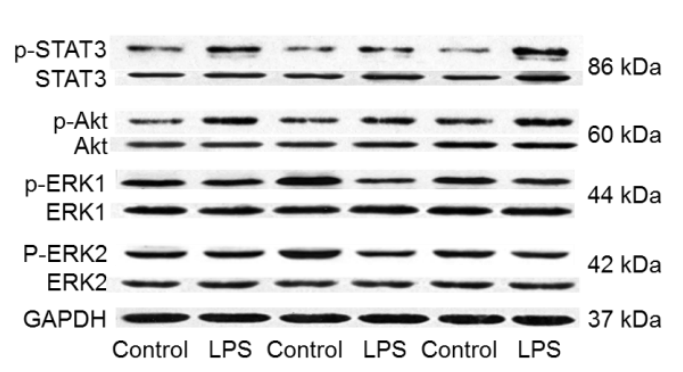

B
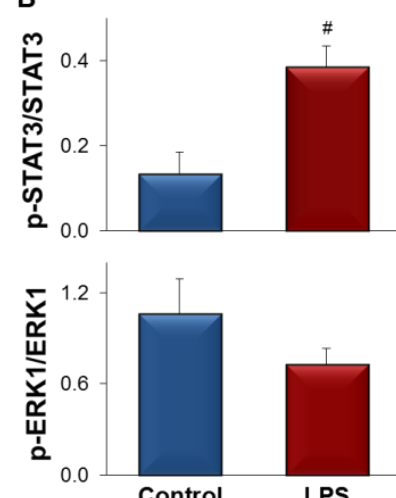
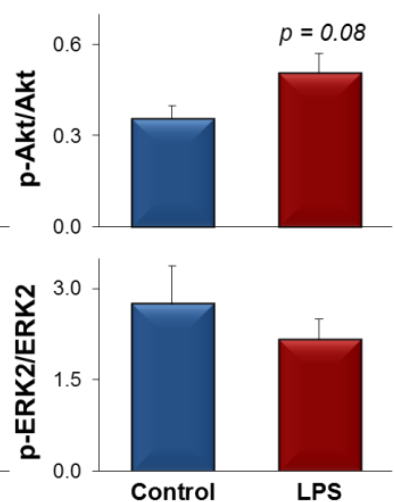

Figure 16. LPS-pretreatment results in enhanced phosphorylation of STAT3

Figure shows representative images $(A)$ and quantification $(B)$ of western blots. Analysis was performed from hearts, $24 \mathrm{~h}$ after in vivo $0.5 \mathrm{mg} / \mathrm{kg}$ lipopolysaccharide (LPS) treatment. Values are expressed as mean \pm S.E.M ( $n=7$ in both groups). ${ }^{\#} p<0.05$ vs. Control, unpaired $t$-test. Akt: protein kinase B, ERK1/2: extra-cellular signal-regulated kinase 1 and 2 , GAPDH: glyceraldehyde 3-phosphate dehydrogenase, STAT3: signal transducer and activator of transcription 3 


\subsection{The duration of reperfusion-induced ventricular tachycardia and/or fibrillation is associated with decreased infarct size}

To address the question whether there is an association between the duration of reperfusion-induced ventricular tachyarrhythmias and infarct size, a meta-analysis was done. Meta-analysis of six separate studies previously performed in our laboratory using the same experimental protocol (i.e. isolated rat hearts subjected to ischemia/reperfusion) showed that the presence of VT, VF, or VT+VF with a total duration of longer than $60 \mathrm{~s}$ in the first $10 \mathrm{~min}$ of reperfusion was associated with a markedly decreased infarct size [Figure 17A], respectively. Interestingly, in this analysis a larger area at risk was associated with longer than $60 \mathrm{~s}$ total duration of VT+VF [Figure 17B].

A
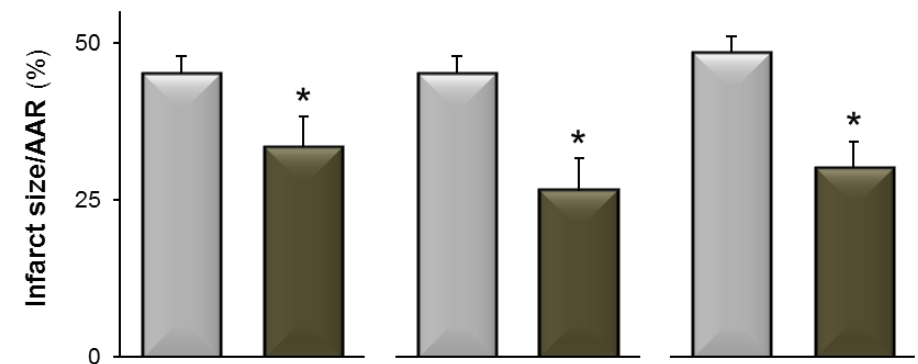

B
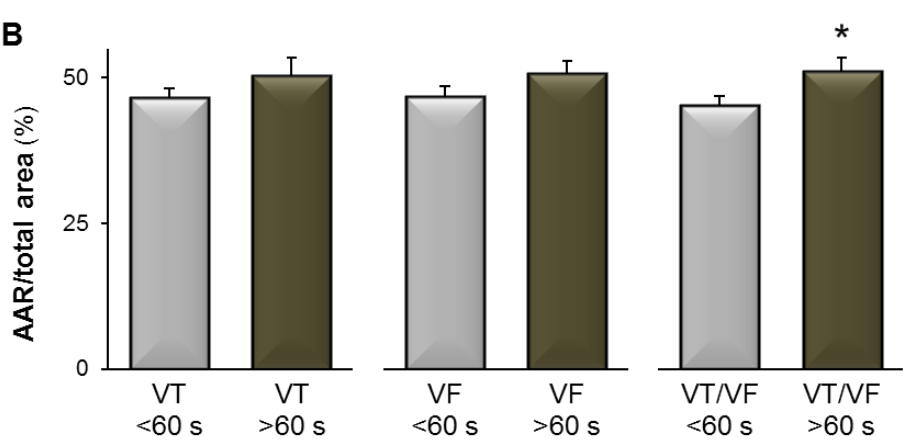

Figure 17. Duration of reperfusion-induced VT and/or VF is associated with decreased infarct size

Results of the meta-analysis (isolated rat hearts subjected to $30 \mathrm{~min}$ regional ischemia and $120 \mathrm{~min}$ reperfusion) shows infarct size normalized to area at risk $(A)$ and area at risk $(B)$ in the presence of shorter $(<60 \mathrm{~s})$ or longer $(>60 \mathrm{~s})$ total durations of $\mathrm{VT}, \mathrm{VF}$, or $\mathrm{VT}+\mathrm{VF}$, respectively. Values are expressed as mean \pm S.E.M. ${ }^{*} p<0.05$ vs. corresponding $<60 \mathrm{~s}$ groups, unpaired $t$-test. AAR: area at risk, VT: ventricular tachycardia, VF: ventricular fibrillation

\subsection{Rapid ventricular pacing exerts a cardioprotective effect: limits the infarction and reperfusion-induced arrhythmias \\ In order to assess the possible cardioprotective effect of rapid ventricular pacing, the extent of myocardial infarction (infarct size and LDH release) was measured and reperfusion- induced arrhythmias were analyzed.}


Infarct size normalized to area at risk was significantly decreased by short periods of rapid ventricular pacing [Figure 18A], similarly to ischemic postconditioning. There was no difference in the area at risk between experimental groups [Figure 18B].
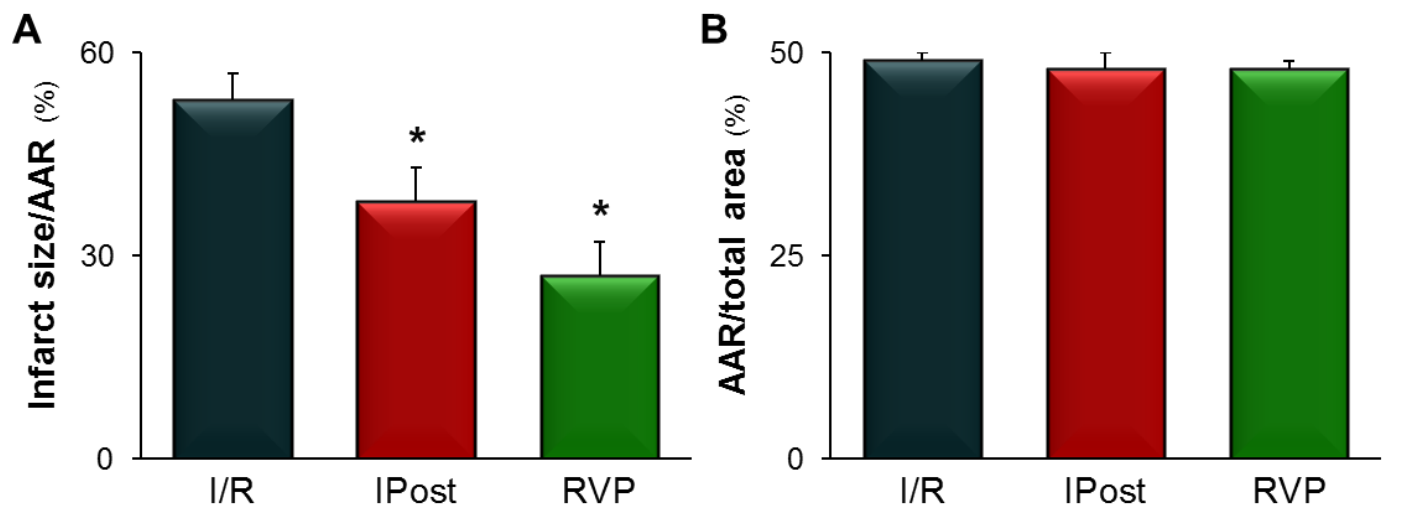

Figure 18. Rapid ventricular pacing attenuates infarct size

Hearts were subjected to 15 min equilibration period, followed by 30 min regional ischemia and 120 min reperfusion with or without ischemic postconditioning (IPost) or rapid ventricular pacing (RVP). Values are expressed as mean \pm S.E.M $(n=12$ in each group). $*_{p}<0.05$ vs. ischemia/reperfusion (I/R), one-way ANOVA. AAR: area at risk

The post-ischemic LDH release was significantly reduced by rapid ventricular pacing [Figure 19]. Ischemic postconditioning also reduced LDH release; however, the difference did not reach the level of statistical significance [Figure 19].

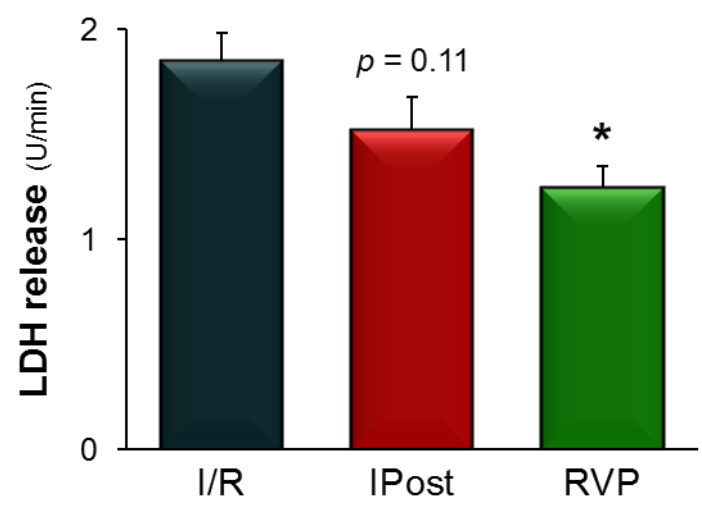

Figure 19. Rapid ventricular pacing decreases post-ischemic LDH release

Hearts were subjected to 15 min equilibration period, followed by 30 min regional ischemia and 120 min reperfusion with or without ischemic postconditioning (IPost) or rapid ventricular pacing (RVP). Values are expressed as mean \pm S.E.M $(n=5$ in each group). ${ }^{*} p<0.05$ vs. ischemia/reperfusion (I/R), one-way ANOVA.

Short periods of rapid ventricular pacing decreased the incidence of reperfusion-induced VT without having a significant effect on VF [Figure 20A, B]. In contrast, the incidence of 
VT and VF was not affected significantly by ischemic postconditioning in our present study [Figure 20A, B].
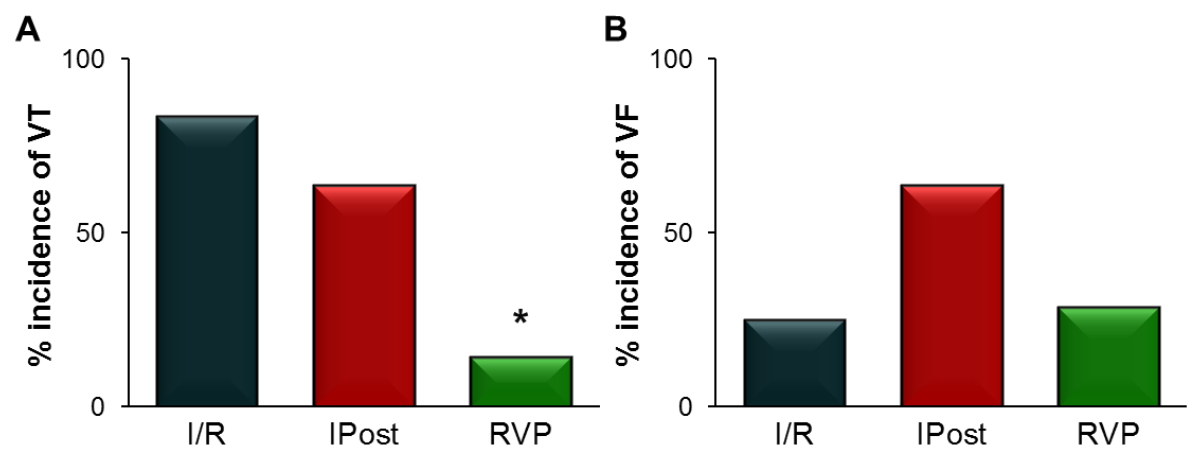

Figure 20. Rapid ventricular pacing attenuates reperfusion-induced arrhythmias

Hearts were subjected to 15 min equilibration period, followed by 30 min regional ischemia and 120 min reperfusion with or without ischemic postconditioning (IPost) or rapid ventricular pacing (RVP). $*_{p}<0.05$ vs. ischemia/reperfusion (I/R), Fisher's exact test ( $n=11-14$ in each group). VT: ventricular tachycardia, VF: ventricular fibrillation

There was no difference in animal weight, heart wet weight, baseline heart rate, and coronary flow (baseline, beginning of ischemia, end of reperfusion) between the experimental groups [Table 2]. In contrast to ischemic postconditioning, coronary flow at the onset of reperfusion was not changed by short periods of rapid ventricular pacing compared to ischemia/reperfusion control [Table 2].

Table 2. Morphological and ex vivo hemodynamic parameters

\begin{tabular}{|lccc|}
\hline \multicolumn{1}{|c}{ I/R } & IPost & RVP \\
\hline Animal weight $(\mathrm{g})$ & $367 \pm 8$ & $358 \pm 10$ & $345 \pm 10$ \\
\hline Heart wet weight $(\mathrm{g})$ & $1.28 \pm 0.03$ & $1.22 \pm 0.04$ & $1.30 \pm 0.06$ \\
\hline Basal heart rate $(\mathrm{bpm})$ & $301 \pm 11$ & $291 \pm 12$ & $304 \pm 8$ \\
\hline Coronary flow $(\mathrm{mL} / \mathrm{min})$ & & & \\
\hline Before ischemia & $18.8 \pm 1.5$ & $16.7 \pm 1.2$ & $18.7 \pm 1.1$ \\
\hline Beginning of ischemia $^{\mathrm{a}}$ & $10.7 \pm 1.0$ & $9.0 \pm 0.8$ & $11.5 \pm 1.0$ \\
\hline Beginning of reperfusion $^{\mathrm{b}}$ & $16.5 \pm 1.0$ & $8.7 \pm 0.6^{*}$ & $17.9 \pm 0.7$ \\
\hline End of reperfusion & $11.5 \pm 1.5$ & $9.9 \pm 0.9$ & $11.8 \pm 1.5$ \\
\hline
\end{tabular}

\footnotetext{
${ }^{\mathrm{a}}$ regional ischemia, ${ }^{\mathrm{b}} 6 \mathrm{x} 10 \mathrm{~s}$ global ischemia was applied to induce ischemic postconditioning (IPost) in the first 2 min of reperfusion. Coronary flow was measured by collecting coronary effluent for $2 \mathrm{~min}$ and then was expressed as $\mathrm{mL} / \mathrm{min}$.

Hearts were subjected to 15 min equilibration period, followed by 30 min regional ischemia and 120 min reperfusion with or without IPost or rapid ventricular pacing (RVP). Results are expressed as mean \pm S.E.M ( $n=12$ in each group). * $p<0.05$ vs. ischemia/reperfusion (I/R) and RVP, one-way ANOVA.
} 


\subsection{Peroxynitrite is likely involved in rapid ventricular pacing induced-postconditioning}

To obtain some mechanistic insight into the beneficial effect of rapid ventricular pacing, cardiac 3-nitrotyrosine and $\mathrm{O}_{2}{ }^{--}$were measured at the $7^{\text {th }}$ min of reperfusion following the 30 min index ischemia.

Postconditioning induced by rapid ventricular pacing significantly increased cardiac 3nitrotyrosine level (a marker of peroxynitrite formation) [Figure 21A], similarly to ischemic postconditioning. Moreover, the peroxynitrite precursor $\mathrm{O}_{2}{ }^{--}$was mildly, but significantly elevated in both postconditioning groups [Figure 21B, C].

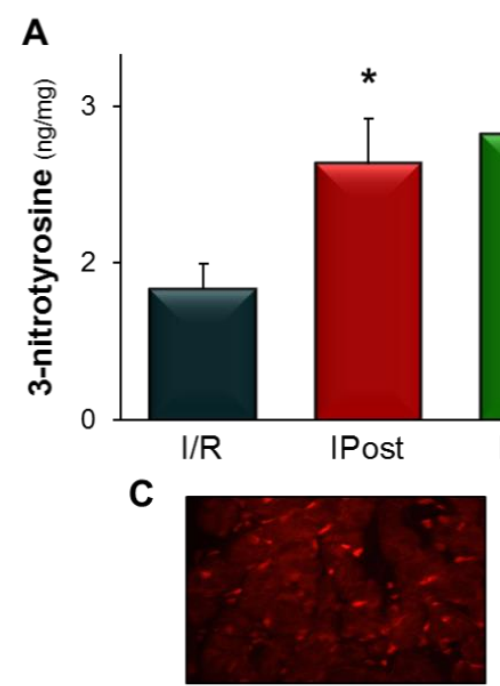

I/R

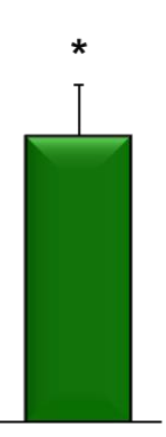

RVP

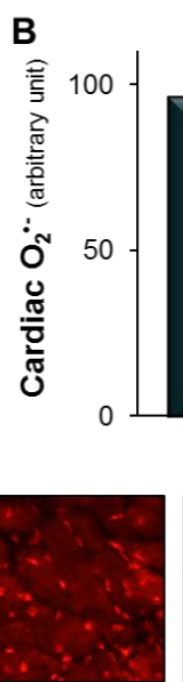

IPost

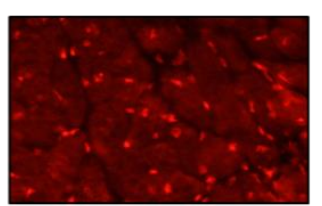

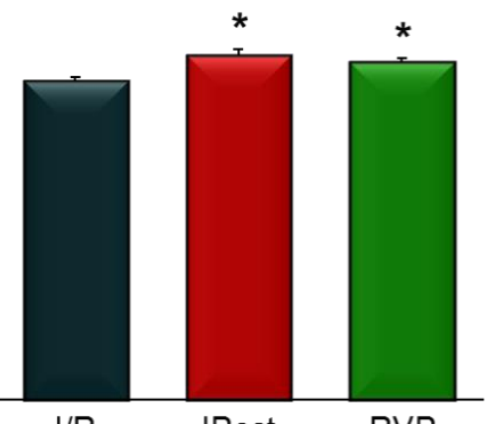

I/R

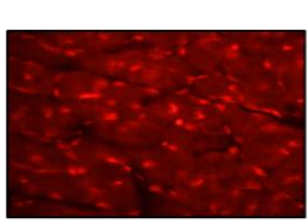

RVP

Figure 21. Postconditioning induced by rapid ventricular pacing enhances formation of 3-nitrotyrosine and superoxide $\left(\mathrm{O}_{2}{ }^{\circ}\right)$

Figure shows the cardiac level of a peroxynitrite marker $(A)$, in situ $\mathrm{O}_{2}{ }^{-}(B)$ and representative images of in situ $\mathrm{O}_{2}{ }^{*-}$ detection $(C)$. Analyses were performed after the hearts were subjected to 15 min equilibration period, followed by $30 \mathrm{~min}$ regional ischemia and $7 \mathrm{~min}$ reperfusion with or without ischemic postconditioning (IPost) or rapid ventricular pacing (RVP). Values are expressed as mean \pm S.E.M ( $n=5$ for 3-nitrotyrosine and $n=3$ for $\mathrm{O}_{2}{ }^{-}$in each group). ${ }^{*} p<0.05$ vs. ischemia/reperfusion (I/R), one-way ANOVA.

To further prove that the postconditioning maneuvers induce nitrative stress, cardiac 3nitrotyrosine was measured after the postconditioning stimuli applied following normoxic perfusion without index ischemia. The application of brief ischemia/reperfusion cycles or periodic rapid ventricular pacing increased the cardiac formation of 3 -nitrotyrosine in the absence of index ischemia [Figure 22]. 


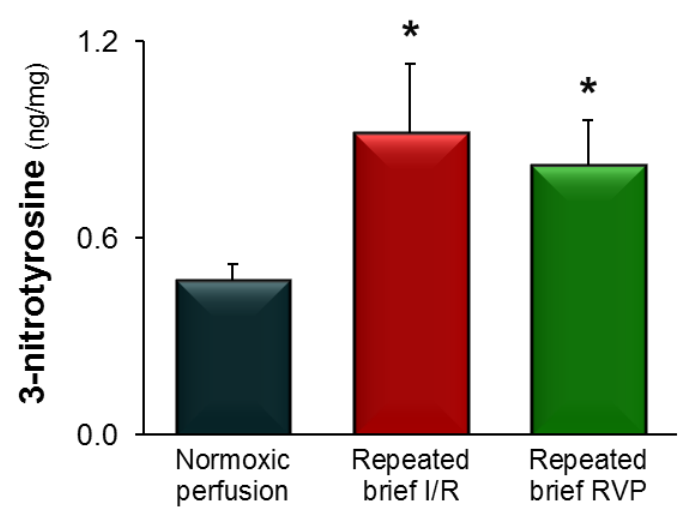

Figure 22. Short periods of rapid ventricular pacing without a preceding index ischemia enhances cardiac 3-nitrotyrosine formation

Figure shows the level of a peroxynitrite marker. Analysis was performed after hearts were subjected to 45 min normoxic perfusion, repeated (6 x 10/10-s) brief cycles of no-flow global ischemia/reperfusion (I/R) or rapid ventricular pacing (RVP) at $600 \mathrm{bpm} / \mathrm{spontaneous} \mathrm{rhythm} \mathrm{of} \mathrm{the} \mathrm{hearts} \mathrm{followed} \mathrm{by} 5 \mathrm{~min}$ perfusion. Values are expressed as mean \pm S.E.M $(n=7-8$ in each group). ${ }^{*} p<0.05$ vs. normoxic perfusion, one-way ANOVA.

\subsection{Phosphorylation rate of ERK1/2, Akt, and STAT3 proteins were not changed in rapid ventricular pacing-induced cardioprotection}

To elucidate the possible downstream targets of postconditioning induced by rapid ventricular pacing, RISK and SAFE pathways were investigated.
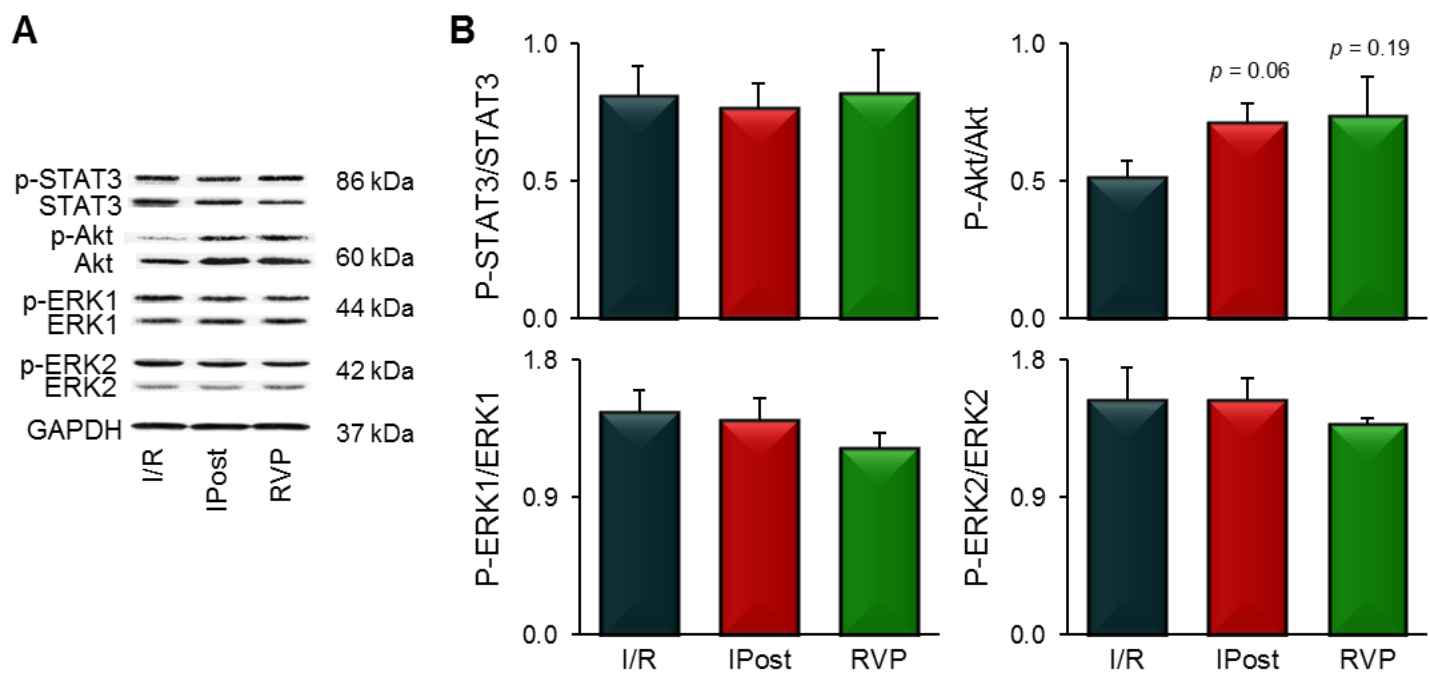

Figure 23. Rapid ventricular pacing has no effect on the phosphorylation of ERK1/2, Akt, and STAT3 Figure shows representative images $(A)$ and quantification $(B)$ of western blots. Analysis was performed after the hearts were subjected to $15 \mathrm{~min}$ equilibration, $30 \mathrm{~min}$ regional ischemia nad $7 \mathrm{~min}$ reperfusion with or without ischemic postconditioning (IPost) or rapid ventricular pacing (RVP). Values are expressed as mean \pm S.E.M ( $n=5$ in each group). $* p<0.05$ vs. ischemia/reperfusion (IR), one-way ANOVA. Akt: protein kinase B, ERK1/2: extra-cellular signal-regulated kinase 1 and 2, GAPDH: glyceraldehyde 3-phosphate dehydrogenase, STAT3: signal transducer and activator of transcription 3 
Rapid ventricular pacing non-significantly enhanced Akt phosphorylation after the index ischemia at the beginning of reperfusion without affecting phosphorylation of ERK1/2 and STAT3 [Figure 23A, B], similarly to ischemic postconditioning.

\subsection{Repeated brief periods of rapid ventricular pacing increased STAT3 phosphorylation in the absence of index ischemia}

The possible effect of both ischemic postconditioning and rapid ventricular pacing protocols (i.e. application of brief ischemia/reperfusion or rapid ventricular pacing) on myocardial RISK and SAFE pathways was also examined in the absence of preceding index ischemia.

Applying short periods of rapid ventricular pacing protocol increased STAT3 phosphorylation in normoxic perfusion without index ischemia, in contrast to brief cycles of ischemia/reperfusion [Figure 24A, B]. Phosphorylation of Akt and ERK1/2 was not affected significantly by any of the interventions in the absence of index ischemia [Figure 24A, B].

A

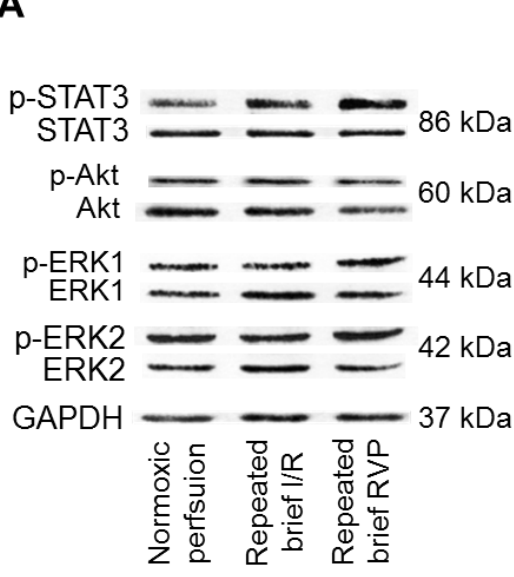

B
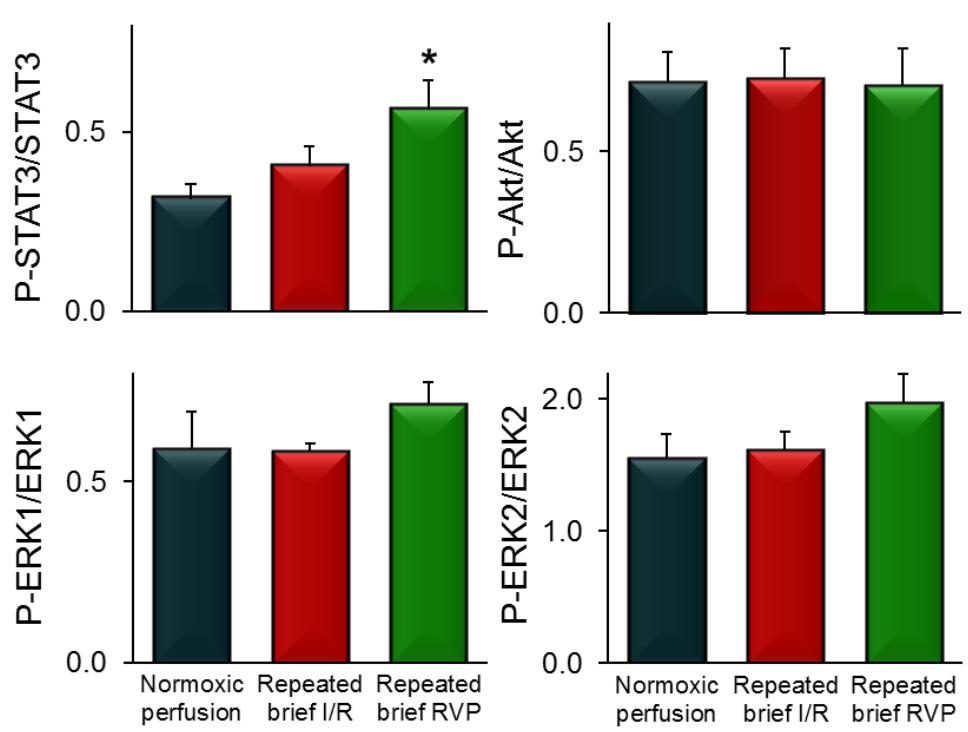

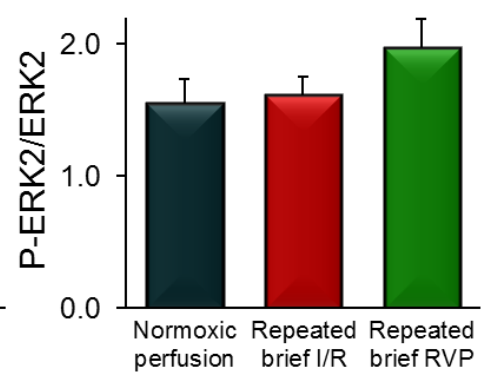

Figure 24. Short periods of rapid ventricular pacing without a preceding index ischemia enhances

STAT3 phosphorylation

Figure shows representative images $(A)$ and quantification $(B)$ of western blots. Analysis was performed after hearts were subjected to 45 min normoxic perfusion, repeated (6 x 10/10-s) brief cycles of no-flow global ischemia/reperfusion (I/R) or rapid ventricular pacing (RVP) at $600 \mathrm{bpm} /$ spontaneous rhythm of the hearts followed by 5 min perfusion. Values are expressed as mean \pm S.E.M ( $n=5$ in each group). ${ }^{*} P<0.05$ vs. normoxic perfusion, one-way ANOVA. Akt: protein kinase B, ERK1/2: extra-cellular signal-regulated kinase 1 and 2, GAPDH: glyceraldehyde 3-phosphate dehydrogenase, STAT3: signal transducer and activator of transcription 3 


\section{Discussion}

In our present work, we examined LPS-induced late preconditioning and rapidventricular pacing-induced postconditioning, two distinct alternative cardioprotective approaches of ischemic pre- and postconditioning, focusing on their effects on myocardial peroxynitrite, RISK and SAFE pathways.

\subsection{New findings}

- low-dose LPS-pretreatment enhances the myocardial peroxynitrite marker, 3nitrotyrosine formation

- low-dose LPS-pretreatment results in increased phosphorylation of STAT3, indicating activation of SAFE pathway

- rapid endogenous ventricular arrhythmias in the early phase of reperfusion are associated with decreased infarct size

- short periods of rapid ventricular pacing performed at the early phase of reperfusion attenuate reperfusion injury and induces postconditioning

- peroxynitrite may be involved in the rapid ventricular pacing-induced postconditioning

- RISK and SAFE pathways are not activated in mechanism of rapid ventricular pacinginduced cardioprotection

\subsection{Alternative cardioprotective approaches}

\subsubsection{LPS-induced late preconditioning}

Ischemic preconditioning is a widely used method to protect the heart against ischemia/reperfusion injury (Eisen et al., 2004; Das et al., 2008); however, the approach is invasive so it is limited to use as a preventive intervention in daily life. Instead, pharmacological preconditioning is a non-invasive way to confer protection, thereby having a great preventive and therapeutic potential in the field of cardiovascular diseases. We demonstrated that in vivo administration of low-dose LPS ameliorated post-ischemic cardiac function and $\mathrm{LDH}$ release in isolated rat hearts subjected to ischemia/reperfusion $24 \mathrm{~h}$ after the treatment. Our results are in accordance with literature data showing that endotoxin exerts 
late preconditioning by improving post-ischemic cardiac recovery (Brown et al., 1989; Maulik et al., 1995; Wang et al., 2011).

Although LPS as an endotoxin may induce systemic and cellular toxicity, which limits its clinical application, preclinical experiments still provide valuable data to gain mechanistic insights in field of cardioprotection. To overcome unfeasible property of LPS, intensive research has focused on developing nontoxic metabolites of endotoxin. Monophosphoryl lipid A, one of the proposed derivatives, has been shown to induce a similar delayed cardioprotection in animal studies (Nelson et al., 1991; Baxter et al., 1996; Yamashita et al., 1999) and seems to be safe in humans as a vaccine adjuvant (Casella et al., 2008).

\subsubsection{Rapid ventricular pacing-induced postconditioning}

The cardioprotective outcome of ischemic postconditioning depends on several factors which indicate the necessity to develop new alternative methods and models to induce ischemic postconditioning.

In a meta-analysis of our previous studies on isolated hearts subjected ischemia/reperfusion we analyzed if there is an association between the duration of reperfusion-induced ventricular tachyarrhythmias (VT, VF, or VT+VF) and infarct size. It is well accepted in the literature that ischemia/reperfusion induces cellular damage that makes the myocardium more susceptible to arrhythmogenesis, and thus reperfusion-induced arrhythmias are considered as indicators of ischemia/reperfusion injury (Engelen et al., 2003; Majidi et al., 2009). For instance, Majidi et al. have reported that presence of reperfusion arrhythmia bursts in patients with ST-segment elevation myocardial infarction are associated with worse outcome (larger infarct size and decreased ejection fraction) (Majidi et al., 2009). However, here we found surprisingly that longer than $60 \mathrm{~s}$ reperfusion-induced VT/VF was associated with decreased infarct size. In this analysis, a larger area at risk was associated with longer total duration of VT+VF in accordance with literature data (Curtis et al., 1989). Interpretation of these results is difficult since causality was not examined in these studies. A possible explanation for the results of our meta-analysis is that the size of infarction affects the occurrence of sustained VT and/or VF, while another possibility is that longer tachyarrhythmias at the beginning of reperfusion somehow attenuate infarct development. To the best of our knowledge, this latter approach has not been investigated in the literature, and 
therefore these findings served as a basis for our current experimental study to investigate whether exogenous application of controlled tachycardia induced by rapid ventricular pacing at the onset of reperfusion can elicit cardioprotection.

Heart rate is known to play a role in the development of ischemia/reperfusion injury (Bernier et al., 1989) and its controlled modification may elicit cardioprotection. For instance, pharmacologically-induced bradycardia (Tosaki et al., 1987), slow- (Tosaki et al., 1988) or rapid (Ferdinandy et al., 1998; Hearse et al., 1999) pacing before ischemia was reported to limit myocardial injury. Since the presence of longer reperfusion-induced tachyarrhythmias was associated with lower infarct size in our meta-analysis, we wanted to test whether exogenous rapid pacing exerts protection. We demonstrated for the first time in the literature that the application of short periods of rapid $(600 \mathrm{bpm})$ ventricular pacing at the beginning of reperfusion reduces infarct size and reperfusion-induced arrhythmias.

Infarct size is a key determinant of major clinical outcomes (mortality and morbidity of consequent heart failure) (Gibbons et al., 2004); therefore, development of procedures which effectively decrease infarct size along with reperfusion therapy is in the focus of preclinical and clinical studies (Ovize et al., 2010). In the present study, both rapid ventricular pacing and classic ischemic postconditioning decreased infarct size. The beneficial effect of rapid ventricular pacing on infarct size was further confirmed by a reduction of LDH release into coronary effluent. We also suggest that rapid ventricular pacing-induced postconditioning is a simple method that eliminates technical problems associated with induction of ischemic postconditioning.

Besides infarct size reduction, rapid ventricular pacing-induced postconditioning decreased reperfusion-induced ventricular arrhythmias as well. Reperfusion therapy is accompanied by occurrence of arrhythmias (Krumholz et al., 1991). Some of them are benign (e.g. accelerated idioventricular rhythm, the most common type) but other ones are potentially life-threatening malignant arrhythmias such as VT or VF that need to be managed in the clinical practice to avoid fatal consequences. Based on literature data (Kloner et al., 2006), ischemic postconditioning effectively decreases ventricular arrhythmias. However, in our present study, solely rapid ventricular pacing-induced postconditioning reduced the incidence of reperfusion-induced VT with no significant effect on VF. The reason for the inability of rapid ventricular pacing to improve post-ischemic VF is not clear. However, one may 
speculate that some interacting triggers of reperfusion-induced VF (e.g. reactive oxygen intermediates and calcium) may interfere with the possible anti-VF effect of rapid ventricular pacing (Hearse et al., 1988).

\subsection{Peroxynitrite}

To our current knowledge, peroxynitrite seems to be a double-edged sword, as it has potential deleterious and cardioprotective effects as well (Ferdinandy et al., 2003). We showed in this thesis that both alternative approaches, low-dose LPS-pretreatment and rapid ventricular pacing enhances formation of myocardial 3-nitrotyrosine, a marker of peroxynitrite.

Although in LPS-induced late preconditioning of the brain, peroxynitrite has emerged as an early mediator (Kawano et al., 2007), peroxynitrite was not examined in the LPS-induced late cardioprotection. We showed that low-dose LPS-pretreatment enhances cardiac 3nitrotyrosine, thereby indicating a possible role for peroxynitrite in endotoxin-induced late preconditioning. Peroxynitrite arises from the non-enzymatic reaction of $\mathrm{O}_{2}{ }^{-}$with $\mathrm{NO}^{\circ}$. In order to elucidate the source of enhanced cardiac peroxynitrite formation induced by LPS, here we measured both precursors and found that cardiac levels of both $\mathrm{O}_{2}{ }^{-}$and $\mathrm{NO}^{\circ}$ were increased in low-dose LPS-pretreated hearts. Previous findings have suggested that $\mathrm{O}_{2}{ }^{--}$may be involved in endotoxin-induced late cardioprotection (Brown et al., 1989; Maulik et al., 1995); however, our study provided first direct data that cardiac level of $\mathrm{O}_{2}{ }^{-}{ }^{-}$is increased after a low-dose LPS-pretreatment. $\mathrm{O}_{2}{ }^{--}$is produced by enzymatic and non-enzymatic processes. XOR is a prominent enzymatic source for $\mathrm{O}_{2}{ }^{--}$(Afanas'ev, 2011), and in addition, XOR has been reported to contribute to post-ischemic preservation of left ventricular developed pressure in early ischemic preconditioning (Gelpi et al., 2002). The potential role of XOR in endotoxin-induced delayed preconditioning is not known. It was reported in endotoxemic animal models that high-dose LPS induces XOR in the heart (Khadour et al., 2002) and in the lung (Faggioni et al., 1994) $6 \mathrm{~h}$ or $24 \mathrm{~h}$ after the treatment, respectively. However, our study has revealed that cardioprotective low-dose LPS-pretreatment $24 \mathrm{~h}$ later increases the activity of XOR enzyme in the heart. This finding suggests that XOR contributes to LPS-induced delayed preconditioning by producing $\mathrm{O}_{2}{ }^{\circ-}$. Beside the $\mathrm{O}_{2}{ }^{\circ-}$, $\mathrm{NO}^{\circ}$ has already been implicated as a mediator of the endotoxin-induced cardiac late preconditioning (Bolli et al., 1997a; Qiu 
et al., 1997; Wang et al., 2002; Portnychenko et al., 2005; Wang et al., 2011) and our finding is consistent with these studies. $\mathrm{NO}^{\circ}$ can be produced by three isoforms of $\mathrm{NO}^{\circ}$ synthases: the $\mathrm{Ca}^{2+}$-independent iNOS and the $\mathrm{Ca}^{2+}$-dependent endothelial and neuronal NOS. Several studies have demonstrated the role of iNOS in delayed ischemic preconditioning (Wang et al., 2002; Bencsik et al., 2010; Wang et al., 2011). It has been also reported that iNOS mediates endotoxin-induced late preconditioning as well (Bolli et al., 1997b; Imagawa et al., 1999; Wang et al., 2002; Portnychenko et al., 2005; Wang et al., 2011). Our findings support these data since low-dose LPS-pretreatment increased the activity of $\mathrm{Ca}^{2+}$-independent-NOS without affecting the $\mathrm{Ca}^{2+}$-dependent isoforms in our present study.

Our research group has previously reported for the first time that peroxynitrite is a trigger of ischemic postconditioning, since the peroxynitrite scavenger, FeTPPS interfered with the cardioprotective effect of ischemic postconditioning (Kupai et al., 2009). Our results were confirmed by $\mathrm{Li}$ et al. showing that peroxynitrite is a key mediator of ischemic postconditioning in vivo ( $\mathrm{Li}$ et al., 2013). Here we demonstrated that ischemic postconditioning and rapid ventricular pacing-induced postconditioning enhanced peroxynitrite formation at the onset of reperfusion after an index ischemia. In addition, postconditioning maneuvers themselves (i.e. brief ischemia/reperfusion and rapid ventricular pacing) increased peroxynitrite formation without a preceding index ischemia. Since peroxynitrite is reported as a possible trigger of ischemic postconditioning (Kupai et al., 2009), based on our current results, we propose that the enhanced peroxynitrite formation also plays a role in triggering rapid ventricular pacing-induced postconditioning. Nevertheless, the possible mechanisms lying downstream of peroxynitrite formation in postconditioning have not been elucidated.

\subsection{RISK and SAFE pathways}

We also investigated the activation of RISK and SAFE pathways in our present study to further explore possible downstream mechanisms of alternative cardioprotective approaches.

These pro-survival signaling pathways are barely investigated in endotoxin-induced late preconditioning. Non-LPS induced activation of Akt (member of RISK) and STAT3 (member of SAFE) before a lethal injury was shown to confer cardioprotection (Matsui et al., 2001; Nduhirabandi et al., 2016). Ischemic preconditioning stimulus itself (i.e. brief 
ischemia/reperfusion cycles) increases cardiac Akt phosphorylation before a test ischemia (Yang et al., 2013) and in the present study, we showed that LPS-pretreatment also nonsignificantly increased Akt phosphorylation before the test ischemia. Post-ischemic activation of Akt in response to LPS-pretreatment was demonstrated by Ha et al. (Ha et al., 2008); however, data on pre-ischemic Akt activation is lacking in that study. In our present work the phosphorylation of ERK1/2 (members of RISK) was not changed significantly; nevertheless, a slight tendency of decrease can be noted, which is congruent with a study demonstrating that super-low-dose LPS preconditioning lowers the phosphorylation of ERKs in neutrophils (Chen et al., 2015). Although the transcription factor STAT3 has been implicated in late ischemic preconditioning (Xuan et al., 2001; Xuan et al., 2003), its role in endotoxin-induced delayed preconditioning has not yet been investigated. This is the first demonstration that low-dose LPS enhances the phosphorylation of cardiac STAT3 $24 \mathrm{~h}$ after the treatment thereby suggesting that activation of STAT3 before the ischemia may play a role in endotoxin-induced late preconditioning. Our hypothesis is supported by a finding that hydrogen peroxide-induced preconditioning stimulus itself activates STAT3 in PC12 cells before a lethal injury, which contributes to protection ( $\mathrm{Yu}$ et al., 2006). We also showed increased total STAT3 level in response to LPS-pretreatment, which is consistent with literature data (Huang et al., 2009; Chaves de Souza et al., 2013), and may indicate proteinlevel changes.

Here we also looked at possible targets of endogenous peroxynitrite formation induced by ischemic postconditioning or by rapid ventricular pacing. Several studies have reported that the activation of RISK and SAFE pathways at the onset of reperfusion might play a role in the cardioprotective effect of ischemic postconditioning (Hausenloy, 2009; Lecour, 2009a). In our present study, both ischemic- and rapid ventricular pacing-induced postconditioning nonsignificantly enhanced Akt phosphorylation without affecting ERK1/2 and STAT3 at the beginning of reperfusion. Although several studies showed increased phosphorylation of Akt and/or ERK1/2 due to ischemic postconditioning (Tsang et al., 2004; Yang et al., 2004), some recent papers suggested that postconditioning did not activate RISK pathway in the early phase of reperfusion (Skyschally et al., 2009a; Musiolik et al., 2010; Fekete et al., 2013). We also examined the effect of postconditioning maneuvers (i.e. repeated brief cycles of ischemia/reperfusion or rapid ventricular pacing) in the absence of a preceding index ischemia 
and found no activation of the RISK pathway. In these experiments, STAT3 phosphorylation was increased only by short periods of rapid ventricular pacing protocol. Taken together, our present results indicate that the precise role of the RISK and SAFE pathways remains to be elucidated in future studies. Involvement of alternative molecular pathways in the protective effect of rapid ventricular pacing-induced postconditioning is likely, and may include for instance activation of $\mathrm{NO}^{\circ}$-cGMP-PKG, sphingosine-, PKC-, or calcitonin gene-related peptide-mediated pathways (Heusch et al., 2008; Bice et al., 2014). Since endogenous NOcGMP play a role in protection against reperfusion injury by attenuating infarct size (Penna et al., 2006) and reperfusion-induced VF (Pabla et al., 1995; Pabla et al., 1996), investigation of the exact role of $\mathrm{NO}^{\circ}$ in rapid ventricular pacing would be interesting.

\subsection{Limitations of our studies and future perspectives}

Although specific clinical translational goals were beyond the scope of the present work, our findings may contribute to progress the state of current science on several fields. First, the role of peroxynitrite in cardioprotection, and the interplay between moderate oxidative stress and cardioprotective pathways are still unclear. Our results indicate that enhanced peroxynitrite formation and STAT3 phosphorylation (together or separately) may play a role in LPS-induced cardioprotection. Based on literature data it is feasible to suggest that peroxynitrite itself leads to STAT3 phosphorylation (Platt et al., 2005). This finding may facilitate further proof-of-concept studies to elucidate the exact interplay between peroxynitrite and STAT3 in cardiomyocytes during adaptive processes. Second, our results may strengthen the concept that activation of STAT3 transcription factor seems to be a significant step in cardioprotection (Heusch et al., 2011), which may support the importance of developing novel STAT3 activators or modulators that can be tested for their potential cardioprotective effects. Third, as we also showed that LPS-pretreatment has a great preventive potential, our findings may promote new research to find clinically applicable analogue molecules of LPS to induce pharmacological preconditioning.

Although we clearly demonstrated that rapid ventricular pacing induces cardioprotection when applied at the onset of reperfusion, some further limitations of our study may be considered. First, ventricular pacing was reported to have direct pro-arrhythmic effects caused by the stimulus itself independently from the heart rate (Nakata et al., 1990). Although in our 
study ventricular pacing last only for short periods $(6 \times 10 \mathrm{~s})$, and the incidence of reperfusion-induced VF was not increased in the rapid ventricular pacing group when compared to ischemia/reperfusion controls, consideration of pacing as an ectopic focus cannot be excluded. Second, in rapid ventricular pacing-induced postconditioning ventricles were activated in a non-physiological way in the present ex vivo study. Although the atrioventricular conduction system of rats was reported to be suitable for reaching $600 \mathrm{bpm}$ heart rate by atrial pacing in an in vivo model (Gonzalez et al., 1998), further in vivo studies are needed to investigate the infarct size limiting effect of postconditioning induced by rapid atrial or ventricular pacing at different rates. Third, our study suggests that rapid heart rate at the early phase of reperfusion may contribute to initiation of adaptive molecular mechanisms to prevent ischemia/reperfusion-induced cellular damage. However, further studies are needed to analyze (1) the precise molecular nature of these mechanisms and (2) if reperfusioninduced spontaneous arrhythmias also trigger adaptive mechanisms in the myocardium. Our findings may also suggest that reperfusion-induced tachyarrhythmias require attention in future studies focusing on cardioprotection assessed by infarct size. 


\section{Conclusions}

We can conclude that peroxynitrite may be somehow involved in both alternative cardioprotective approaches, i.e. in LPS-induced late preconditioning and rapid ventricular pacing-induced postconditioning. The role of RISK and SAFE pathways seems to be not clear and partly different in these alternative conditionings.

Low-dose LPS-pretreatment induces pharmacological late preconditioning and enhances cardiac peroxynitrite formation $24 \mathrm{~h}$ after the treatment by stimulating cardiac $\mathrm{O}_{2}{ }^{--}$and $\mathrm{NO}^{\circ}$ production through XOR and $\mathrm{Ca}^{2+}{ }^{2+}$-independent NOS enzymes. Activation of STAT3 before a lethal ischemia may play a role in the beneficial effect of endotoxin-induced delayed preconditioning.

Application of short periods of rapid ventricular pacing at the onset of reperfusion beneficially affects essential components of reperfusion injury: the infarct size and reperfusion-induced ventricular arrhythmias. In addition, rapid ventricular pacing increases peroxynitrite formation, which likely plays a role in triggering cardioprotection similarly to ischemic postconditioning. Nevertheless, rapid ventricular pacing-induced postconditioning seems to be independent of RISK and SAFE pathways, and further research is needed to elucidate downstream mechanisms. Since rapid ventricular pacing exerted a similar cardioprotective effect to ischemic postconditioning, we feel that rapid ventricular pacinginduced postconditioning may serve as an alternative experimental model of ischemic postconditioning. Moreover, rapid ventricular pacing could be performed in more controlled manner than applying brief ischemia/reperfusion cycles in ischemic postconditioning, which is an important technical advantage compared to the classic method. 


\section{Acknowledgement}

We acknowledge the support of grants from the Hungarian Scientific Research Fund (OTKA K79167 and F046810), National Office for Research and Technology Grants (NKTH MED_FOOD, TÁMOP-4.2.1/B-09/1/KONV-2010-0005, TÁMOP-4.2.2.A-11/1/KONV2012-0035). This work was prepared in the frame of the GINOP-2.3.2-15-2016-00040 (MYOTeam) project.

I would like to express my sincere acknowledgement to Prof. László Dux for providing me with the opportunity to work at the Department of Biochemistry and to Prof. Péter Ferdinandy, the leader of Cardiovascular Research Group.

I owe my heart-felt gratitude to my supervisors, Tamás Csont and Csaba Csonka. Without their support, guidance, encouragement and friendship throughout my undergraduate and $\mathrm{PhD}$ student years this thesis would not have been possible.

I would like to offer my special thanks to Zoltán V. Varga for his teaching, significant contribution, friendly support and insightful suggestions.

I am particularly grateful to Renáta Gáspár for the years working together, her constructive comments and warm encouragement.

I wish to thank the members of research group: Gabriella F. Kocsis, Veronika Fekete, Márta Sárközy, Gergő Szűcs, János Pálóczi, Krisztina Kupai, Péter Bencsik, Anikó Görbe, Krisztina Kiss, László Sárváry-Arantes and all the members of the Department of Biochemistry. I received generous technical support and assistance from Szilvia Török, Erzsébet Balázsházyné, Fatime Hawchar, Zita Felhő Makráné, Judit Kovács, Nóra Bagi, Zsuzsanna Lajtos, Klára Szunyi, Éva Makra, Tünde Bodnár, Ildikó Engi and Imre Ocsovszki.

Above all, I am deeply thankful for the support of my family. Without their help this thesis would not have materialized. At the final stage, Virág Demján provided me a stable background to overcome the difficulties. I wish to dedicate this work to her and my family. 


\section{References}

Afanas'ev I (2011). ROS and RNS signaling in heart disorders: could antioxidant treatment be successful? Oxid Med Cell Longev 2011: 293769.

Altug S, Demiryurek AT, Kane KA, Kanzik I (2000). Evidence for the involvement of peroxynitrite in ischaemic preconditioning in rat isolated hearts. Br J Pharmacol 130: 125131.

Baxter GF, Ferdinandy P (2001). Delayed preconditioning of myocardium: current perspectives. Basic Res Cardiol 96: 329-344.

Baxter GF, Goodwin RW, Wright MJ, Kerac M, Heads RJ, Yellon DM (1996). Myocardial protection after monophosphoryl lipid A: studies of delayed anti-ischaemic properties in rabbit heart. Br J Pharmacol 117: 1685-1692.

Beckman JS, Parks DA, Pearson JD, Marshall PA, Freeman BA (1989). A sensitive fluorometric assay for measuring xanthine dehydrogenase and oxidase in tissues. Free Radic Biol Med 6: 607-615.

Bencsik P, Kupai K, Giricz Z, Gorbe A, Pipis J, Murlasits Z, et al. (2010). Role of iNOS and peroxynitrite-matrix metalloproteinase-2 signaling in myocardial late preconditioning in rats. Am J Physiol Heart Circ Physiol 299: H512-518.

Bensard DD, Brown JM, Anderson BO, Banerjee A, Shanley PF, Grosso MA, et al. (1990). Induction of endogenous tissue antioxidant enzyme activity attenuates myocardial reperfusion injury. J Surg Res 49: 126-131.

Bernier M, Curtis MJ, Hearse DJ (1989). Ischemia-induced and reperfusion-induced arrhythmias: importance of heart rate. Am J Physiol 256: H21-31.

Bice JS, Baxter GF (2014). Postconditioning signalling in the heart: mechanisms and translatability. Br J Pharmacol 172: 1933-1946.

Bolli R (2000). The late phase of preconditioning. Circ Res 87: 972-983.

Bolli R, Bhatti ZA, Tang XL, Qiu Y, Zhang Q, Guo Y, et al. (1997a). Evidence that late preconditioning against myocardial stunning in conscious rabbits is triggered by the generation of nitric oxide. Circ Res 81: 42-52.

Bolli R, Manchikalapudi S, Tang XL, Takano H, Qiu Y, Guo Y, et al. (1997b). The protective effect of late preconditioning against myocardial stunning in conscious rabbits is mediated by nitric oxide synthase. Evidence that nitric oxide acts both as a trigger and as a mediator of the late phase of ischemic preconditioning. Circ Res 81: 1094-1107. 
Brown JM, Grosso MA, Terada LS, Whitman GJ, Banerjee A, White CW, et al. (1989). Endotoxin pretreatment increases endogenous myocardial catalase activity and decreases ischemia-reperfusion injury of isolated rat hearts. Proc Natl Acad Sci USA 86: 2516-2520.

Casella CR, Mitchell TC (2008). Putting endotoxin to work for us: monophosphoryl lipid A as a safe and effective vaccine adjuvant. Cell Mol Life Sci 65: 3231-3240.

Cave AC, Hearse DJ (1992). Ischaemic preconditioning and contractile function: studies with normothermic and hypothermic global ischaemia. J Mol Cell Cardiol 24: 1113-1123.

Chaves de Souza JA, Nogueira AV, Chaves de Souza PP, Kim YJ, Silva Lobo C, Pimentel Lopes de Oliveira GJ, et al. (2013). SOCS3 expression correlates with severity of inflammation, expression of proinflammatory cytokines, and activation of STAT3 and p38 MAPK in LPS-induced inflammation in vivo. Mediators Inflamm 2013: 650812.

Chen K, Geng S, Yuan R, Diao N, Upchurch Z, Li L (2015). Super-low dose endotoxin preconditioning exacerbates sepsis mortality. EBioMedicine 2: 324-333.

Currie RW, Karmazyn M, Kloc M, Mailer K (1988). Heat-shock response is associated with enhanced postischemic ventricular recovery. Circ Res 63: 543-549.

Curtis MJ, Hearse DJ (1989). Reperfusion-induced arrhythmias are critically dependent upon occluded zone size: relevance to the mechanism of arrhythmogenesis. J Mol Cell Cardiol 21: 625-637.

Csonka C, Csont T, Onody A, Ferdinandy P (2001). Preconditioning decreases ischemia/reperfusion-induced peroxynitrite formation. Biochem Biophys Res Commun 285: 1217-1219.

Csonka C, Kupai K, Kocsis GF, Novak G, Fekete V, Bencsik P, et al. (2010). Measurement of myocardial infarct size in preclinical studies. J Pharmacol Toxicol Methods 61: 163-170.

Csonka C, Pali T, Bencsik P, Gorbe A, Ferdinandy P, Csont T (2015). Measurement of NO in biological samples. Br J Pharmacol 172: 1620-1632.

Csonka C, Szilvassy Z, Fulop F, Pali T, Blasig IE, Tosaki A, et al. (1999). Classic preconditioning decreases the harmful accumulation of nitric oxide during ischemia and reperfusion in rat hearts. Circulation 100: 2260-2266.

Csont T, Bereczki E, Bencsik P, Fodor G, Gorbe A, Zvara A, et al. (2007). Hypercholesterolemia increases myocardial oxidative and nitrosative stress thereby leading to cardiac dysfunction in apoB-100 transgenic mice. Cardiovasc Res 76: 100-109.

Csont T, Csonka C, Kovacs P, Jancso G, Ferdinandy P (2003). Capsaicin-sensitive sensory neurons regulate myocardial nitric oxide and cGMP signaling. Eur J Pharmacol 476: 107113. 
Csont T, Csonka C, Onody A, Gorbe A, Dux L, Schulz R, et al. (2002). Nitrate tolerance does not increase production of peroxynitrite in the heart. Am J Physiol Heart Circ Physiol 283: H69-76.

Csont T, Pali T, Szilvassy Z, Ferdinandy P (1998). Lack of correlation between myocardial nitric oxide and cyclic guanosine monophosphate content in both nitrate-tolerant and nontolerant rats. Biochem Pharmacol 56: 1139-1144.

Csont T, Szilvassy Z, Fulop F, Nedeianu S, Pali T, Tosaki A, et al. (1999). Direct myocardial anti-ischaemic effect of GTN in both nitrate-tolerant and nontolerant rats: a cyclic GMPindependent activation of KATP. Br J Pharmacol 128: 1427-1434.

Darling CE, Solari PB, Smith CS, Furman MI, Przyklenk K (2007). 'Postconditioning' the human heart: multiple balloon inflations during primary angioplasty may confer cardioprotection. Basic Res Cardiol 102: 274-278.

Das M, Das DK (2008). Molecular mechanism of preconditioning. IUBMB Life 60: 199-203.

Downey JM, Hearse DJ, Yellon DM (1988). The role of xanthine oxidase during myocardial ischemia in several species including man. J Mol Cell Cardiol 20 Suppl 2: 55-63.

Eisen A, Fisman EZ, Rubenfire M, Freimark D, McKechnie R, Tenenbaum A, et al. (2004). Ischemic preconditioning: nearly two decades of research. A comprehensive review. Atherosclerosis 172: 201-210.

Engelen DJ, Gressin V, Krucoff MW, Theuns DA, Green C, Cheriex EC, et al. (2003). Usefulness of frequent arrhythmias after epicardial recanalization in anterior wall acute myocardial infarction as a marker of cellular injury leading to poor recovery of left ventricular function. Am J Cardiol 92: 1143-1149.

Faggioni R, Gatti S, Demitri MT, Delgado R, Echtenacher B, Gnocchi P, et al. (1994). Role of xanthine oxidase and reactive oxygen intermediates in LPS- and TNF-induced pulmonary edema. J Lab Clin Med 123: 394-399.

Fekete V, Murlasits Z, Aypar E, Bencsik P, Sarkozy M, Szenasi G, et al. (2013). Myocardial postconditioning is lost in vascular nitrate tolerance. J Cardiovasc Pharmacol 62: 298-303.

Ferdinandy P, Csonka C, Csont T, Szilvassy Z, Dux L (1998). Rapid pacing-induced preconditioning is recaptured by farnesol treatment in hearts of cholesterol-fed rats: role of polyprenyl derivatives and nitric oxide. Mol Cell Biochem 186: 27-34.

Ferdinandy P, Csont T, Csonka C, Torok M, Dux M, Nemeth J, et al. (1997a). Capsaicinsensitive local sensory innervation is involved in pacing-induced preconditioning in rat hearts: role of nitric oxide and CGRP? Naunyn Schmiedebergs Arch Pharmacol 356: 356-363.

Ferdinandy P, Schulz R (2003). Nitric oxide, superoxide, and peroxynitrite in myocardial ischaemia-reperfusion injury and preconditioning. Br J Pharmacol 138: 532-543. 
Ferdinandy P, Schulz R, Baxter GF (2007). Interaction of cardiovascular risk factors with myocardial ischemia/reperfusion injury, preconditioning, and postconditioning. Pharmacol Rev 59: 418-458.

Ferdinandy P, Szilvassy Z, Horvath LI, Csont T, Csonka C, Nagy E, et al. (1997b). Loss of pacing-induced preconditioning in rat hearts: role of nitric oxide and cholesterol-enriched diet. J Mol Cell Cardiol 29: 3321-3333.

Frasier CR, Moore RL, Brown DA (2011). Exercise-induced cardiac preconditioning: how exercise protects your achy-breaky heart. J Appl Physiol (1985) 111: 905-915.

Gelpi RJ, Morales C, Cohen MV, Downey JM (2002). Xanthine oxidase contributes to preconditioning's preservation of left ventricular developed pressure in isolated rat heart: developed pressure may not be an appropriate end-point for studies of preconditioning. Basic Res Cardiol 97: 40-46.

Gibbons RJ, Valeti US, Araoz PA, Jaffe AS (2004). The quantification of infarct size. $J$ Am Coll Cardiol 44: 1533-1542.

Gonzalez NC, Clancy RL, Moue Y, Richalet JP (1998). Increasing maximal heart rate increases maximal O2 uptake in rats acclimatized to simulated altitude. J Appl Physiol (1985) 84: 164-168.

Goto M, Liu Y, Yang XM, Ardell JL, Cohen MV, Downey JM (1995). Role of bradykinin in protection of ischemic preconditioning in rabbit hearts. Circ Res 77: 611-621.

Gowda A, Yang CJ, Asimakis GK, Ruef J, Rastegar S, Runge MS, et al. (1998). Cardioprotection by local heating: improved myocardial salvage after ischemia and reperfusion. Ann Thorac Surg 65: 1241-1247.

Gross ER, Gross GJ (2006). Ligand triggers of classical preconditioning and postconditioning. Cardiovasc Res 70: 212-221.

Ha T, Hua F, Liu X, Ma J, McMullen JR, Shioi T, et al. (2008). Lipopolysaccharide-induced myocardial protection against ischaemia/reperfusion injury is mediated through a PI3K/Aktdependent mechanism. Cardiovasc Res 78: 546-553.

Hahn JY, Song YB, Kim EK, Yu CW, Bae JW, Chung WY, et al. (2013). Ischemic postconditioning during primary percutaneous coronary intervention: the effects of postconditioning on myocardial reperfusion in patients with ST-segment elevation myocardial infarction (POST) randomized trial. Circulation 128: 1889-1896.

Hausenloy DJ (2009). Signalling pathways in ischaemic postconditioning. Thromb Haemost 101: 626-634.

Hausenloy DJ, Ong SB, Yellon DM (2009). The mitochondrial permeability transition pore as a target for preconditioning and postconditioning. Basic Res Cardiol 104: 189-202. 
Hausenloy DJ, Yellon DM (2004). New directions for protecting the heart against ischaemiareperfusion injury: targeting the Reperfusion Injury Salvage Kinase (RISK)-pathway. Cardiovasc Res 61: 448-460.

Hausenloy DJ, Yellon DM (2016). Ischaemic conditioning and reperfusion injury. Nat Rev Cardiol 13: 193-209.

HCSO: Hungarian Central Statistical Office HCSO (2015). Common Causes of Mortality http://www.ksh.hu/docs/hun/xstadat/xstadat_eves/i_wnh001.html last vidited on 29/10/2017.

Hearse DJ, Ferrari R, Sutherland FJ (1999). Cardioprotection: intermittent ventricular fibrillation and rapid pacing can induce preconditioning in the blood-perfused rat heart. $J \mathrm{Mol}$ Cell Cardiol 31: 1961-1973.

Hearse DJ, Tosaki A (1988). Free radicals and calcium: simultaneous interacting triggers as determinants of vulnerability to reperfusion-induced arrhythmias in the rat heart. J Mol Cell Cardiol 20: 213-223.

Heusch G, Boengler K, Schulz R (2008). Cardioprotection: nitric oxide, protein kinases, and mitochondria. Circulation 118: 1915-1919.

Heusch G, Musiolik J, Gedik N, Skyschally A (2011). Mitochondrial STAT3 activation and cardioprotection by ischemic postconditioning in pigs with regional myocardial ischemia/reperfusion. Circ Res 109: 1302-1308.

Huang H, Constante M, Layoun A, Santos MM (2009). Contribution of STAT3 and SMAD4 pathways to the regulation of hepcidin by opposing stimuli. Blood 113: 3593-3599.

Ibanez B, James S, Agewall S, Antunes MJ, Bucciarelli-Ducci C, Bueno H, et al. (2017). 2017 ESC Guidelines for the management of acute myocardial infarction in patients presenting with ST-segment elevation: The Task Force for the management of acute myocardial infarction in patients presenting with ST-segment elevation of the European Society of Cardiology (ESC). Eur Heart J.

Iliodromitis EK, Georgiadis M, Cohen MV, Downey JM, Bofilis E, Kremastinos DT (2006). Protection from post-conditioning depends on the number of short ischemic insults in anesthetized pigs. Basic Res Cardiol 101: 502-507.

Imagawa J, Yellon DM, Baxter GF (1999). Pharmacological evidence that inducible nitric oxide synthase is a mediator of delayed preconditioning. Br J Pharmacol 126: 701-708.

Jenkins DP, Pugsley WB, Alkhulaifi AM, Kemp M, Hooper J, Yellon DM (1997). Ischaemic preconditioning reduces troponin $\mathrm{T}$ release in patients undergoing coronary artery bypass surgery. Heart 77: 314-318. 
Ji B, Liu M, Liu J, Wang G, Feng W, Lu F, et al. (2007). Evaluation by cardiac troponin I: the effect of ischemic preconditioning as an adjunct to intermittent blood cardioplegia on coronary artery bypass grafting. J Card Surg 22: 394-400.

Kawano T, Kunz A, Abe T, Girouard H, Anrather J, Zhou P, et al. (2007). iNOS-derived NO and nox2-derived superoxide confer tolerance to excitotoxic brain injury through peroxynitrite. J Cereb Blood Flow Metab 27: 1453-1462.

Khadour FH, Panas D, Ferdinandy P, Schulze C, Csont T, Lalu MM, et al. (2002). Enhanced $\mathrm{NO}$ and superoxide generation in dysfunctional hearts from endotoxemic rats. Am J Physiol Heart Circ Physiol 283: H1108-1115.

Kingma JG, Jr. (1999). Cardiac adaptation to ischemia-reperfusion injury. Ann N Y Acad Sci 874: 83-99.

Kloner RA, Dow J, Bhandari A (2006). Postconditioning markedly attenuates ventricular arrhythmias after ischemia-reperfusion. J Cardiovasc Pharmacol Ther 11: 55-63.

Kocsis GF, Pipis J, Fekete V, Kovacs-Simon A, Odendaal L, Molnar E, et al. (2008). Lovastatin interferes with the infarct size-limiting effect of ischemic preconditioning and postconditioning in rat hearts. Am J Physiol Heart Circ Physiol 294: H2406-2409.

Kocsis GF, Sarkozy M, Bencsik P, Pipicz M, Varga ZV, Paloczi J, et al. (2012). Preconditioning protects the heart in a prolonged uremic condition. Am J Physiol Heart Circ Physiol 303: H1229-1236.

Krumholz HM, Goldberger AL (1991). Reperfusion arrhythmias after thrombolysis. Electrophysiologic tempest, or much ado about nothing. Chest 99: 135S-140S.

Ku DD, Liu S, Dai J (1995). Coronary Vascular and Antiplatelet Effects of Peroxynitrite in Human Tissues. Endothelium 3: 309-319.

Kupai K, Csonka C, Fekete V, Odendaal L, van Rooyen J, Marais de W, et al. (2009). Cholesterol diet-induced hyperlipidemia impairs the cardioprotective effect of postconditioning: role of peroxynitrite. Am J Physiol Heart Circ Physiol 297: H1729-1735.

Laskey WK, Yoon S, Calzada N, Ricciardi MJ (2008). Concordant improvements in coronary flow reserve and ST-segment resolution during percutaneous coronary intervention for acute myocardial infarction: a benefit of postconditioning. Catheter Cardiovasc Interv 72: 212-220.

Laurikka J, Wu ZK, Iisalo P, Kaukinen L, Honkonen EL, Kaukinen S, et al. (2002). Regional ischemic preconditioning enhances myocardial performance in off-pump coronary artery bypass grafting. Chest 121: 1183-1189.

Lecour S (2009a). Activation of the protective Survivor Activating Factor Enhancement (SAFE) pathway against reperfusion injury: Does it go beyond the RISK pathway? J Mol Cell Cardiol 47: 32-40. 
Lecour S (2009b). Multiple protective pathways against reperfusion injury: a SAFE path without Aktion? J Mol Cell Cardiol 46: 607-609.

Lecour S, Suleman N, Deuchar GA, Somers S, Lacerda L, Huisamen B, et al. (2005). Pharmacological preconditioning with tumor necrosis factor-alpha activates signal transducer and activator of transcription-3 at reperfusion without involving classic prosurvival kinases (Akt and extracellular signal-regulated kinase). Circulation 112: 3911-3918.

Lefer DJ, Scalia R, Campbell B, Nossuli T, Hayward R, Salamon M, et al. (1997). Peroxynitrite inhibits leukocyte-endothelial cell interactions and protects against ischemiareperfusion injury in rats. J Clin Invest 99: 684-691.

Li J, Loukili N, Rosenblatt-Velin N, Pacher P, Feihl F, Waeber B, et al. (2013). Peroxynitrite is a key mediator of the cardioprotection afforded by ischemic postconditioning in vivo. PLoS One 8: e70331.

Liu S, Beckman JS, Ku DD (1994). Peroxynitrite, a product of superoxide and nitric oxide, produces coronary vasorelaxation in dogs. J Pharmacol Exp Ther 268: 1114-1121.

Liu Y, Downey JM (1992). Ischemic preconditioning protects against infarction in rat heart. Am J Physiol 263: H1107-1112.

Majidi M, Kosinski AS, Al-Khatib SM, Lemmert ME, Smolders L, van Weert A, et al. (2009). Reperfusion ventricular arrhythmia 'bursts' predict larger infarct size despite TIMI 3 flow restoration with primary angioplasty for anterior ST-elevation myocardial infarction. Eur Heart J 30: 757-764.

Marber MS, Latchman DS, Walker JM, Yellon DM (1993). Cardiac stress protein elevation 24 hours after brief ischemia or heat stress is associated with resistance to myocardial infarction. Circulation 88: 1264-1272.

Matsui T, Tao J, del Monte F, Lee KH, Li L, Picard M, et al. (2001). Akt activation preserves cardiac function and prevents injury after transient cardiac ischemia in vivo. Circulation 104: 330-335.

Maulik N, Watanabe M, Engelman D, Engelman RM, Kagan VE, Kisin E, et al. (1995). Myocardial adaptation to ischemia by oxidative stress induced by endotoxin. Am J Physiol 269: C907-916.

Meldrum DR, Sheridan BC, Cleveland JC, Jr., Fullerton DA, Banerjee A, Harken AH (1996). Neutrophils are required for endotoxin-induced myocardial cross-tolerance to ischemiareperfusion injury. Arch Surg 131: 1203-1208.

Miller DL, Van Winkle DM (1999). Ischemic preconditioning limits infarct size following regional ischemia-reperfusion in in situ mouse hearts. Cardiovasc Res 42: 680-684. 
Morris JN, Everitt MG, Pollard R, Chave SP, Semmence AM (1980). Vigorous exercise in leisure-time: protection against coronary heart disease. Lancet 2: 1207-1210.

Mozaffarian D, Benjamin EJ, Go AS, Arnett DK, Blaha MJ, Cushman M, et al. (2016). Heart Disease and Stroke Statistics-2016 Update: A Report From the American Heart Association. Circulation 133: e38-360.

Murry CE, Jennings RB, Reimer KA (1986). Preconditioning with ischemia: a delay of lethal cell injury in ischemic myocardium. Circulation 74: 1124-1136.

Musiolik J, van Caster P, Skyschally A, Boengler K, Gres P, Schulz R, et al. (2010). Reduction of infarct size by gentle reperfusion without activation of reperfusion injury salvage kinases in pigs. Cardiovasc Res 85: 110-117.

Nakata T, Hearse DJ, Curtis MJ (1990). Are reperfusion-induced arrhythmias caused by disinhibition of an arrhythmogenic component of ischemia? J Mol Cell Cardiol 22: 843-858.

Nduhirabandi F, Lamont K, Albertyn Z, Opie LH, Lecour S (2016). Role of toll-like receptor 4 in melatonin-induced cardioprotection. J Pineal Res 60: 39-47.

Nelson DW, Brown JM, Banerjee A, Bensard DD, Rogers KB, Locke-Winter CR, et al. (1991). Pretreatment with a nontoxic derivative of endotoxin induces functional protection against cardiac ischemia/reperfusion injury. Surgery 110: 365-369.

Ovize M, Baxter GF, Di Lisa F, Ferdinandy P, Garcia-Dorado D, Hausenloy DJ, et al. (2010). Postconditioning and protection from reperfusion injury: where do we stand? Position paper from the Working Group of Cellular Biology of the Heart of the European Society of Cardiology. Cardiovasc Res 87: 406-423.

Pabla R, Bland-Ward P, Moore PK, Curtis MJ (1995). An endogenous protectant effect of cardiac cyclic GMP against reperfusion-induced ventricular fibrillation in the rat heart. $\mathrm{Br} J$ Pharmacol 116: 2923-2930.

Pabla R, Curtis MJ (1996). Endogenous protection against reperfusion-induced ventricular fibrillation: role of neuronal versus non-neuronal sources of nitric oxide and species dependence in the rat versus rabbit isolated heart. J Mol Cell Cardiol 28: 2097-2110.

Pacher P, Beckman JS, Liaudet L (2007). Nitric oxide and peroxynitrite in health and disease. Physiol Rev 87: 315-424.

Penna C, Cappello S, Mancardi D, Raimondo S, Rastaldo R, Gattullo D, et al. (2006). Postconditioning reduces infarct size in the isolated rat heart: role of coronary flow and pressure and the nitric oxide/cGMP pathway. Basic Res Cardiol 101: 168-179.

Penna C, Tullio F, Merlino A, Moro F, Raimondo S, Rastaldo R, et al. (2009). Postconditioning cardioprotection against infarct size and post-ischemic systolic dysfunction is influenced by gender. Basic Res Cardiol 104: 390-402. 
Perrelli MG, Pagliaro P, Penna C (2011). Ischemia/reperfusion injury and cardioprotective mechanisms: Role of mitochondria and reactive oxygen species. World J Cardiol 3: 186-200.

Philipp S, Yang XM, Cui L, Davis AM, Downey JM, Cohen MV (2006). Postconditioning protects rabbit hearts through a protein kinase $\mathrm{C}$-adenosine $\mathrm{A} 2 \mathrm{~b}$ receptor cascade. Cardiovasc Res 70: 308-314.

Pinheiro BB, Fiorelli AI, Gomes OM (2009). Effects of ischemic postconditioning on left ventricular function of isolated rat hearts. Rev Bras Cir Cardiovasc 24: 31-37.

Piot C, Croisille P, Staat P, Thibault H, Rioufol G, Mewton N, et al. (2008). Effect of cyclosporine on reperfusion injury in acute myocardial infarction. $N$ Engl J Med 359: 473481.

Platt DH, Bartoli M, El-Remessy AB, Al-Shabrawey M, Lemtalsi T, Fulton D, et al. (2005). Peroxynitrite increases VEGF expression in vascular endothelial cells via STAT3. Free Radic Biol Med 39: 1353-1361.

Portnychenko AG, Harmatina OY, Kotsuruba AV, Moybenko OO (2005). The role of nitric oxide in endotoxin-induced cardiodepression. Exp Clin Cardiol 10: 223-228.

Qiu Y, Rizvi A, Tang XL, Manchikalapudi S, Takano H, Jadoon AK, et al. (1997). Nitric oxide triggers late preconditioning against myocardial infarction in conscious rabbits. Am $J$ Physiol 273: H2931-2936.

Reimer KA, Lowe JE, Rasmussen MM, Jennings RB (1977). The wavefront phenomenon of ischemic cell death. 1. Myocardial infarct size vs duration of coronary occlusion in dogs. Circulation 56: 786-794.

Schott RJ, Rohmann S, Braun ER, Schaper W (1990). Ischemic preconditioning reduces infarct size in swine myocardium. Circ Res 66: 1133-1142.

Schulman D, Latchman DS, Yellon DM (2002). Urocortin protects the heart from reperfusion injury via upregulation of p42/p44 MAPK signaling pathway. Am J Physiol Heart Circ Physiol 283: H1481-1488.

Shiki K, Hearse DJ (1987). Preconditioning of ischemic myocardium: reperfusion-induced arrhythmias. Am J Physiol 253: H1470-1476.

Skyschally A, van Caster P, Boengler K, Gres P, Musiolik J, Schilawa D, et al. (2009a). Ischemic postconditioning in pigs: no causal role for RISK activation. Circ Res 104: 15-18.

Skyschally A, van Caster P, Iliodromitis EK, Schulz R, Kremastinos DT, Heusch G (2009b). Ischemic postconditioning: experimental models and protocol algorithms. Basic Res Cardiol 104: 469-483. 
Staat P, Rioufol G, Piot C, Cottin Y, Cung TT, L'Huillier I, et al. (2005). Postconditioning the human heart. Circulation 112: 2143-2148.

Stein AB, Tang XL, Guo Y, Xuan YT, Dawn B, Bolli R (2004). Delayed adaptation of the heart to stress: late preconditioning. Stroke 35: 2676-2679.

Tang XL, Takano H, Rizvi A, Turrens JF, Qiu Y, Wu WJ, et al. (2002). Oxidant species trigger late preconditioning against myocardial stunning in conscious rabbits. Am J Physiol Heart Circ Physiol 282: H281-291.

Thibault H, Piot C, Ovize M (2007). Postconditioning in man. Heart Fail Rev 12: 245-248.

Thibault H, Piot C, Staat P, Bontemps L, Sportouch C, Rioufol G, et al. (2008). Long-term benefit of postconditioning. Circulation 117: 1037-1044.

Tosaki A, Balint S, Szekeres L (1988). Pacing and reperfusion induced arrhythmias: protection by slow heart rate in the rat heart. Cardiovasc Res 22: 818-825.

Tosaki A, Szekeres L, Hearse DJ (1987). Metoprolol reduces reperfusion-induced fibrillation in the isolated rat heart: protection is secondary to bradycardia. J Cardiovasc Pharmacol 10: 489-497.

Townsend N, Wilson L, Bhatnagar P, Wickramasinghe K, Rayner M, Nichols M (2016). Cardiovascular disease in Europe: epidemiological update 2016. Eur Heart J 37: 3232-3245.

Tsang A, Hausenloy DJ, Mocanu MM, Yellon DM (2004). Postconditioning: a form of "modified reperfusion" protects the myocardium by activating the phosphatidylinositol 3kinase-Akt pathway. Circ Res 95: 230-232.

Tsutsumi YM, Yokoyama T, Horikawa Y, Roth DM, Patel HH (2007). Reactive oxygen species trigger ischemic and pharmacological postconditioning: in vivo and in vitro characterization. Life Sci 81: 1223-1227.

Varga ZV, Kupai K, Szucs G, Gaspar R, Paloczi J, Farago N, et al. (2013). MicroRNA-25dependent up-regulation of NADPH oxidase 4 (NOX4) mediates hypercholesterolemiainduced oxidative/nitrative stress and subsequent dysfunction in the heart. J Mol Cell Cardiol 62: 111-121.

Varga ZV, Zvara A, Farago N, Kocsis GF, Pipicz M, Gaspar R, et al. (2014). MicroRNAs associated with ischemia-reperfusion injury and cardioprotection by ischemic pre- and postconditioning: protectomiRs. Am J Physiol Heart Circ Physiol 307: H216-227.

Walker MJ, Curtis MJ, Hearse DJ, Campbell RW, Janse MJ, Yellon DM, et al. (1988). The Lambeth Conventions: guidelines for the study of arrhythmias in ischaemia infarction, and reperfusion. Cardiovasc Res 22: 447-455. 
Wang E, Feng Y, Zhang M, Zou L, Li Y, Buys ES, et al. (2011). Toll-like receptor 4 signaling confers cardiac protection against ischemic injury via inducible nitric oxide synthase- and soluble guanylate cyclase-dependent mechanisms. Anesthesiology 114: 603613.

Wang H, Naghavi M, Allen C, Barber RM, Bhutta ZA, Carter A, et al. (2016). Global, regional, and national life expectancy, all-cause mortality, and cause-specific mortality for 249 causes of death, 1980-2015: a systematic analysis for the Global Burden of Disease Study 2015. Lancet 388: 1459-1544.

Wang YP, Sato C, Mizoguchi K, Yamashita Y, Oe M, Maeta H (2002). Lipopolysaccharide triggers late preconditioning against myocardial infarction via inducible nitric oxide synthase. Cardiovasc Res 56: 33-42.

Xi L, Das A, Zhao ZQ, Merino VF, Bader M, Kukreja RC (2008). Loss of myocardial ischemic postconditioning in adenosine $\mathrm{A} 1$ and bradykinin $\mathrm{B} 2$ receptors gene knockout mice. Circulation 118: S32-37.

Xuan YT, Guo Y, Han H, Zhu Y, Bolli R (2001). An essential role of the JAK-STAT pathway in ischemic preconditioning. Proc Natl Acad Sci U S A 98: 9050-9055.

Xuan YT, Guo Y, Zhu Y, Han H, Langenbach R, Dawn B, et al. (2003). Mechanism of cyclooxygenase-2 upregulation in late preconditioning. J Mol Cell Cardiol 35: 525-537.

Yamashita N, Hoshida S, Otsu K, Taniguchi N, Kuzuya T, Hori M (1999). Monophosphoryl lipid A provides biphasic cardioprotection against ischaemia-reperfusion injury in rat hearts. Br J Pharmacol 128: 412-418.

Yang C, Talukder MA, Varadharaj S, Velayutham M, Zweier JL (2013). Early ischaemic preconditioning requires Akt- and PKA-mediated activation of eNOS via serine1176 phosphorylation. Cardiovasc Res 97: 33-43.

Yang XC, Liu Y, Wang LF, Cui L, Wang T, Ge YG, et al. (2007). Reduction in myocardial infarct size by postconditioning in patients after percutaneous coronary intervention. $J$ Invasive Cardiol 19: 424-430.

Yang XM, Proctor JB, Cui L, Krieg T, Downey JM, Cohen MV (2004). Multiple, brief coronary occlusions during early reperfusion protect rabbit hearts by targeting cell signaling pathways. J Am Coll Cardiol 44: 1103-1110.

Yasmin W, Strynadka KD, Schulz R (1997). Generation of peroxynitrite contributes to ischemia-reperfusion injury in isolated rat hearts. Cardiovasc Res 33: 422-432.

Yellon DM, Alkhulaifi AM, Pugsley WB (1993). Preconditioning the human myocardium. Lancet 342: 276-277. 
Yellon DM, Downey JM (2003). Preconditioning the myocardium: from cellular physiology to clinical cardiology. Physiol Rev 83: 1113-1151.

Yellon DM, Hausenloy DJ (2007). Myocardial reperfusion injury. N Engl J Med 357: 11211135 .

Yu HM, Zhi JL, Cui Y, Tang EH, Sun SN, Feng JQ, et al. (2006). Role of the JAK-STAT pathway in protection of hydrogen peroxide preconditioning against apoptosis induced by oxidative stress in PC12 cells. Apoptosis 11: 931-941.

Zhao ZQ, Corvera JS, Halkos ME, Kerendi F, Wang NP, Guyton RA, et al. (2003). Inhibition of myocardial injury by ischemic postconditioning during reperfusion: comparison with ischemic preconditioning. Am J Physiol Heart Circ Physiol 285: H579-588. 
11. Annex 


\section{I.}

Pipicz M.; Kocsis G.F.; Sarvary-Arantes L.; Bencsik P.; Varga Z.V.; Ferdinandy P.; Csont T. Low-dose endotoxin induces late preconditioning, increases peroxynitrite formation, and activates STAT3 in the rat heart. Molecules 2017, 22. [IF: 2.861] 


\title{
Low-Dose Endotoxin Induces Late Preconditioning, Increases Peroxynitrite Formation, and Activates STAT3 in the Rat Heart
}

\author{
Márton Pipicz ${ }^{1}$, Gabriella F. Kocsis ${ }^{1}$, László Sárváry-Arantes ${ }^{1}$, Péter Bencsik ${ }^{1,2}$, \\ Zoltán V. Varga ${ }^{1,3}$, Péter Ferdinandy ${ }^{1,2,3}$ and Tamás Csont ${ }^{1, *}$ \\ 1 Department of Biochemistry, Faculty of Medicine, University of Szeged, Dóm tér. 9., H-6720 Szeged, \\ Hungary; pipicz.marton@med.u-szeged.hu (M.P.); gokf1@leicester.ac.uk (G.F.K.); \\ sarvaryl@gmail.com (L.S-A.); bencsik.peter@med.u-szeged.hu (P.B.); \\ varga.zoltan@med.semmelweis-univ.hu (Z.V.V.); peter.ferdinandy@pharmahungary.com (P.F.) \\ 2 Pharmahungary 2000 Ltd., Dóm tér. 9., H-6720 Szeged, Hungary \\ 3 Department of Pharmacology and Pharmacotherapy, Semmelweis University, Nagyvárad tér. 4., \\ H-1089 Budapest, Hungary \\ * Correspondence: csont.tamas@med.u-szeged.hu; Tel.: +36-62-545-096
}

Academic Editor: Diego Muñoz-Torrero

Received: 19 December 2016; Accepted: 1 March 2017; Published: 8 March 2017

\begin{abstract}
Administration of low-dose endotoxin (lipopolysaccharide, LPS) $24 \mathrm{~h}$ before a lethal ischemia induces pharmacological late preconditioning. The exact mechanism of this phenomenon is not clear. Here we aimed to investigate whether low-dose LPS exerts late effects on peroxynitrite formation and activation of Akt, Erk, and STAT3 in the heart. Male Wistar rats were injected with LPS (S. typhimurium; $0.5 \mathrm{mg} / \mathrm{kg}$ i.p.) or saline. Twenty-four hours later, hearts were isolated, perfused for $10 \mathrm{~min}$, and then used for biochemical analyses. LPS pretreatment enhanced cardiac formation of the peroxynitrite marker 3-nitrotyrosine. LPS pretreatment also increased cardiac levels of the peroxynitrite precursor nitric oxide $(\mathrm{NO})$ and superoxide. The activities of $\mathrm{Ca}^{2+}$-independent $\mathrm{NO}$ synthase and xanthine oxidoreductase increased in LPS-pretreated hearts. LPS pretreatment resulted in significantly enhanced phosphorylation of STAT3 and non-significantly increased phosphorylation of Akt without affecting the activation of Erk. In separate experiments, isolated working hearts were subjected to $30 \mathrm{~min}$ global ischemia and $20 \mathrm{~min}$ reperfusion. LPS pretreatment significantly improved ischemia-reperfusion-induced deterioration of cardiac function. We conclude that LPS pretreatment enhances cardiac peroxynitrite formation and activates STAT3 $24 \mathrm{~h}$ later, which may contribute to LPS-induced late preconditioning.
\end{abstract}

Keywords: oxidative stress; $\mathrm{ONOO}^{-}$; iNOS; XOR; SAFE pathway; cardioprotection

\section{Introduction}

Cardiovascular diseases including myocardial infarction are the leading cause of death in western societies. Cardiac injury associated with myocardial infarction and subsequent reperfusion due to therapeutic restoration of blood supply (i.e., ischemia-reperfusion injury) includes cell death, life-threatening arrhythmias, and myocardial contractile dysfunction [1]. Preconditioning (PreC) is a well-known phenomenon applied before a lethal ischemia to protect the heart [2]. The protection is biphasic with an early phase (lasts for hours) and a late phase (starts $12 \mathrm{~h}$ after PreC stimuli and lasts for $\sim 72 \mathrm{~h}$ ) [3]. The latter lasts longer and protects against myocardial stunning as well, which makes the late phase of PreC clinically more relevant [4]. Late PreC can be elicited by a wide variety of non-pharmacological (e.g., ischemia-reperfusion, heat stress, rapid ventricular pacing, exercise) and pharmacological (e.g., endotoxin, cytokines, nitric oxide donors, opioids) stimuli $[5,6]$. 
Pharmacological PreC is a non-invasive way to confer cardioprotection, therefore it has a great preventive and therapeutic potential.

Administration of a low-dose endotoxin, lipopolysaccharide (LPS), $24 \mathrm{~h}$ before a test ischemia-reperfusion has been shown to improve post-ischemic cardiac functional recovery thereby exerting pharmacological PreC [7]. The exact mechanism of endotoxin-induced late PreC is not entirely clear. Nitric oxide (NO) has been implicated as a mediator, and inducible NO synthase (iNOS) has been identified as a major source of $\mathrm{NO}$ in endotoxin-induced late PreC in the heart [8-10]. Besides $\mathrm{NO}$, indirect evidence suggests that superoxide $\left(\mathrm{O}_{2}{ }^{\bullet-}\right)$ may also be involved in endotoxin-induced late cardioprotection [7,11]; however, the cardiac level of $\mathrm{O}_{2}{ }^{\bullet-}$ after low-dose LPS pretreatment has not been determined yet.

Furthermore, increasing evidence suggests that enhanced formation of cardiac peroxynitrite $\left(\mathrm{ONOO}^{-}\right)$, the reaction product of $\mathrm{NO}$ and $\mathrm{O}_{2}{ }^{\bullet-}$, plays a role in early $[12,13]$ and late phase of ischemia-induced delayed PreC as well [14]. However, data is still lacking regarding the delayed effect of cardioprotective low-dose LPS on $\mathrm{ONOO}^{-}$formation in the heart.

Cardioprotective signalling pathways are barely investigated in late PreC elicited by LPS. Reperfusion injury salvage kinase (RISK) and survival activating factor enhancement (SAFE) signalling are well-known cardioprotective pathways $[15,16]$ and have been implicated in the mechanism of ischemic and certain-types of pharmacological late PreC [5,17]. In LPS-induced late PreC the activation of Akt, a protein kinase of RISK pathway was shown to play a role [18]; however, the potential implication of transcription factor STAT3 - the key member of SAFE- has not yet been tested.

Therefore, here we investigated whether low-dose cardioprotective LPS has any delayed effect on $\mathrm{ONOO}^{-}$formation in the heart. Furthermore, we tested the late effect of low-dose LPS treatment on the activation of cardiac RISK (Akt, Erk) and SAFE (STAT3) pathways.

\section{Results}

\subsection{LPS Pretreatment Improves Post-Ischemic Cardiac Function and LDH Release: Evidence for Delayed Cardioprotection}

Cardiac performance was measured in isolated hearts subjected to global ischemia $24 \mathrm{~h}$ after in vivo low-dose LPS (S. typhimurium; $0.5 \mathrm{mg} / \mathrm{kg}$ i.p.) or saline injection. Cardiac function of both the control and LPS-pretreated groups was deteriorated during reperfusion after global ischemia (Figure 1).
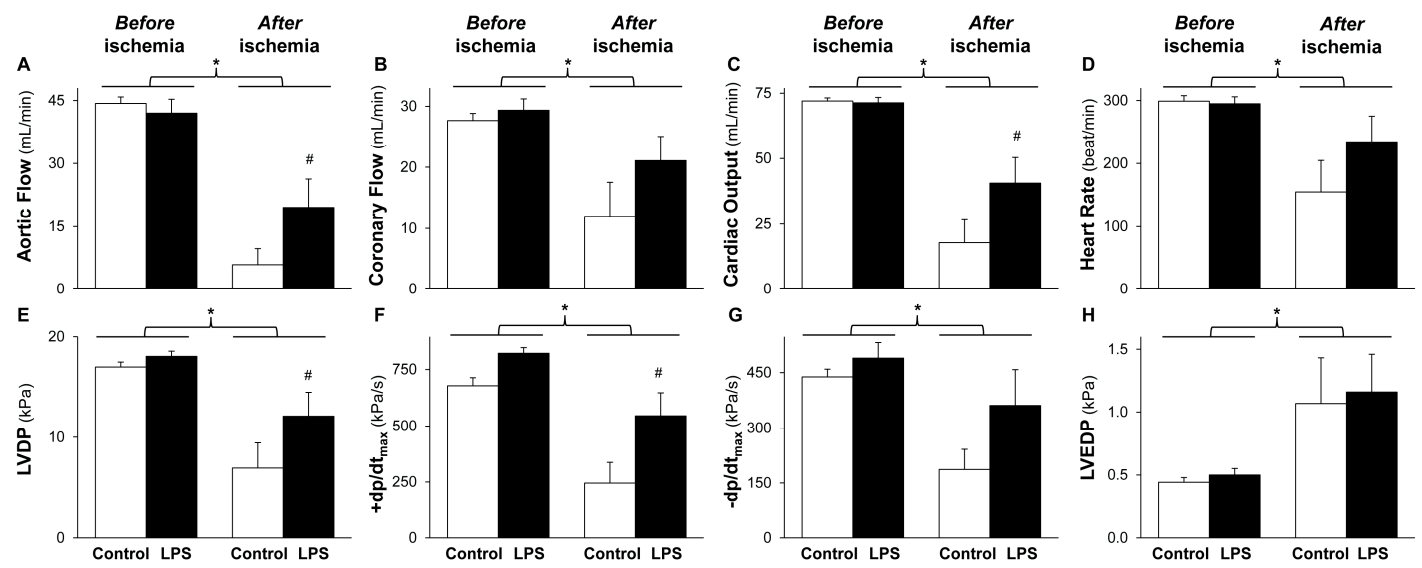

Figure 1. LPS pretreatment improves post-ischemic cardiac function. The figure shows cardiac functional parameters (A-H). Isolated rat hearts were subjected to $10 \mathrm{~min}$ equilibration period and $30 \mathrm{~min}$ normothermic global ischemia, followed by $20 \mathrm{~min}$ reperfusion, $24 \mathrm{~h}$ after in vivo $0.5 \mathrm{mg} / \mathrm{kg}$ low-dose lipopolysaccharide (LPS) treatment. Values are expressed as mean \pm S.E.M $(n=6-7) .{ }^{*} p<0.05$ vs. before ischemia, ${ }^{\#} p<0.05$ vs. control, two-way ANOVA. LVDP: left ventricular developed pressure, $\pm \mathrm{d} p / \mathrm{d} t_{\text {max }}$ : first derivatives of LVDP, LVEDP: left ventricular end-diastolic pressure. 
The post-ischemic aortic flow, coronary flow, cardiac output, heart rate, left ventricular developed pressure, and its first derivatives ( $\pm \mathrm{d} p / \mathrm{d} t_{\max }$ ) were decreased (Figure $\left.1 \mathrm{~A}-\mathrm{G}\right)$, while left ventricular end-diastolic pressure was increased (Figure $1 \mathrm{H}$ ) compared to the pre-ischemic values. However, post-ischemic decline of aortic flow, cardiac output, left ventricular developed pressure, and $+\mathrm{d} p / \mathrm{d} t_{\max }$ was significantly improved by LPS pretreatment (Figure 1A,C,E,F). Coronary flow, heart rate, $-\mathrm{d} p / \mathrm{d} t_{\max }$, and left ventricular end-diastolic pressure were not affected significantly by low-dose LPS pretreatment after the ischemia (Figure 1B,D,G,H). There was no difference in cardiac performance before the ischemia between control and LPS-pretreated animals (Figure 1). Post-ischemic LDH release was significantly reduced by low-dose LPS treatment (Table 1). There was no difference in animal weight, heart wet weight, and basal heart rate between the experimental groups (Table 1).

Table 1. Morphological parameters and LDH release.

\begin{tabular}{ccc}
\hline & Control & LPS \\
\hline Animal weight $(\mathrm{g})$ & $307 \pm 5$ & $301 \pm 5$ \\
Heart wet weight $(\mathrm{mg})$ & $928 \pm 25$ & $927 \pm 28$ \\
Basal heart rate $(\mathrm{bpm})$ & $299 \pm 7$ & $295 \pm 11$ \\
LDH release (U/min) & & \\
Before ischemia & $1.1 \pm 0.2$ & $1.5 \pm 0.3$ \\
After ischemia & $5.8 \pm 0.7^{*}$ & $2.3 \pm 0.4^{\#}$
\end{tabular}

Values are expressed as mean \pm S.E.M ( $n=3-7$ in each groups). ${ }^{*} p<0.05$ vs before ischemia, ${ }^{\#} p<0.05$ vs control, two-way ANOVA.

\subsection{LPS Pretreatment Enhances Cardiac 3-Nitrotyrosine Formation}

To assess the delayed effect of cardioprotective LPS on $\mathrm{ONOO}^{-}$formation, the level of cardiac and serum 3-nitrotyrosine, a maker of $\mathrm{ONOO}^{-}$was measured. A low dose of LPS significantly enhanced both the formation of cardiac (Figure 2A) and serum (Figure 2B) 3-nitrotyrosine $24 \mathrm{~h}$ after the in vivo administration of LPS.
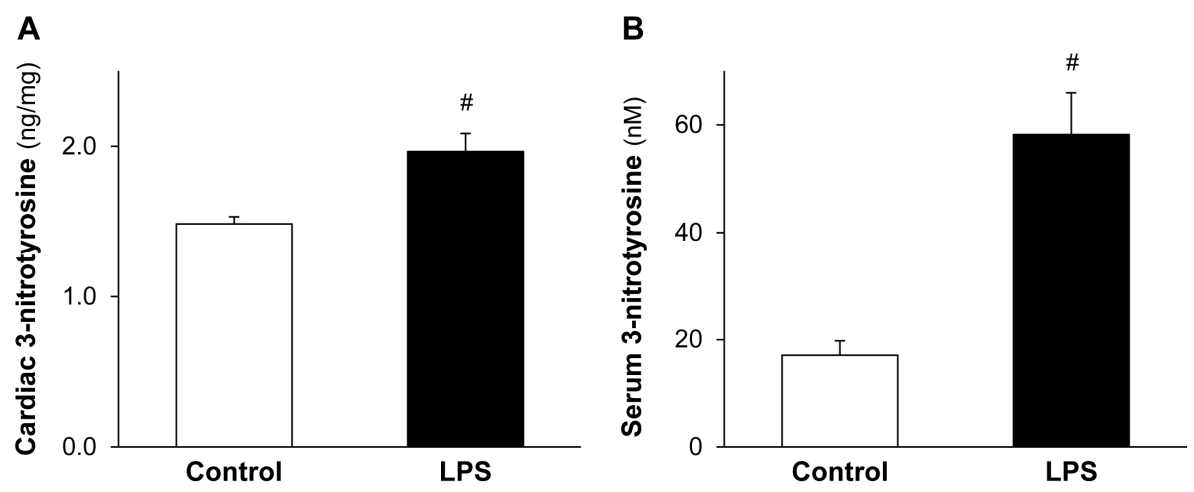

Figure 2. LPS pretreatment enhances cardiac and serum 3-nitrotyrosine formation. Figure shows cardiac (A) and serum (B) 3-nitrotyrosine levels $24 \mathrm{~h}$ after in vivo treatment of Wistar rats with $0.5 \mathrm{mg} / \mathrm{kg}$ lipopolysaccharide (LPS). Values are expressed as mean \pm S.E.M. $(n=7-9) .{ }^{\#} p<0.05$ vs. control, unpaired $t$-test.

\subsection{LPS Pretreatment Leads to Increased Level of Cardiac $\mathrm{NO}$ and $\mathrm{O}_{2}{ }^{\bullet-}$}

In order to elucidate the source of enhanced cardiac $\mathrm{ONOO}^{-}$formation induced by low-dose LPS, $\mathrm{NO}$, and $\mathrm{O}_{2}{ }^{\bullet-}$ the precursors of $\mathrm{ONOO}^{-}$were measured. The cardiac levels of both NO (Figure 3A) and $\mathrm{O}_{2}{ }^{\bullet-}$ (Figure 3B) were significantly increased in LPS-pretreated hearts. 
A

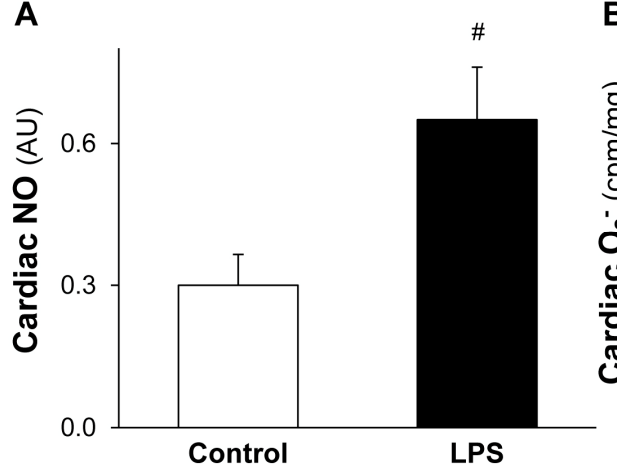

B

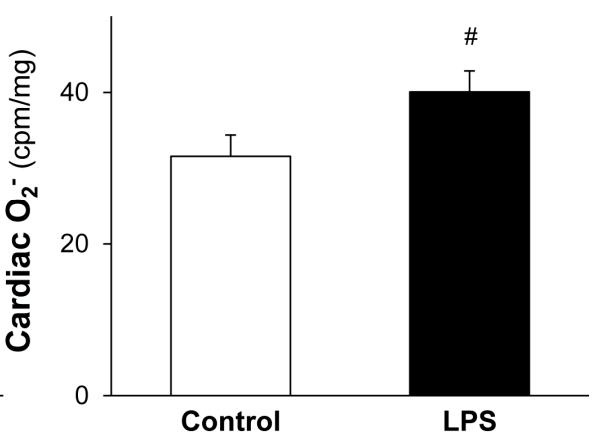

Figure 3. LPS pretreatment leads to increased level of cardiac $\mathrm{NO}$ and $\mathrm{O}_{2}{ }^{\bullet-}$. Figure shows cardiac peroxynitrite precursor nitric oxide (NO) (A) and superoxide $\left(\mathrm{O}_{2}{ }^{\bullet-}\right)(\mathbf{B})$ levels $24 \mathrm{~h}$ after in vivo $0.5 \mathrm{mg} / \mathrm{kg}$ lipopolysaccharide (LPS) treatment. Values are expressed as mean \pm S.E.M. $(n=7-12)$. \# $p<0.05$ vs. control, unpaired $t$-test.

\subsection{NOS and XOR Enzymes Contribute to Elevated $\mathrm{NO}$ and $\mathrm{O}_{2}{ }^{\bullet-}$ Production Induced by LPS}

To reveal the possible source of increased cardiac $\mathrm{NO}$ and $\mathrm{O}_{2}{ }^{\bullet-}$ levels induced by low-dose LPS, activity of NOS and XOR enzymes were measured. The activities of $\mathrm{Ca}^{2+}$-independent NOS and XOR were significantly increased in LPS-pretreated hearts without affecting the $\mathrm{Ca}^{2+}$-dependent-NOS activity (Figure 4A,B). SOD activity was not changed in response to LPS pretreatment (Figure 4C).

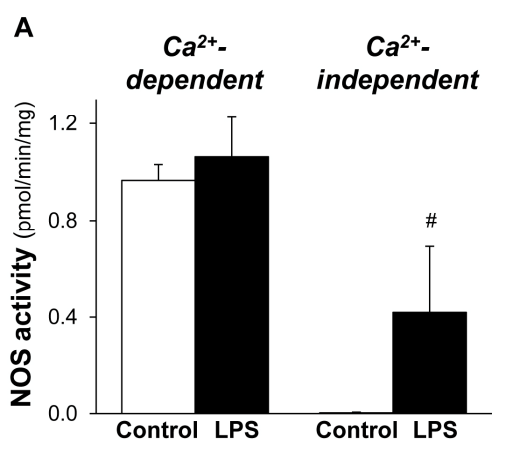

B

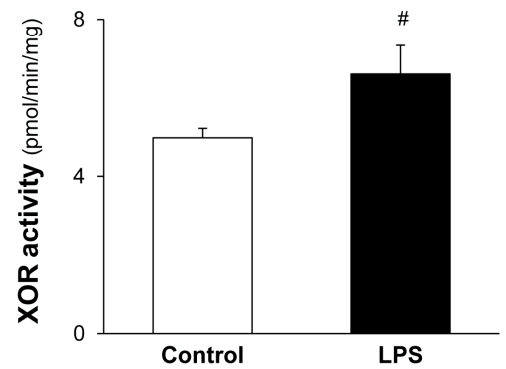

C

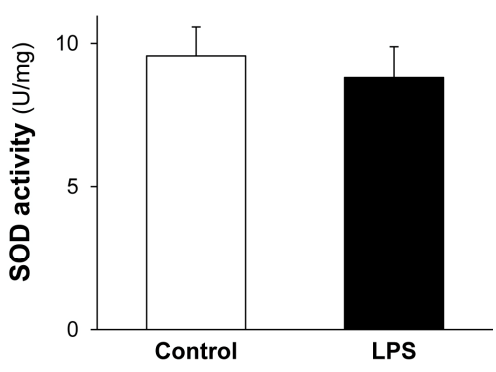

Figure 4. NOS and XOR enzymes contribute to elevated $\mathrm{NO}$ and $\mathrm{O}_{2}{ }^{\bullet-}$ production induced by lipopolysaccharide (LPS). Figure shows cardiac NO synthases (NOS) (A), xanthine oxidoreductase (XOR) (B), and superoxide dismutase (SOD) (C) activities $24 \mathrm{~h}$ after in vivo $0.5 \mathrm{mg} / \mathrm{kg}$ LPS treatment. Values are expressed as mean \pm S.E.M. $(n=7-12) .{ }^{*} p<0.05$ vs. control, unpaired $t$-test.

\subsection{LPS Pretreatment Results in Enhanced Phosphorylation of STAT3}

In order to elucidate the possible downstream targets of low-dose LPS, the activations of Akt, Erk, and STAT3 were investigated $24 \mathrm{~h}$ after LPS pretreatment. Low-dose LPS significantly enhanced cardiac STAT3 phosphorylation and non-significantly increased Akt phosphorylation without affecting phosphorylation of Erk1/2 (Figure 5). Total STAT3 (both phosphorylated and non-phosphorylated forms) was increased by approximately $20 \%$ due to LPS pretreatment ( $p=0.044$ ) (Figure 5A). 
A

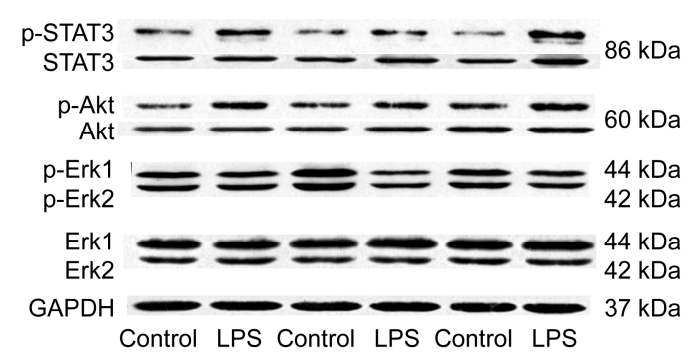

B
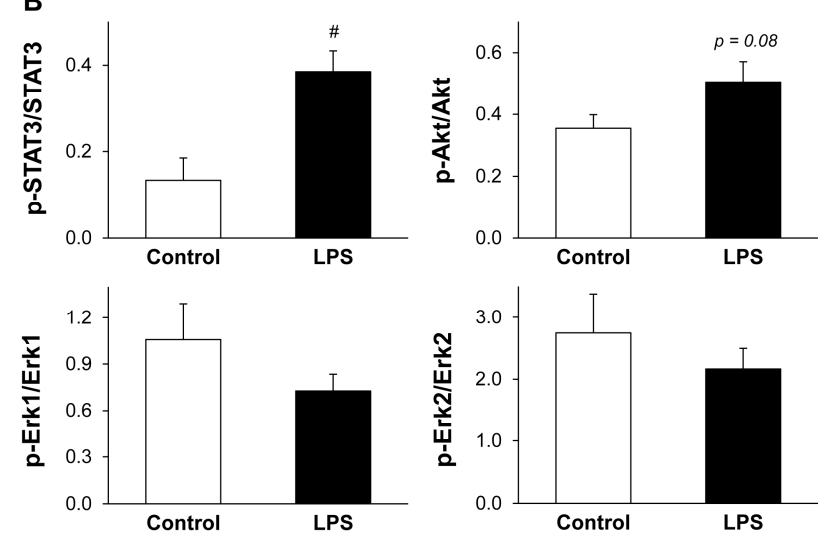

Figure 5. LPS pretreatment results in enhanced phosphorylation of STAT3. Figure shows representative images (A) and quantification (B) of western blots of possible cardiac pathways in LPS-induced delayed preconditioning. Analysis was performed $24 \mathrm{~h}$ after in vivo $0.5 \mathrm{mg} / \mathrm{kg}$ low-dose lipopolysaccharide (LPS) treatment. Values are expressed as mean \pm S.E.M. ( $n=7$ in each groups). ${ }^{\#} p<0.05$ vs. control, unpaired $t$-test. p-STAT3: phospho(Tyr705)-STAT3, p-Akt: phospho(Ser473)-Akt, p-Erk1/2: phospho(Thr202/204)-Erk1/2, GAPDH: glyceraldehyde 3-phosphate dehydrogenase.

\section{Discussion}

In our present study, we showed that low-dose LPS pretreatment induces late PreC by improving post-ischemic cardiac function and LDH release in isolated rat hearts. Moreover, we demonstrated for the first time in the literature that low-dose LPS pretreatment enhanced cardiac and serum 3-nitrotyrosine, a marker of $\mathrm{ONOO}^{-}$formation. The precursors of $\mathrm{ONOO}^{-}, \mathrm{NO}$ and $\mathrm{O}_{2}{ }^{\bullet-}$, were also increased in the heart as a result of LPS pretreatment. Our work revealed that enhanced $\mathrm{Ca}^{2+}$-independent NOS and XOR activities contribute to elevated levels of cardiac $\mathrm{NO}$ and $\mathrm{O}_{2}{ }^{\bullet-}$. In addition, we also demonstrated an enhanced delayed phosphorylation of STAT3 after low-dose LPS pretreatment.

Ischemic PreC is a widely used method to protect the heart against ischemia-reperfusion injury [17,19]; however, the approach is invasive so it is limited to use as a preventive intervention in daily life. Pharmacological preconditioning may confer significant benefits thereby having a great potential in the clinical field including prevention of cardiovascular diseases. We demonstrated that in vivo low-dose LPS injection ameliorated post-ischemic cardiac function and LDH release in isolated rat hearts subjected to ischemia-reperfusion $24 \mathrm{~h}$ after the treatment. Our results are in accordance with literature data showing that endotoxin exerts late PreC by improving post-ischemic cardiac recovery $[7,9,11]$. Nevertheless, the molecular mechanism of endotoxin-induced delayed PreC is barely investigated. Since peroxynitrite has emerged as a potential mediator of cardioprotection [13,20,21], we focused on LPS-induced delayed cardiac $\mathrm{ONOO}^{-}$formation in our present study.

Although enhanced peroxynitrite formation contributes to the pathophysiology of cardiovascular diseases by inducing oxidative- and nitrative stress [22], Lefer et al. has demonstrated that peroxynitrite inhibits leukocyte-endothelial cell interaction, which improves post-ischemic myocardial function [23]. Moreover, several further studies have shown that enhanced formation of cardiac $\mathrm{ONOO}^{-}$plays a role in the early phase $[12,13]$ as well as the late phase of ischemia-induced delayed PreC [14]. In the LPS-induced late PreC of the brain, $\mathrm{ONOO}^{-}$has emerged as an early mediator [24]. We showed that low-dose LPS pretreatment enhances cardiac 3-nitrotyrosine, a marker of $\mathrm{ONOO}^{-}$, thereby indicating a possible role for $\mathrm{ONOO}^{-}$in endotoxin-induced late PreC.

Peroxynitrite arises from the non-enzymatic reaction of $\mathrm{NO}_{\text {with }} \mathrm{O}_{2}{ }^{\bullet-}$. In order to elucidate the source of enhanced cardiac $\mathrm{ONOO}^{-}$formation induced by LPS, here we measured both precursors and found that cardiac levels of both $\mathrm{NO}$ and $\mathrm{O}_{2}{ }^{\bullet-}$ were increased in low-dose LPS-pretreated hearts. NO has been already implicated as a mediator of the endotoxin-induced cardiac late PreC $[8-10,25,26]$ and 
our finding is consistent with these studies. NO can be produced by three isoforms of NO syntheses: the $\mathrm{Ca}^{2+}$-independent inducible NOS (iNOS) and the $\mathrm{Ca}^{2+}$-dependent endothelial and neuronal NOS. Several studies have demonstrated the role of iNOS in delayed ischemic PreC $[8,9,27]$. It has been also reported that iNOS mediates endotoxin-induced late PreC as well [8-10,28,29]. Our findings support these data since low-dose LPS pretreatment increased the activity of $\mathrm{Ca}^{2+}$-independent NOS without affecting the $\mathrm{Ca}^{2+}$-dependent isoforms in our present study.

Besides the role of $\mathrm{NO}$, indirect evidence suggested that $\mathrm{O}_{2}{ }^{--}$may also be involved in endotoxin-induced late cardioprotection [7,11]; however, our study provided direct data that cardiac level of $\mathrm{O}_{2}{ }^{\bullet-}$ is increased after a low-dose LPS pretreatment. $\mathrm{O}_{2}{ }^{--}$is produced by enzymatic and non-enzymatic processes. XOR is a prominent enzymatic source for $\mathrm{O}_{2}{ }^{\bullet-}$ [30], and in addition, XOR has been reported to contribute to post-ischemic preservation of left ventricular developed pressure in early ischemic PreC [31]. The potential role of XOR in endotoxin-induced delayed PreC is not known. It was reported in endotoxemic animal models that high-dose LPS induces XOR in the heart [32] and in the lung [33] $6 \mathrm{~h}$ or $24 \mathrm{~h}$ after the treatment, respectively. However, our study has revealed that cardioprotective low-dose LPS pretreatment $24 \mathrm{~h}$ later increases the activity of XOR enzyme in the heart. This finding suggests that XOR contributes to LPS-induced delayed PreC by producing $\mathrm{O}_{2}{ }^{\bullet-}$.

We also investigated the activation of RISK and SAFE pathways in our present study to further explore possible downstream mechanisms of LPS-induced late PreC. These cardioprotective signalling pathways are barely investigated in endotoxin-induced late PreC. Non-LPS induced activation of Akt (member of RISK) and STAT3 (member of SAFE) before a lethal injury was shown to confer cardioprotection [34,35]. Ischemic PreC stimulus itself (i.e., brief ischemia-reperfusion cycles) increases cardiac Akt phosphorylation before a test ischemia [36] and in the present study, we showed that LPS pretreatment also non-significantly increased Akt phosphorylation before the test ischemia. Post-ischemic activation of Akt in response to LPS pretreatment was demonstrated by Ha et al. [18]; however, data on pre-ischemic Akt activation is lacking in that study. Although the transcription factor STAT3 has been implicated in late ischemic PreC [37,38], its role in endotoxin-induced delayed PreC has not yet been investigated. This is the first demonstration that low-dose LPS enhances the phosphorylation of cardiac STAT3 $24 \mathrm{~h}$ after the treatment, thereby suggesting that activation of STAT3 before the ischemia may play a role in endotoxin-induced late PreC. Our hypothesis is supported by a finding that hydrogen peroxide-induced PreC stimulus itself activates STAT3 in PC12 cells before a lethal injury, which contributes to protection [39]. We also showed increased total STAT3 level in response to LPS pretreatment, which is consistent with literature data [40,41] and may indicate protein-level changes.

Although specific clinical translational goals were beyond the scope of the present experimental work, our findings may contribute to progress the current science on several fields. First, the role of peroxynitrite in cardioprotection and the interplay between moderate oxidative stress and cardioprotective pathways are still unclear. Our results indicate that enhanced peroxynitrite formation and STAT3 phosphorylation (together or separately) may play a role in LPS-induced cardioprotection. Based on literature data, it is feasible to suggest that peroxynitrite itself leads to STAT3 phosphorylation [42]. This finding may facilitate further proof-of-concept studies to elucidate the exact interplay between peroxynitrite and STAT3 in cardiomyocytes during adaptive processes. Second, our results may strengthen the concept that activation of STAT3 transcription factor seems to be a significant step in cardioprotection [43], which may support the importance of developing novel STAT3 activators or modulators that can be tested for their potential cardioprotective effects. Third, as we also showed that LPS pretreatment has a great preventive potential, our findings may promote new research to find clinically applicable analog molecules of LPS to induce pharmacological preconditioning.

In conclusion, low-dose LPS pretreatment induces pharmacological late PreC and enhances cardiac $\mathrm{ONOO}^{-}$formation $24 \mathrm{~h}$ after the treatment by stimulating cardiac $\mathrm{NO}$ and $\mathrm{O}_{2}{ }^{\bullet-}$ production through $\mathrm{Ca}^{2+}$-independent NOS and XOR enzymes. Activation of STAT3 before a lethal ischemia may play a role in the beneficial effect of endotoxin-induced delayed PreC. 


\section{Materials and Methods}

Male Wistar rats (250-350 g) were used in the present study. The study conforms to the 'Guide for the care and use of laboratory animals' published by the US National Institutes of Health (NIH publication No. 85-23, revised 1996) and was approved by local ethics committees. The animals were kept at 12/12-hour light/dark cycle and had free access to standard laboratory chow and drinking water.

\subsection{Materials}

Bovine serum albumin (BSA), lipopolysaccharid from Salmonella enterica serotype typhimurium (\#L-7261), HEPES, dithiothreitol, trypsin inhibitor, leupeptin, aprotinin, phenylmethylsulfonyl fluoride (PMSF), lucigenin, L- $\left[{ }^{14} \mathrm{C}\right]$ arginine, EGTA, $N^{\mathrm{G}}$-monomethyl-L-arginine, L-citrulline, pterin and methylene blue, protease inhibitor cocktail (\#8340) were purchased from Sigma Aldrich (Saint Louis, MO, USA). Sucrose, $\mathrm{Na}_{2} \mathrm{EDTA}$, and $\mathrm{FeSO}_{4} \cdot 7 \mathrm{H}_{2} \mathrm{O}$ were from Reanal (Budapest, Hungary). N-methyl-D-glucamine-dithiocarbamate (MGD) was synthetized by Fülöp F (Department of Pharmaceutical Chemistry, Faculty of Pharmacy, Szeged, Hungary). BCA Protein Assay Kit was from Pierce (Rockford, IL, USA). Saline was from TEVA (Petah Tikva, Israel). Lactate dehydrogenase (LDH)-P kit was purchased from Diagnosticum (Budapest, Hungary). Peroxynitrite marker 3-nitrotyrosine enzyme-linked immunosorbent assay (ELISA) was from Cayman Chemical (Ann Arbor, MI, USA). Superoxide dismutase (SOD) assay was from Randox Laboratories (Crumlin, UK). Western blotting reagents were from Bio-Rad (Hercules, CA, USA). Radioimmunoprecipitation assay (RIPA) buffer and primary antibodies were purchased from Cell Signaling Technology (Danvers, MA, USA): anti-phospho(Tyr705)-STAT3 (\#9145), anti-phospho(Ser473)-Akt (\#9271), anti-phospho(Thr202/204)-Erk1/2 (\#9101), anti-total STAT3 (\#4904), anti-total Akt (\#9272), anti-total ERK (\#9102), anti-glyceraldehyde 3-phosphate dehydrogenase (GAPDH, \#2118). HRP-conjugated secondary antibody was from Dako Corporation (Santa Barbara, CA, USA). Price Western blotting Detection Reagent was from Amersham (Buckinghamshire, UK).

\subsection{Experimental Design and Isolated Heart Perfusion}

Rats were treated intraperitoneally (i.p.) with saline or low-dose $0.5 \mathrm{mg} / \mathrm{kg}$ LPS from Salmonella enterica serotype typhimurium. Twenty four hours after LPS treatment, rats were anesthetized with diethyl ether and were given $500 \mathrm{U} \cdot \mathrm{kg}^{-1}$ heparin intravenously. Hearts were then isolated and perfused according to Langendorff for $5 \mathrm{~min}$ at $37^{\circ} \mathrm{C}$ with Krebs-Henseleit buffer containing $\mathrm{NaCl}$ $118 \mathrm{mM}, \mathrm{NaHCO}_{3} 25 \mathrm{mM}, \mathrm{KCl} 4.3 \mathrm{mM}, \mathrm{CaCl}_{2} 2.4 \mathrm{mM}, \mathrm{KH}_{2} \mathrm{PO}_{4}, 1.2 \mathrm{mM}, \mathrm{MgSO}_{4} 1.2 \mathrm{mM}$, glucose $11 \mathrm{mM}$, gassed with $95 \% \mathrm{O}_{2}$ and $5 \% \mathrm{CO}_{2}[44,45]$. Then the perfusion system was switched to working mode according to Neely with recirculating buffer $[44,46]$. Hydrostatic preload and afterload were kept constant at $1.7 \mathrm{kPa}$ and $9.8 \mathrm{kPa}$, respectively throughout the experiments. Hearts were subjected to 10 min equilibration period followed by 30 min normothermic global ischemia and 20 min reperfusion $(n=6-7)$. Before ischemia and during reperfusion cardiac functional parameters including heart rate, coronary flow, aortic flow, left ventricular developed pressure and its first derivatives $\left( \pm \mathrm{d} p / \mathrm{d} t_{\max }\right)$, and left ventricular end-diastolic pressure were measured. To estimate the severity of cellular damage in the heart, the activity of LDH was measured from coronary effluents (collected during the first 5 min of reperfusion) using a LDH-P kit $(n=3-4)$. The enzyme activity ( $\mathrm{U} / \mathrm{mL}$ ) measured in an effluent was multiplied with the corresponding coronary flow $(\mathrm{mL} / \mathrm{min})$ to give LDH release expressed as $\mathrm{U} / \mathrm{min}$.

In separate experiments, hearts were harvested at the end of a 5-min Langendorff perfusion for biochemical analyses. After removing atria, ventricles were used freshly or were rapidly freeze-clamped, powdered with a pestle and mortar in liquid nitrogen, and stored in cryovials at $-80{ }^{\circ} \mathrm{C}$ until further analysis. 


\subsection{Assessment of Cardiac and Serum $\mathrm{ONOO}^{-}$Formation}

To estimate cardiac and serum $\mathrm{ONOO}^{-}$formation, free 3-nitrotyrosine, a marker of peroxynitrite was measured by ELISA $(n=7-9)$ as described $[20,44]$.

Heart samples were homogenized in a buffer containing HEPES (10 mM), sucrose $(0.32 \mathrm{M})$, $\mathrm{Na}_{2}$ EDTA $(0.1 \mathrm{mM})$, dithiothreitol $(1.0 \mathrm{mM})$, trypsin inhibitor $(10 \mathrm{mg} / \mathrm{mL})$, leupeptin $(10 \mathrm{mg} / \mathrm{mL})$, aprotinin $(2 \mathrm{mg} / \mathrm{mL})$, and PMSF $(125 \mu \mathrm{g} / \mathrm{mL})$ at $\mathrm{pH} 7.4$. The crude homogenates were centrifuged at $10,000 \times g$ for $10 \mathrm{~min}$ at $4{ }^{\circ} \mathrm{C}$, and supernatants were then used for 3-nitrotyrosine quantification. Serum samples $(210 \mu \mathrm{L})$ were mixed with four volumes $4{ }^{\circ} \mathrm{C}$ ethanol, and centrifuged at $3000 \times g$ for $10 \mathrm{~min}$ at $4{ }^{\circ} \mathrm{C}$. Supernatants were evaporated under a flow of nitrogen and redissolved in $105 \mu \mathrm{L}$ ultra-pure water.

According to the manufacturer's instructions, supernatants from the heart homogenates and redissolved supernatants from the serum samples were incubated overnight at $4{ }^{\circ} \mathrm{C}$ with nitrotyrosine acetylcholinesterase tracer and anti-nitrotyrosine rabbit IgG in microplates precoated with mouse anti-rabbit IgG. Ellman's reagent was then used for development. Free nitrotyrosine content was normalized to protein content of cardiac homogenates and expressed as $\mathrm{ng} / \mathrm{mg}$ protein. Serum nitrotyrosine concentration was expressed as nmol/L.

\subsection{Measurement of Cardiac $\mathrm{NO}$ and $\mathrm{O}_{2}{ }^{\bullet-}$ Levels}

Since $\mathrm{ONOO}^{-}$is formed as a result of the reaction of $\mathrm{NO}$ and $\mathrm{O}_{2}{ }^{\bullet-}$, the cardiac level of these intermediates were also measured in the present study.

The level of NO in ventricular tissue was measured by electron paramagnetic resonance (EPR) spectroscopy as described $[47,48]$. Hearts were loaded with the freshly prepared NO-specific spin trap $\mathrm{Fe}^{2+}(\mathrm{MGD})_{2}$. The spin trap (175 $\mathrm{mg} \mathrm{MGD}$ and $50 \mathrm{mg} \mathrm{FeSO}$ dissolved in $6 \mathrm{~mL}$ distilled water and $\mathrm{pH}$ set to 7.4) was infused for $5 \mathrm{~min}$ into the aorta during Langendorff perfusion at a rate of $1 \mathrm{~mL} / \mathrm{min}$. At the end of the infusion of $\mathrm{Fe}^{2+}(\mathrm{MGD})_{2}$, myocardial tissue samples were collected, minced, and pushed into the bottom of quartz EPR tubes and frozen carefully in liquid nitrogen. EPR spectra of NO-Fe ${ }^{2+}-(\mathrm{MGD})_{2}$ adducts were recorded with an EPR spectrometer (model ECS106, Bruker; Rheinstetten, Germany) and analyzed for NO signal intensity as described $[49,50]$.

Cardiac $\mathrm{O}_{2}{ }^{\bullet-}$ production was assessed by lucigenin-enhanced chemiluminescence as described earlier $[44,51]$. The apex of the heart was cut into small pieces and placed in Krebs-Henseleit buffer containing $10 \mu \mathrm{mol} / \mathrm{L}$ lucigenin and $10 \mathrm{mmol} / \mathrm{L}$ HEPES-NaOH (1 mL, pH 7.4). Luminescence was measured using a liquid scintillation counter (Tri-Carb 2100TR, Packard Instrument Company, Meriden, CT, USA) as described [21,30].

\subsection{Measurement of Cardiac NO Synthases (NOS), Xanthine Oxidoreductase (XOR), and SOD Activities}

Powdered frozen ventricular tissue was homogenized in 4 volumes (NOS, XOR) or 10 volumes (SOD) of ice-cold homogenization buffer (composition is same as described above for $\mathrm{ONOO}^{-}$ measurement) with an Ultra-Turrex disperser using three 20-s strokes. The homogenate was centrifuged $(1000 \times g$ for $10 \mathrm{~min})$ at $4{ }^{\circ} \mathrm{C}$ and the supernatant was kept on ice for immediate assays of enzyme activities.

To determine enzymatic NO production in the hearts, $\mathrm{Ca}^{2+}$-dependent and -independent NOS activities were assessed as described [44,51]. The conversion of L-[ $\left.{ }^{14} \mathrm{C}\right]$ arginine to L- $\left[{ }^{14} \mathrm{C}\right]$ citrulline was measured in supernatants with or without EGTA $(1 \mathrm{mM})$ or EGTA plus $N^{\mathrm{G}}$-monomethyl-L-arginine $(1 \mathrm{mM})$ to estimate $\mathrm{Ca}^{2+}$-dependent and -independent NOS activities, respectively. NOS activities were expressed in $\mathrm{pmol} / \mathrm{min} / \mathrm{mg}$ protein.

Since XOR is a major source of superoxide in the rat heart [52], the activity of XOR was determined in supernatants. A fluorometric kinetic assay was performed as described previously [44,53], by measuring the conversion of pterine to isoxanthopterine in the presence as well as in the absence of methylene blue. 
SOD activity was measured by a spectrophotometric assay based on the inhibition of superoxide-induced formazan dye formation [51].

\subsection{Investigation of Akt, Erk, and STAT3 Activation with Western Blot}

To assess the activation of Akt, Erk and STAT3, the phosphorylation rate of these proteins was determined by Western blot as described earlier [54,55] with some modifications. Briefly, powdered ventricular tissue samples were homogenized in RIPA buffer supplemented with protease inhibitors using an ultrasonicator (UP100H Hielscher, Teltow, Germany). The homogenates were spun at $15,000 \times \mathrm{g}\left(30 \mathrm{~min}, 4^{\circ} \mathrm{C}\right)$. The protein concentrations in each supernatant were determined by the BCA assay. Reduced and denaturized samples ( $25 \mu \mathrm{g}$ protein) were loaded on $10 \%$ polyacrylamide gel, and proteins were separated by standard SDS-PAGE $(90 \mathrm{~V}, 1.5 \mathrm{~h})$ followed by wet-transfer onto nitrocellulose membrane ( $20 \%$ methanol, $35 \mathrm{~V}, 2 \mathrm{~h}$ ). Membranes blocked in $5 \% w / v$ BSA ( $1 \mathrm{~h}$, room temperature) were incubated with primary antibodies generated against the following antigens: phospho(Ser473)-Akt (1:500), total Akt (1:2000); phospho(Thr202/Tyr204)-Erk1/Erk2 (1:2000), total Erk1/Erk2 1:1000; phospho(Tyr705)-STAT3 (1:1000), total STAT3 (1:2000) (overnight, $4{ }^{\circ} \mathrm{C}, 5 \%$ BSA); or GAPDH $(1: 10,000 ; 1 \mathrm{~h}$, room temperature, $1 \%$ milk). Then the membranes were incubated with a HRP-conjugated secondary antibody (1:5000 or 1:20,000 for GAPDH; $1 \mathrm{~h}$, room temperature, $1 \%$ milk). Enhanced chemiluminescence kit was used to develop the membranes.

\subsection{Statistical Analysis}

Data were expressed as mean \pm S.E.M. and analyzed with unpaired $t$-test or two-way analysis of variance (ANOVA) as appropriate. If a difference was established in ANOVA, Fisher's Least Significant Difference (LSD) post hoc test was applied. Differences were considered significant at $p<0.05$.

Acknowledgments: This work was supported by the National Research, Development, and Innovation Agency [OTKA-F046810] and by the GINOP-2.3.2-15-2016-00040 project. The project is co-financed by the European Union and the European Regional Development Fund.

Author Contributions: T.C., M.P., and P.F. conceived and designed the experiments; T.C., M.P., G.F.K., L.S-A., P.B., and Z.V.V. performed the experiments; T.C. and M.P. analyzed the data; P.F. contributed reagents/materials/analysis tools; M.P. and T.C. wrote the paper.

Conflicts of Interest: The authors declare no conflict of interest.

\section{References}

1. Yellon, D.M.; Hausenloy, D.J. Myocardial reperfusion injury. N. Engl. J. Med. 2007, 357, 1121-1135. [CrossRef] [PubMed]

2. Murry, C.E.; Jennings, R.B.; Reimer, K.A. Preconditioning with ischemia: A delay of lethal cell injury in ischemic myocardium. Circulation 1986, 74, 1124-1136. [CrossRef] [PubMed]

3. Yellon, D.M.; Downey, J.M. Preconditioning the myocardium: From cellular physiology to clinical cardiology. Physiol. Rev. 2003, 83, 1113-1151. [CrossRef] [PubMed]

4. Stein, A.B.; Tang, X.L.; Guo, Y.; Xuan, Y.T.; Dawn, B.; Bolli, R. Delayed adaptation of the heart to stress: Late preconditioning. Stroke 2004, 35, 2676-2679. [CrossRef] [PubMed]

5. Bolli, R. The late phase of preconditioning. Circ. Res. 2000, 87, 972-983. [CrossRef] [PubMed]

6. Baxter, G.F.; Ferdinandy, P. Delayed preconditioning of myocardium: Current perspectives. Basic Res. Cardiol. 2001, 96, 329-344. [CrossRef] [PubMed]

7. Brown, J.M.; Grosso, M.A.; Terada, L.S.; Whitman, G.J.; Banerjee, A.; White, C.W.; Harken, A.H.; Repine, J.E. Endotoxin pretreatment increases endogenous myocardial catalase activity and decreases ischemia-reperfusion injury of isolated rat hearts. Proc. Natl. Acad. Sci. USA 1989, 86, 2516-2520. [CrossRef] [PubMed]

8. Wang, Y.P.; Sato, C.; Mizoguchi, K.; Yamashita, Y.; Oe, M.; Maeta, H. Lipopolysaccharide triggers late preconditioning against myocardial infarction via inducible nitric oxide synthase. Cardiovasc. Res. 2002, 56, 33-42. [CrossRef] 
9. Wang, E.; Feng, Y.; Zhang, M.; Zou, L.; Li, Y.; Buys, E.S.; Huang, P.; Brouckaert, P.; Chao, W. Toll-like receptor 4 signaling confers cardiac protection against ischemic injury via inducible nitric oxide synthase- and soluble guanylate cyclase-dependent mechanisms. Anesthesiology 2011, 114, 603-613. [CrossRef] [PubMed]

10. Portnychenko, A.G.; Harmatina, O.Y.; Kotsuruba, A.V.; Moybenko, O.O. The role of nitric oxide in endotoxin-induced cardiodepression. Exp. Clin. Cardiol. 2005, 10, 223-228. [PubMed]

11. Maulik, N.; Watanabe, M.; Engelman, D.; Engelman, R.M.; Kagan, V.E.; Kisin, E.; Tyurin, V.; Cordis, G.A.; Das, D.K. Myocardial adaptation to ischemia by oxidative stress induced by endotoxin. Am. J. Physiol. 1995, 269, C907-C916. [PubMed]

12. Csonka, C.; Csont, T.; Onody, A.; Ferdinandy, P. Preconditioning decreases ischemia/reperfusion-induced peroxynitrite formation. Biochem. Biophys. Res. Commun. 2001, 285, 1217-1219. [CrossRef] [PubMed]

13. Altug, S.; Demiryurek, A.T.; Kane, K.A.; Kanzik, I. Evidence for the involvement of peroxynitrite in ischaemic preconditioning in rat isolated hearts. Br. J. Pharmacol. 2000, 130, 125-131. [CrossRef] [PubMed]

14. Tang, X.L.; Takano, H.; Rizvi, A.; Turrens, J.F.; Qiu, Y.; Wu, W.J.; Zhang, Q.; Bolli, R. Oxidant species trigger late preconditioning against myocardial stunning in conscious rabbits. Am. J. Physiol. Heart Circ. Physiol. 2002, 282, H281-H291. [PubMed]

15. Heusch, G.; Boengler, K.; Schulz, R. Cardioprotection: Nitric oxide, protein kinases, and mitochondria. Circulation 2008, 118, 1915-1919. [CrossRef] [PubMed]

16. Lecour, S. Activation of the protective survivor activating factor enhancement (safe) pathway against reperfusion injury: Does it go beyond the risk pathway? J. Mol. Cell. Cardiol. 2009, 47, 32-40. [CrossRef] [PubMed]

17. Das, M.; Das, D.K. Molecular mechanism of preconditioning. IUBMB Life 2008, 60, 199-203. [CrossRef] [PubMed]

18. Ha, T.; Hua, F.; Liu, X.; Ma, J.; McMullen, J.R.; Shioi, T.; Izumo, S.; Kelley, J.; Gao, X.; Browder, W.; et al. Lipopolysaccharide-induced myocardial protection against ischaemia/reperfusion injury is mediated through a pi3k/akt-dependent mechanism. Cardiovasc. Res. 2008, 78, 546-553. [CrossRef] [PubMed]

19. Eisen, A.; Fisman, E.Z.; Rubenfire, M.; Freimark, D.; McKechnie, R.; Tenenbaum, A.; Motro, M.; Adler, Y. Ischemic preconditioning: Nearly two decades of research. A comprehensive review. Atherosclerosis 2004, 172, 201-210. [CrossRef]

20. Pipicz, M.; Varga, Z.V.; Kupai, K.; Gaspar, R.; Kocsis, G.F.; Csonka, C.; Csont, T. Rapid ventricular pacing-induced postconditioning attenuates reperfusion injury: Effects on peroxynitrite, risk and safe pathways. Br. J. Pharmacol. 2015, 172, 3472-3483. [CrossRef] [PubMed]

21. Li, J.; Loukili, N.; Rosenblatt-Velin, N.; Pacher, P.; Feihl, F.; Waeber, B.; Liaudet, L. Peroxynitrite is a key mediator of the cardioprotection afforded by ischemic postconditioning in vivo. PLoS ONE 2013, 8, e70331.

22. Pacher, P.; Beckman, J.S.; Liaudet, L. Nitric oxide and peroxynitrite in health and disease. Physiol. Rev. 2007, 87, 315-424. [CrossRef] [PubMed]

23. Lefer, D.J.; Scalia, R.; Campbell, B.; Nossuli, T.; Hayward, R.; Salamon, M.; Grayson, J.; Lefer, A.M. Peroxynitrite inhibits leukocyte-endothelial cell interactions and protects against ischemia-reperfusion injury in rats. J. Clin. Invest. 1997, 99, 684-691. [CrossRef] [PubMed]

24. Kawano, T.; Kunz, A.; Abe, T.; Girouard, H.; Anrather, J.; Zhou, P.; Iadecola, C. Inos-derived no and nox2-derived superoxide confer tolerance to excitotoxic brain injury through peroxynitrite. J. Cereb. Blood Flow. Metab. 2007, 27, 1453-1462. [CrossRef] [PubMed]

25. Qiu, Y.; Rizvi, A.; Tang, X.L.; Manchikalapudi, S.; Takano, H.; Jadoon, A.K.; Wu, W.J.; Bolli, R. Nitric oxide triggers late preconditioning against myocardial infarction in conscious rabbits. Am. J. Physiol. 1997, 273, H2931-H2936. [PubMed]

26. Bolli, R.; Bhatti, Z.A.; Tang, X.L.; Qiu, Y.; Zhang, Q.; Guo, Y.; Jadoon, A.K. Evidence that late preconditioning against myocardial stunning in conscious rabbits is triggered by the generation of nitric oxide. Circ. Res. 1997, 81, 42-52. [CrossRef] [PubMed]

27. Bencsik, P.; Kupai, K.; Giricz, Z.; Gorbe, A.; Pipis, J.; Murlasits, Z.; Kocsis, G.F.; Varga-Orvos, Z.; Puskas, L.G.; Csonka, C.; et al. Role of inos and peroxynitrite-matrix metalloproteinase-2 signaling in myocardial late preconditioning in rats. Am. J. Physiol. Heart Circ. Physiol. 2010, 299, H512-H518. [CrossRef] [PubMed]

28. Imagawa, J.; Yellon, D.M.; Baxter, G.F. Pharmacological evidence that inducible nitric oxide synthase is a mediator of delayed preconditioning. Br. J. Pharmacol. 1999, 126, 701-708. [CrossRef] [PubMed] 
29. Bolli, R.; Manchikalapudi, S.; Tang, X.L.; Takano, H.; Qiu, Y.; Guo, Y.; Zhang, Q.; Jadoon, A.K. The protective effect of late preconditioning against myocardial stunning in conscious rabbits is mediated by nitric oxide synthase. Evidence that nitric oxide acts both as a trigger and as a mediator of the late phase of ischemic preconditioning. Circ. Res. 1997, 81, 1094-1107. [CrossRef] [PubMed]

30. Afanas'ev, I. Ros and rns signaling in heart disorders: Could antioxidant treatment be successful? Oxid. Med. Cell. Longev. 2011, 2011, 293769. [CrossRef] [PubMed]

31. Gelpi, R.J.; Morales, C.; Cohen, M.V.; Downey, J.M. Xanthine oxidase contributes to preconditioning's preservation of left ventricular developed pressure in isolated rat heart: Developed pressure may not be an appropriate end-point for studies of preconditioning. Basic Res. Cardiol. 2002, 97, 40-46. [CrossRef] [PubMed]

32. Khadour, F.H.; Panas, D.; Ferdinandy, P.; Schulze, C.; Csont, T.; Lalu, M.M.; Wildhirt, S.M.; Schulz, R. Enhanced no and superoxide generation in dysfunctional hearts from endotoxemic rats. Am. J. Physiol. Heart Circ. Physiol. 2002, 283, H1108-H1115. [CrossRef] [PubMed]

33. Faggioni, R.; Gatti, S.; Demitri, M.T.; Delgado, R.; Echtenacher, B.; Gnocchi, P.; Heremans, H.; Ghezzi, P. Role of xanthine oxidase and reactive oxygen intermediates in LPS- and TNF-induced pulmonary edema. J. Lab. Clin. Med. 1994, 123, 394-399. [PubMed]

34. Nduhirabandi, F.; Lamont, K.; Albertyn, Z.; Opie, L.H.; Lecour, S. Role of toll-like receptor 4 in melatonin-induced cardioprotection. J. Pineal Res. 2016, 60, 39-47. [CrossRef] [PubMed]

35. Matsui, T.; Tao, J.; del Monte, F.; Lee, K.H.; Li, L.; Picard, M.; Force, T.L.; Franke, T.F.; Hajjar, R.J.; Rosenzweig, A. Akt activation preserves cardiac function and prevents injury after transient cardiac ischemia in vivo. Circulation 2001, 104, 330-335. [CrossRef] [PubMed]

36. Yang, C.; Talukder, M.A.; Varadharaj, S.; Velayutham, M.; Zweier, J.L. Early ischaemic preconditioning requires Akt- and Pka-mediated activation of enos via serine1176 phosphorylation. Cardiovasc. Res. 2013, 97, 33-43. [CrossRef] [PubMed]

37. Xuan, Y.T.; Guo, Y.; Han, H.; Zhu, Y.; Bolli, R. An essential role of the JAK-stat pathway in ischemic preconditioning. Proc. Natl. Acad. Sci. USA 2001, 98, 9050-9055. [CrossRef] [PubMed]

38. Xuan, Y.T.; Guo, Y.; Zhu, Y.; Han, H.; Langenbach, R.; Dawn, B.; Bolli, R. Mechanism of cyclooxygenase-2 upregulation in late preconditioning. J. Mol. Cell. Cardiol. 2003, 35, 525-537. [CrossRef]

39. Yu, H.M.; Zhi, J.L.; Cui, Y.; Tang, E.H.; Sun, S.N.; Feng, J.Q.; Chen, P.X. Role of the jak-stat pathway in protection of hydrogen peroxide preconditioning against apoptosis induced by oxidative stress in pc12 cells. Apoptosis 2006, 11, 931-941. [CrossRef] [PubMed]

40. Huang, H.; Constante, M.; Layoun, A.; Santos, M.M. Contribution of stat 3 and smad4 pathways to the regulation of hepcidin by opposing stimuli. Blood 2009, 113, 3593-3599. [CrossRef] [PubMed]

41. Chaves de Souza, J.A.; Nogueira, A.V.; Chaves de Souza, P.P.; Kim, Y.J.; Silva Lobo, C.; Pimentel Lopes de Oliveira, G.J.; Cirelli, J.A.; Garlet, G.P.; Rossa, C., Jr. Socs3 expression correlates with severity of inflammation, expression of proinflammatory cytokines, and activation of stat3 and p38 mapk in LPS-induced inflammation in vivo. Mediat. Inflamm. 2013, 2013, 650812. [CrossRef] [PubMed]

42. Platt, D.H.; Bartoli, M.; El-Remessy, A.B.; Al-Shabrawey, M.; Lemtalsi, T.; Fulton, D.; Caldwell, R.B. Peroxynitrite increases vegf expression in vascular endothelial cells via stat3. Free Radic. Biol. Med. 2005, 39, 1353-1361. [CrossRef] [PubMed]

43. Heusch, G.; Musiolik, J.; Gedik, N.; Skyschally, A. Mitochondrial stat3 activation and cardioprotection by ischemic postconditioning in pigs with regional myocardial ischemia/reperfusion. Circ. Res. 2011, 109, 1302-1308. [CrossRef] [PubMed]

44. Csont, T.; Csonka, C.; Onody, A.; Gorbe, A.; Dux, L.; Schulz, R.; Baxter, G.F.; Ferdinandy, P. Nitrate tolerance does not increase production of peroxynitrite in the heart. Am. J. Physiol. Heart Circ. Physiol. 2002, 283, H69-H76. [CrossRef] [PubMed]

45. Kocsis, G.F.; Sarkozy, M.; Bencsik, P.; Pipicz, M.; Varga, Z.V.; Paloczi, J.; Csonka, C.; Ferdinandy, P.; Csont, T. Preconditioning protects the heart in a prolonged uremic condition. Am. J. Physiol. Heart Circ. Physiol. 2012, 303, H1229-H1236. [CrossRef] [PubMed]

46. Csont, T.; Csonka, C.; Kovacs, P.; Jancso, G.; Ferdinandy, P. Capsaicin-sensitive sensory neurons regulate myocardial nitric oxide and cgmp signaling. Eur. J. Pharmacol. 2003, 476, 107-113. [CrossRef] 
47. Csonka, C.; Szilvassy, Z.; Fulop, F.; Pali, T.; Blasig, I.E.; Tosaki, A.; Schulz, R.; Ferdinandy, P. Classic preconditioning decreases the harmful accumulation of nitric oxide during ischemia and reperfusion in rat hearts. Circulation 1999, 100, 2260-2266. [CrossRef] [PubMed]

48. Csont, T.; Szilvassy, Z.; Fulop, F.; Nedeianu, S.; Pali, T.; Tosaki, A.; Dux, L.; Ferdinandy, P. Direct myocardial anti-ischaemic effect of gtn in both nitrate-tolerant and nontolerant rats: A cyclic GMP-independent activation of katp. Br. J. Pharmacol. 1999, 128, 1427-1434. [CrossRef] [PubMed]

49. Csont, T.; Pali, T.; Szilvassy, Z.; Ferdinandy, P. Lack of correlation between myocardial nitric oxide and cyclic guanosine monophosphate content in both nitrate-tolerant and -nontolerant rats. Biochem. Pharmacol. 1998, 56, 1139-1144. [CrossRef]

50. Csonka, C.; Pali, T.; Bencsik, P.; Gorbe, A.; Ferdinandy, P.; Csont, T. Measurement of no in biological samples. Br. J. Pharmacol. 2015, 172, 1620-1632. [CrossRef] [PubMed]

51. Csont, T.; Bereczki, E.; Bencsik, P.; Fodor, G.; Gorbe, A.; Zvara, A.; Csonka, C.; Puskas, L.G.; Santha, M.; Ferdinandy, P. Hypercholesterolemia increases myocardial oxidative and nitrosative stress thereby leading to cardiac dysfunction in apob-100 transgenic mice. Cardiovasc. Res. 2007, 76, 100-109. [CrossRef] [PubMed]

52. Downey, J.M.; Hearse, D.J.; Yellon, D.M. The role of xanthine oxidase during myocardial ischemia in several species including man. J. Mol. Cell. Cardiol. 1988, 20, 55-63. [CrossRef]

53. Beckman, J.S.; Parks, D.A.; Pearson, J.D.; Marshall, P.A.; Freeman, B.A. A sensitive fluorometric assay for measuring xanthine dehydrogenase and oxidase in tissues. Free Radic. Biol. Med. 1989, 6, 607-615. [CrossRef]

54. Fekete, V.; Murlasits, Z.; Aypar, E.; Bencsik, P.; Sarkozy, M.; Szenasi, G.; Ferdinandy, P.; Csont, T. Myocardial postconditioning is lost in vascular nitrate tolerance. J. Cardiovasc. Pharmacol. 2013, 62, 298-303. [CrossRef] [PubMed]

55. Kocsis, G.F.; Pipis, J.; Fekete, V.; Kovacs-Simon, A.; Odendaal, L.; Molnar, E.; Giricz, Z.; Janaky, T.; van Rooyen, J.; Csont, T.; et al. Lovastatin interferes with the infarct size-limiting effect of ischemic preconditioning and postconditioning in rat hearts. Am. J. Physiol. Heart Circ. Physiol. 2008, 294, H2406-H2409. [CrossRef] [PubMed]

Sample Availability: Samples of the compounds are available from the authors.

(C) 2017 by the authors. Licensee MDPI, Basel, Switzerland. This article is an open access article distributed under the terms and conditions of the Creative Commons Attribution (CC BY) license (http:/ / creativecommons.org/licenses/by/4.0/). 


\section{II.}

Pipicz M.; Varga Z.V.; Kupai K.; Gaspar R.; Kocsis G.F.; Csonka C.; Csont T. Rapid ventricular pacing-induced postconditioning attenuates reperfusion injury: Effects on peroxynitrite, RISK and SAFE pathways. British Journal of Pharmacology 2015, 172, 3472-3483. [IF: 5.259] 


\section{RESEARCH PAPER THEMED ISSUE}

\section{Rapid ventricular pacing-induced} postconditioning attenuates reperfusion injury: effects on peroxynitrite, RISK and SAFE pathways

\section{Correspondence}

Tamás Csont, Department of Biochemistry, University of Szeged, Dóm tér 9, H-6720 Szeged, Hungary. E-mail: csont.tamas@med.u-szeged.hu

*These authors contributed equally to this work.

Received

27 August 2014

Revised

18 March 2015

Accepted

25 March 2015

Márton Pipicz ${ }^{1, *}$, Zoltán V Varga ${ }^{1,2, *}$, Krisztina Kupai ${ }^{1}$, Renáta Gáspár ${ }^{1}$, Gabriella F Kocsis ${ }^{1}$, Csaba Csonka ${ }^{1}$ and Tamás Csont ${ }^{1}$

${ }^{1}$ Department of Biochemistry, University of Szeged, Szeged, Hungary, and ${ }^{2}$ Department of

Pharmacology and Pharmacotherapy, Semmelweis University, Budapest, Hungary

\section{BACKGROUND AND PURPOSE}

Rapid ventricular pacing (RVP) applied before an index ischaemia has anti-ischaemic effects. Here, we investigated whether RVP applied after index ischaemia attenuates reperfusion injury and whether peroxynitrite, reperfusion injury salvage kinase (RISK) and survival activating factor enhancement (SAFE) pathways as well as haem oxygenase 1 (HO1) are involved in the mechanism of RVP-induced postconditioning.

\section{EXPERIMENTAL APPROACH}

Langendorff perfused rat hearts were subjected to $30 \mathrm{~min}$ regional ischaemia and $120 \mathrm{~min}$ reperfusion with or without ischaemic postconditioning $(6 \times 10 / 10 \mathrm{~s}$ reperfusion/ischaemia; IPost $)$ or RVP $(6 \times 10 / 10 \mathrm{~s}$ non-pacing/rapid pacing at $600 \mathrm{bpm}$ ) applied at the onset of reperfusion.

\section{KEY RESULTS}

Meta-analysis of our previous studies revealed an association between longer reperfusion-induced ventricular tachycardia/fibrillation with decreased infarct size. In the present experiments, we tested whether RVP is cardioprotective and found that both IPost and RVP significantly decreased infarct size; however, only RVP attenuated the incidence of reperfusion-induced ventricular tachycardia. Both postconditioning methods increased the formation of cardiac 3-nitrotyrosine and superoxide, and non-significantly enhanced Akt phosphorylation at the beginning of reperfusion without affecting ERK1/2 and STAT3, while IPost alone induced HO1. Application of brief ischaemia/reperfusion cycles or RVP without preceding index ischaemia also facilitated peroxynitrite formation; nevertheless, only brief RVP increased STAT3 phosphorylation.

\section{CONCLUSIONS AND IMPLICATIONS}

Short periods of RVP at the onset of reperfusion are cardioprotective and increase peroxynitrite formation similarly to IPost and thus may serve as an alternative postconditioning method. However, downstream mechanisms of the protection elicited by IPost and RVP seem to be partially different. 


\section{LINKED ARTICLES}

This article is part of a themed section on Conditioning the Heart - Pathways to Translation. To view the other articles in this section visit http://dx.doi.org/10.1111/bph.2015.172.issue-8

\section{Abbreviations}

HO1, haem oxygenase 1; I/R, ischaemia/reperfusion; IPost, ischaemic postconditioning; LAD, left anterior descending coronary artery; RISK, reperfusion injury salvage kinase; RVP, rapid ventricular pacing; SAFE, survival activating factor enhancement; VF, ventricular fibrillation; VT, ventricular tachycardia

\section{Tables of Links}

\begin{tabular}{|llll|}
\hline TARGETS & & & \\
\hline Acetylcholinesterase & ERK1 & HO1 & PKG \\
Akt (PKB) & ERK2 & PKC & \\
\hline
\end{tabular}

LIGANDS
CGMP
CGRP

These Tables list key protein targets and ligands in this article which are hyperlinked to corresponding entries in http:// www.guidetopharmacology.org, the common portal for data from the IUPHAR/BPS Guide to PHARMACOLOGY (Pawson et al., 2014) and are permanently archived in the Concise Guide to PHARMACOLOGY 2013/14 (Alexander et al., 2013).

\section{Introduction}

Ischaemic heart diseases, including acute myocardial infarction, are the leading cause of death in industrialized countries. Reperfusion therapy for infarction allows rapid return of blood flow to the ischaemic myocardium and decreases mortality rate. However, early reperfusion itself is accompanied by deleterious events: the occurrence of life-threatening arrhythmias, no-reflow phenomenon, myocardial stunning and additional cell death (Yellon and Hausenloy, 2007). This paradoxical reperfusion injury caused by the restoration of blood flow and oxygen supply (Yamada et al., 1990) leads to increased infarct size, impaired contractile function and electrical vulnerability, largely compromising clinical outcomes.

Ischaemic postconditioning (IPost) has emerged in the last decade as a potential therapeutic intervention for limiting reperfusion injury (Zhao et al., 2003; Ovize et al., 2010). The procedure is based upon the application of brief cycles of ischaemia/reperfusion (I/R) immediately after a prolonged ischaemia and it has been reported to reduce myocardial damage both in animal studies and in human clinical trials (Ovize et al., 2010). Nevertheless, some studies have reported the ineffectiveness of IPost both in animals and in humans (Dow and Kloner, 2007; Hahn et al., 2013). A possible explanation for the controversial results could be that the outcome of postconditioning may depend on several factors, such as failure to achieve complete reperfusion during application of brief $\mathrm{I} / \mathrm{R}$ cycles, the duration of index ischaemia, the algorithm of postconditioning manoeuvre, gender, age and temperature (Skyschally et al., 2009b). In addition, co-morbidities, such as hyperlipidaemia (Kupai et al., 2009) and diabetes (Miki et al., 2012), may interfere with the infarct size-limiting effect of postconditioning. These confounding factors indicate the necessity to develop new alternative methods and models to induce postconditioning.

Heart rate is known to play a role in the development of I/R injury (Bernier et al., 1989), and it was shown that either slowing or increasing heart rate before ischaemia limits myocardial injury (Tosaki et al., 1988; Bernier et al., 1989; Hearse et al., 1999). Moreover, we have previously shown that short periods of rapid ventricular pacing (RVP) applied before an index ischaemia has anti-ischaemic effects (pacinginduced preconditioning) (Ferdinandy et al., 1997a,b; 1998). However, the effect of short periods of RVP performed at the early phase of reperfusion has not been investigated so far.

The exact molecular mechanism of myocardial postconditioning is not entirely clear. Increasing evidence suggests that enhanced formation of cardiac peroxynitrite is involved in cardioprotection afforded by both pre- (Altug et al., 2000; Altup et al., 2001; Csonka et al., 2001) and postconditioning (Kupai et al., 2009; Li et al., 2013). Kupai et al. reported first that IPost failed to decrease infarct size in the presence of a peroxynitrite decomposition catalyst, thereby suggesting essential triggering role of peroxynitrite in postconditioninginduced cardioprotection (Kupai et al., 2009).

Therefore, here we aimed to investigate whether RVP applied after index ischaemia has any effect on the markers of reperfusion injury and we studied the role of peroxynitrite in the mechanisms of postconditioning. Furthermore, we looked at activation of reperfusion injury salvage kinase (RISK) and survival activating factor enhancement (SAFE) pathways and haem oxygenase 1 (HO1) as possible downstream targets of RVP-induced postconditioning.

\section{Methods}

Male Wistar rats were used in our previous and present $(n=$ 74) studies. The studies conform to the 'Guide for the care and use of laboratory animals' published by the US National Institutes of Health (NIH Publication No. 85-23, revised 1996) and was approved by local ethics committees. The animals were kept at 12/12h light/dark cycle and had free access to standard laboratory chow and drinking water. All 
studies involving animals are reported in accordance with the ARRIVE guidelines for reporting experiments involving animals (Kilkenny et al., 2010; McGrath et al., 2010).

\section{Isolated heart preparation}

Isolated heart preparation was carried out as described in our previous studies with slight modifications (Ferdinandy et al., 1997a; Kocsis et al., 2012; Varga et al., 2014). Inhalation anaesthesia of rats was induced in a glass desiccator containing cellulose wadding soaked in diethyl ether, an anaesthetic not known to interfere with cardioprotection. During isolation of the heart, rats were removed from the chamber and a beaker containing wadding soaked in ether was held near the muzzle of rats in order to maintain anaesthesia. Rats were given $500 \mathrm{U} \cdot \mathrm{kg}^{-1}$ heparin i.v. Hearts were then isolated and perfused according to Langendorff at $37^{\circ} \mathrm{C}$ with KrebsHenseleit buffer containing $118 \mathrm{mM} \mathrm{NaCl}, 25 \mathrm{mM} \mathrm{NaHCO}_{3}$, $4.3 \mathrm{mM} \mathrm{KCl}, 1.5 \mathrm{mM} \mathrm{CaCl}_{2}, 1.2 \mathrm{mM} \mathrm{KH}_{2} \mathrm{PO}_{4}, 1.2 \mathrm{mM} \mathrm{MgSO}_{4}$, $11 \mathrm{mM}$ glucose, gassed with $95 \% \mathrm{O}_{2}$ and $5 \% \mathrm{CO}_{2}$. Hydrostatic perfusion pressure was kept constant at $100 \mathrm{cmH}_{2} \mathrm{O}(9.8 \mathrm{kPa})$ throughout the experiments. Coronary flow was measured by collecting coronary effluent for a period of time and was expressed as $\mathrm{mL} \cdot \mathrm{min}^{-1}$.

A 3-0 silk suture was placed around the left anterior descending coronary artery (LAD) close to its origin and the snare was tightened by applying a $100 \mathrm{~g}$ hanging weight to induce regional index ischaemia. For IPost, brief no-flow global ischaemia was performed by turning off the perfusion cannula. The presence of ischaemia was verified by monitoring coronary flow. RVP (600 bpm; $10 \mathrm{~Hz}$ ) was performed by an electric stimulator (Experimetria Inc., Budapest, Hungary) with double threshold square, $1 \mathrm{~V}, 1 \mathrm{~mA}$ and $5 \mathrm{~ms}$ impulses conducted by electrodes attached directly to the surface of the right ventricle close to the apex and to the aortic cannula as described previously (Ferdinandy et al., 1997a,b; 1998). Heart rates were monitored (Isosys; Experimetria Inc.) by recording epicardial ECG throughout the whole duration of perfusion.

\section{Relationship between the duration of reperfusion-induced ventricular tachyarrhythmia and infarct size: a meta-analysis}

Meta-analysis was performed on ECGs and infarct size data from our six previous studies performed in our laboratory on isolated rat hearts subjected to $30 \mathrm{~min}$ regional ischaemia and $120 \mathrm{~min}$ reperfusion (Figure 1A). Reperfusion-induced arrhythmias were analysed in the first 10 min of reperfusion. Hearts presenting sustained (>10 min) tachyarrhythmia were excluded $(n=14)$. Three separate evaluations were performed based on the total duration of ventricular tachycardia (VT), ventricular fibrillation (VF) or VT + VF respectively. Infarct size data were presented on the basis of duration (shorter or longer than $60 \mathrm{~s}$ ) of VT, VF or VT + VF. Infarct size data exceeding mean \pm 2 SD were excluded from the analysis $(n=6)$.

\section{Experimental design 1: testing the cardioprotective effect of RVP}

To examine whether RVP applied at the onset of reperfusion induces cardioprotection, isolated hearts were perfused as shown in Figure 2A. Three experimental groups were
Meta-analysis of our previous studies on isolated hearts subjected to 30 min regional ischaemia and 120 min reperfusion $(n=57)$
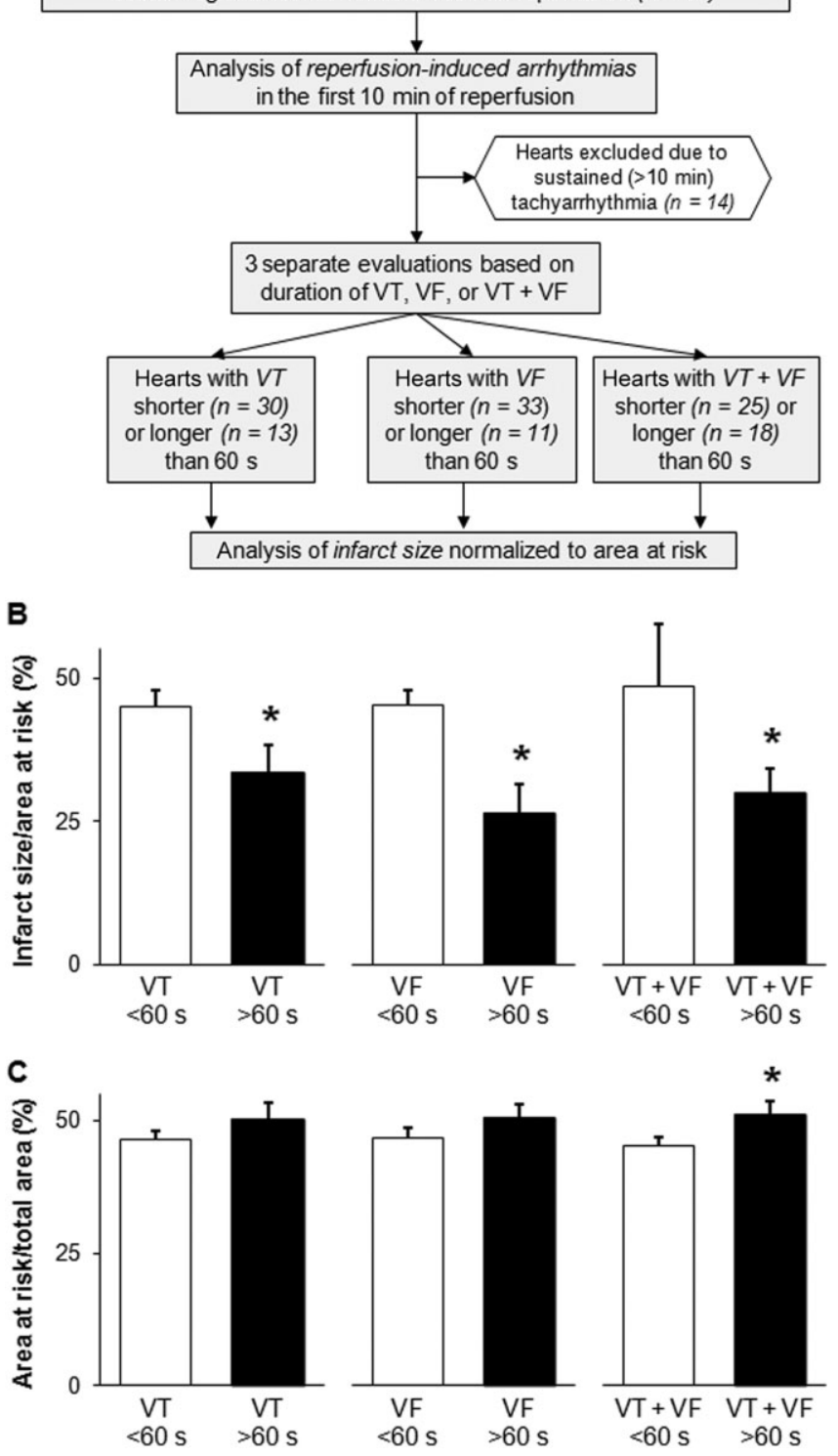

Figure 1

Duration of reperfusion-induced VT and/or VF is associated with decreased infarct size: a meta-analysis. Flow chart of the meta-analysis (A) indicates that reperfusion-induced tachyarrhythmias and infarct size data from our previous studies on isolated rat hearts subjected to $30 \mathrm{~min}$ regional ischaemia and $120 \mathrm{~min}$ reperfusion were analysed in three separate ways considering the duration of either VT, VF or both in the first $10 \mathrm{~min}$ of reperfusion. The results of the meta-analysis show infarct size normalized to area at risk (B) and area at risk (C) in the presence of shorter $(<60 \mathrm{~s}$ ) or longer ( $>60 \mathrm{~s})$ total durations of VT, VF or $\mathrm{VT}+\mathrm{VF}$ respectively. Values are expressed as mean \pm SEM. ${ }^{*} P<0.05$ versus corresponding $<60 \mathrm{~s}$ groups, unpaired $t$-test.

designed: (i) I/R control; (ii) ischaemic postconditioning; and (iii) RVP groups ( $n=12$ in each group). The I/R control group was subjected to a $15 \mathrm{~min}$ equilibration period, followed by 30 min regional index ischaemia and 120 min reperfusion. IPost was induced by six consecutive cycles of $10 \mathrm{~s}$ 
A

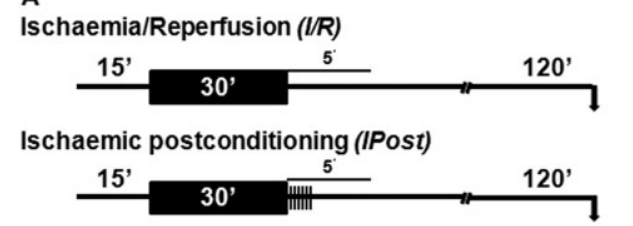

Rapid ventricular pacing (RVP)
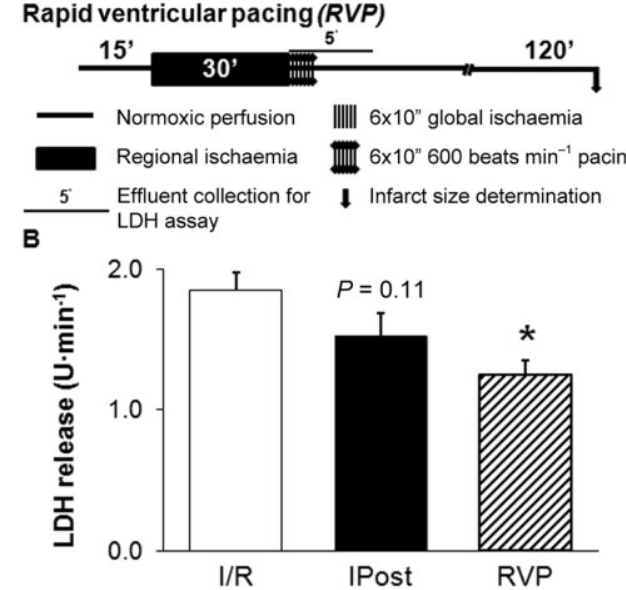

C
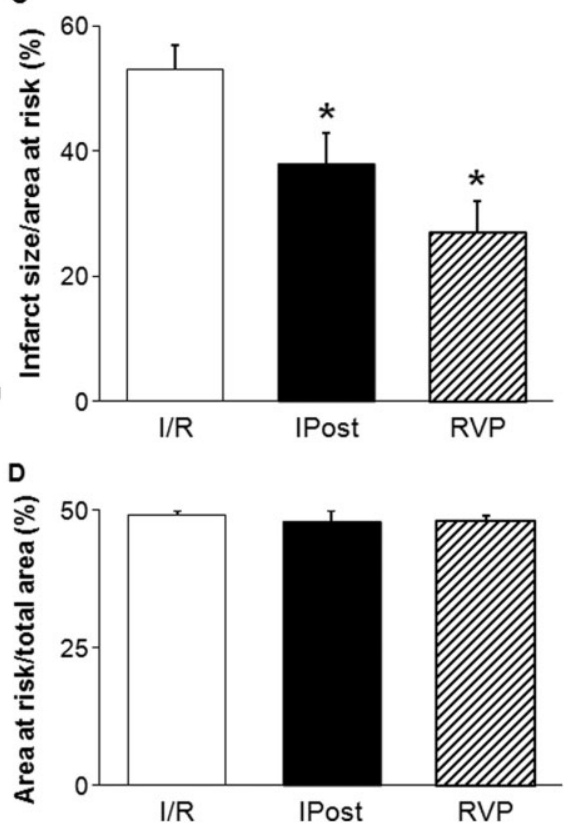

\section{Figure 2}

RVP reduces post-ischaemic LDH release and infarct size. Experimental protocol (A), post-ischaemic LDH release (B), infarct size normalized to area at risk (C) and area at risk (D). Hearts were subjected to a 15 min equilibration period, followed by 30 min regional ischaemia and 120 min reperfusion. Ischaemic postconditioning was induced by $6 \times 10 \mathrm{~s} / 10 \mathrm{~s}$ cycles of reperfusion/no-flow global ischaemia. In the RVP group, the autonomic rhythm of the hearts was replaced by $10 \mathrm{~s}$ pacing period $\left(600\right.$ beats min $\left.^{-1} ; 10 \mathrm{~Hz}\right)$ in six alternating cycles at the onset of reperfusion. Coronary effluent was collected during the first 5 min of reperfusion for $\mathrm{LDH}$ activity determination ( $n=5$ in each group), the measured activities were multiplied by the corresponding coronary flow to give LDH release. Infarct size was measured at the end of reperfusion ( $n=12$ in each group). Values are expressed as mean \pm SEM. ${ }^{*} P<0.05$ versus $I / R$, one-way ANOVA.

reperfusion and $10 \mathrm{~s}$ no-flow global ischaemia at the onset of reperfusion. In the RVP group, the spontaneous rhythm of hearts was replaced by a $10 \mathrm{~s}$ pacing period (600 beats $\mathrm{min}^{-1}$; $10 \mathrm{~Hz}$ ) in six alternating cycles during the first 2 min of reperfusion.

To assess the severity of cellular damage in the myocardium, the activity of LDH enzyme from coronary effluents (collected during the first 5 min of reperfusion) was measured using an LDH-P kit (Diagnosticum, Budapest, Hungary) ( $n=5$ in each group). The enzyme activity $\left(\mathrm{U} \cdot \mathrm{mL}^{-1}\right)$ measured in an effluent was multiplied by the corresponding coronary flow $\left(\mathrm{mL} \cdot \mathrm{min}^{-1}\right)$ to give $\mathrm{LDH}$ release expressed as $\mathrm{U} \cdot \mathrm{min}^{-1}$.

To determine infarct size, the LAD was re-occluded at the end of reperfusion and hearts were stained with $0.1 \%$ Evans blue to determine area at risk (Csonka et al., 2010). Hearts were then frozen at $-20^{\circ} \mathrm{C}$ and cut into approximately $2 \mathrm{~mm}$ thick slices. Each slice was incubated at $37^{\circ} \mathrm{C}$ for $10 \mathrm{~min}$ in $1 \%$ 2,3,4-triphenyl-tetrazolium-chloride solution dissolved in phosphate buffer (pH 7.4). Slices were then fixed in 10\% formaldehyde and scanned. Infarct size was evaluated by planimetry (InfarctSize ${ }^{\mathrm{TM}}$ 2.4.b; Pharmahungary Group, Szeged, Hungary) and normalized to area at risk.

To assess reperfusion-induced tachyarrhythmias (VT and VF), ECG was recorded (Isosys; Experimetria Inc.) during the entire perfusion protocol. Analysis of arrhythmias was carried out according to the original Lambeth conventions (Walker et al., 1988).
Experimental design 2: investigating the role of peroxynitrite and possible downstream targets in RVP-induced postconditioning

To assess the possible role of peroxynitrite in cardioprotection induced by ischaemic- or RVP-induced postconditioning, in separate experiments, cardiac 3-nitrotyrosine, a well-known peroxynitrite marker, was determined. To confirm increased peroxynitrite formation, cardiac superoxide anion was also measured. Furthermore, involvement of molecular mechanisms (i.e. RISK and SAFE pathways, HO1) that have been implicated in cardioprotection (Hausenloy and Yellon, 2004; Lecour, 2009; Bak et al., 2010) was also investigated as possible downstream targets of RVP-induced postconditioning.

Hearts were subjected to 15 min equilibration period, followed by $30 \mathrm{~min}$ regional ischaemia and $7 \mathrm{~min}$ reperfusion with or without IPost or RVP (Figure 4A). At the end of reperfusion, myocardial samples were taken from the ischaemic zone of the left ventricle for 3-nitrotyrosine measurement and Western blot analysis ( $n=5$ in each group). Sampling was carried out by an oblique cut from the origin of the LAD towards the right side of the apical area that involves the majority of the anterior wall of the left ventricle as well as the apex of the heart. Samples were rapidly freeze-clamped, powdered with a pestle and mortar in liquid nitrogen and stored in cryovials at $-80^{\circ} \mathrm{C}$ until further analysis. Sampling for in situ detection of superoxide anion was carried out in separate 
experiments ( $n=3$ in each group) using the same perfusion protocol (Figure 4A). Approximately $3 \mathrm{~mm}$ thick transverse slices were cut from the middle of the ventricles, embedded in Tissue-Tek O.C.T. compound (Sakura Finetek, Zoeterwoude, The Netherlands), carefully frozen in isopentane precooled in liquid nitrogen and stored at $-80^{\circ} \mathrm{C}$ until sectioning with a microtome.

Cardiac free 3-nitrotyrosine content, a marker of peroxynitrite, was measured by ELISA (Cayman Chemical, Ann Arbor, MI, USA) according to the manufacturer's instructions (Kupai et al., 2009; Kocsis et al., 2012). Briefly, homogenates were incubated overnight with nitrotyrosine acetylcholinesterase tracer and anti-nitrotyrosine rabbit IgG in microplates pre-coated with mouse anti-rabbit IgG. Ellman's reagent was used for development. Free nitrotyrosine content was normalized to protein content of cardiac homogenate and expressed as $\mathrm{ng} \mathrm{mg}^{-1}$ protein.

Superoxide anion $\left(\mathrm{O}_{2}^{-}\right)$is a reactive oxygen radical that reacts with NO to form peroxynitrite. The in situ fluorescent dihydroethidium staining was performed to evaluate intracellular production of superoxide anion (Varga et al., 2013). Unfixed frozen heart sections $(30 \mu \mathrm{m})$ were placed on glass slides and incubated in $10^{-6} \mathrm{~mol} \cdot \mathrm{L}^{-1}$ dihydroethidium (Sigma, St. Louis, MO, USA) in PBS buffer (pH 7.4) at $37^{\circ} \mathrm{C}$ for $30 \mathrm{~min}$ in a dark humidified container. Fluorescence was then detected by a fluorescent microscope (Nikon, Tokyo, Japan) with a $590 \mathrm{~nm}$ long-pass filter. Images of the hearts were collected digitally ( $n=20$ in each heart); integrated density was evaluated by ImageJ $1.44 \mathrm{p}$ software and expressed in arbitrary unit.

The involvement of possible downstream targets in the mechanism of RVP-induced postconditioning was examined by standard Western blot techniques (Kocsis et al., 2008; Fekete et al., 2013). Tissue samples were homogenized with an ultrasonicator (UP100H Hielscher, Teltow, Germany) in RIPA buffer [50 mM Tris-HCl (pH 8.0), $150 \mathrm{mM} \mathrm{NaCl}, 0.5 \%$ sodium deoxycholate, $5 \mathrm{mM}$ EDTA, $0.1 \%$ SDS, $1 \%$ NP-40] supplemented with protease inhibitor cocktail (Sigma), PMSF, $\mathrm{NaF}$ and $\mathrm{Na}_{3} \mathrm{VO}_{4}$. The crude homogenates were centrifuged at $10000 \times \mathrm{g}$ for $10 \mathrm{~min}$ at $4^{\circ} \mathrm{C}$. After quantification of protein concentrations of the supernatants using BCA Protein Assay Kit (Pierce, Rockford, IL, USA), $20 \mu \mathrm{g}$ (50 $\mu \mathrm{g}$ for HO1) reduced and denaturated protein was loaded and SDS-PAGE $(10 \%$ gel, $90 \mathrm{~V}, 1.5 \mathrm{~h})$ was performed followed by transfer of proteins onto nitrocellulose membrane (20\% methanol, $35 \mathrm{~V}, 2 \mathrm{~h})$. Membranes were blocked for $1 \mathrm{~h}$ in $5 \%\left(\mathrm{w} \mathrm{v}^{-1}\right)$ BSA at room temperature and then incubated with primary antibodies against phospho(Ser $\left.{ }^{473}\right)$-Akt 1:500, Akt 1:2000, phospho( $\mathrm{Thr}^{202} / \mathrm{Tyr}^{204}$ )-ERK1/ERK2 1:2000, ERK1/ERK2 1:1000, phospho(Tyr ${ }^{705}$ )-STAT3 1:2000, STAT3 1:2000 (Cell Signaling, Beverly, MA, USA; overnight, $4^{\circ} \mathrm{C}, 5 \% \mathrm{BSA}$ ) or HO1 1:2000 (Enzo Life Sciences, Plymouth Meeting, PA, USA; 2 h, room temperature, 1\% milk) or GAPDH 1:10 000 (Cell Signaling, Beverly, MA, USA; $1 \mathrm{~h}$, room temperature, 1\% milk). After incubation with HRP-conjugated secondary antibody 1:5000 (1:20 000 for GAPDH) (Dako Corporation, Santa Barbara, CA, USA; $1 \mathrm{~h}$, room temperature, $1 \%$ milk), membranes were developed using an enhanced chemiluminescence kit (Pierce).

To further prove that both IPost and RVP protocols (i.e. application of brief I/R or RVP) facilitate peroxynitrite forma- tion, 3-nitrotyrosine was measured in the absence of index ischaemia. The effect of the protocols on possible downstream targets of peroxynitrite (i.e. RISK and SAFE pathways) was also examined in the absence of preceding index ischaemia.

In this set of experiments, the time course of the perfusion protocol was adjusted to the previous set-up without index ischaemia (Figure 5A). In the normoxic perfusion group $(n=8)$, hearts were perfused for $52 \mathrm{~min}$. In the repeated brief I/R group $(n=7)$, hearts were subjected to 45 min perfusion followed by $6 \times 10 / 10$ s cycles of no-flow global I/R and 5 min reperfusion. In the repeated brief RVP group $(n=8)$, the spontaneous rhythm of the hearts was replaced by $10 \mathrm{~s}$ pacing period $\left(600\right.$ beats $\mathrm{min}^{-1} ; 10 \mathrm{~Hz}$ ) in six alternating cycles after 45 min perfusion. At the end of perfusion, the cardiac free 3-nitrotyrosine level was determined and RISK as well as SAFE pathways were examined as described earlier.

\section{Statistical analysis}

Data are expressed as mean \pm SEM and analysed by use of Student's unpaired $t$-test, one-way ANOva, or Fisher's exact test as appropriate. If a difference was established in ANOvA, Fisher's least significant difference post hoc test was applied. Differences were considered significant at $P<0.05$.

\section{Results}

\section{Duration of reperfusion-induced $V T$ and/or fibrillation is associated with decreased infarct size}

Meta-analysis of six separate studies previously performed in our laboratory using the same experimental protocol (i.e. isolated rat hearts subjected to I/R) showed that the presence of VT, VF or VT + VF with a total duration of longer than $60 \mathrm{~s}$ in the first 10 min of reperfusion was associated with a markedly decreased infarct size (Figure 1B) respectively. In this analysis, a larger area at risk was associated with longer than $60 \mathrm{~s}$ total duration of VT + VF (Figure 1C).

\section{RVP exerts cardioprotective effect: limits the infarction and reperfusion-induced arrhythmias}

In order to assess the possible cardioprotective effect of RVP, the extent of myocardial infarction (LDH release and infarct size) was measured and reperfusion-induced arrhythmias were analysed.

The post-ischaemic LDH release was significantly reduced by RVP (Figure 2B). IPost also reduced LDH release; however, the difference did not reach the level of statistical significance (Figure 2B). Infarct size was significantly decreased by both IPost and RVP (Figure 2C). There was no difference in the area at risk of either experimental group (Figure 2D).

The incidence of VT and VF was not affected significantly by IPost in our present study (Figure 3). In contrast, short periods of RVP decreased the incidence of reperfusioninduced VT without having a significant effect on VF (Figure 3).

There was no difference in animal weight, heart wet weight, baseline heart rate and coronary flow (baseline, 


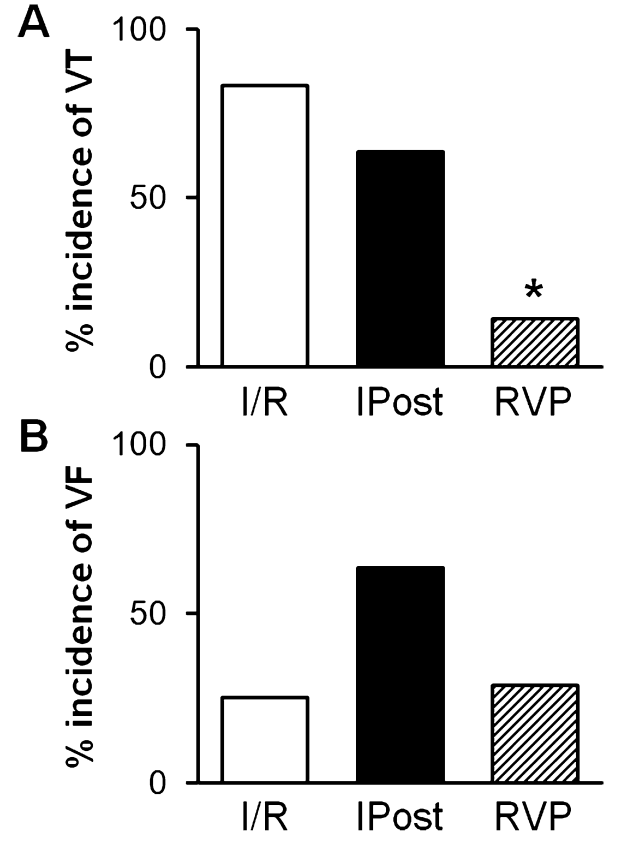

\section{Figure 3}

RVP attenuates reperfusion-induced arrhythmias. Incidence of reperfusion-induced VT (A) and VF (B) are shown. ${ }^{*} P<0.05$ versus $\mathrm{I} / \mathrm{R}$, Fisher's exact test.

beginning of ischaemia, end of reperfusion) between the experimental groups (Table 1). In contrast to IPost, coronary flow at the onset of reperfusion was not changed by short periods of RVP compared with I/R control (Table 1).

\section{Peroxynitrite is likely involved in}

$R V P$-induced postconditioning

To obtain some mechanistic insight into the beneficial effect of RVP, cardiac 3-nitrotyrosine and superoxide were measured at $7 \mathrm{~min}$ of reperfusion following the $30 \mathrm{~min}$ index ischaemia.

Postconditioning induced either by IPost or by RVP significantly increased free cardiac 3-nitrotyrosine level (a marker of peroxynitrite formation) (Figure 4B). Moreover, the peroxynitrite precursor superoxide anion was mildly, but significantly elevated in both postconditioning groups (Figure 4C).

To further prove that the postconditioning manoeuvres induce nitrative stress, cardiac 3-nitrotyrosine was measured after the postconditioning stimuli applied following normoxic perfusion without index ischaemia. The application of brief I/R cycles or periodic RVP increased the cardiac formation of 3-nitrotyrosine in the absence of index ischaemia (Figure 5B).

\section{Downstream mechanisms of RVP-induced cardioprotection differs from that of ischaemic postconditioning}

To elucidate the possible downstream targets of RVP, RISK and SAFE pathways as well as HO1 were investigated either in the presence or absence of index ischaemia.
Both postconditioning methods non-significantly enhanced Akt phosphorylation after index ischaemia at the beginning of reperfusion without affecting phosphorylation of ERK1/2 and STAT3 (Figure 4E,F). Protein level of HO1 was increased by IPost but not RVP (Figure 4E,F). In the absence of index ischaemia, applying short periods of RVP protocol increased STAT3 phosphorylation, in contrast to brief cycles of I/R (Figure 5C,D). Phosphorylation of Akt and ERK1/2 was not affected significantly by any of the interventions in the absence of index ischaemia (Figure 5C,D).

\section{Discussion and conclusion}

In our present study, using an isolated perfused rat heart model, we confirmed that IPost beneficially affects I/R injury. Moreover, we demonstrated for the first time in the literature that applying short periods of RVP at the onset of reperfusion also exerts a cardioprotective effect as it attenuates reperfusion injury by decreasing infarct size and reperfusion-induced arrhythmias. We showed that RVP increased peroxynitrite formation either in the presence or absence of index ischaemia in a way similar to IPost. These findings suggest that the formation of peroxynitrite in early reperfusion is a key event in the development of cardioprotection elicited by IPost or RVP. However, we also demonstrated that the downstream mechanisms of RVP-induced cardioprotection and IPost seem to be partially different.

In a meta-analysis of our previous studies on isolated hearts subjected to I/R, we analysed if there is an association between the duration of reperfusion-induced ventricular tachyarrhythmias (VT, VF or VT + VF) and infarct size. It is well accepted in the literature that $\mathrm{I} / \mathrm{R}$ induces cellular damage that makes the myocardium more susceptible to arrhythmogenesis, and thus reperfusion-induced arrhythmias are considered as indicators of I/R injury (Engelen et al., 2003; Majidi et al., 2009). For instance, Majidi et al. reported that the presence of reperfusion arrhythmia bursts in STEMI patients is associated with a worse outcome (larger infarct size and decreased ejection fraction) (Majidi et al., 2009). However, here we found surprisingly that longer than $60 \mathrm{~s}$ reperfusion-induced VT/VF was associated with a decreased infarct size. In this analysis, a larger area at risk was associated with longer total duration of VT + VF in accordance with the literature data (Curtis and Hearse, 1989). The interpretation of these results is difficult since causality was not examined in these studies. A possible explanation for the results of our meta-analysis is that the size of infarction affects the occurrence of sustained VT and/or VF, while another possibility is that longer tachyarrhythmias at the beginning of reperfusion somehow attenuate infarct development. To the best of our knowledge, this latter approach has not been investigated in the literature and, therefore, these findings served as a basis for our current experimental study to investigate if exogenous application of controlled tachycardia induced by RVP at the onset of reperfusion is able to elicit cardioprotection.

Heart rate is known to play a role in the development of $\mathrm{I} / \mathrm{R}$ injury (Bernier et al., 1989) and its controlled modification may elicit cardioprotection. For instance, pharmacologically-induced bradycardia (Tosaki et al., 1987), slow (Tosaki et al., 1988) or rapid (Ferdinandy et al., 1998; 


\section{Table 1}

Morphological and ex vivo haemodynamic parameters

\begin{tabular}{|c|c|c|c|}
\hline & $\mathbf{I} / \mathbf{R}$ & IPost & RVP \\
\hline Heart wet weight (g) & $1.28 \pm 0.03$ & $1.22 \pm 0.04$ & $1.30 \pm 0.06$ \\
\hline \multicolumn{4}{|l|}{ Coronary flow $\left(\mathrm{mL} \cdot \mathrm{min}^{-1}\right)$} \\
\hline Before ischaemia & $18.8 \pm 1.5$ & $16.7 \pm 1.2$ & $18.7 \pm 1.1$ \\
\hline Beginning of reperfusion ${ }^{b}$ & $16.5 \pm 1.0$ & $8.7 \pm 0.6^{*}$ & $17.9 \pm 0.7$ \\
\hline End of reperfusion & $11.5 \pm 1.5$ & $9.9 \pm 0.9$ & $11.8 \pm 1.5$ \\
\hline
\end{tabular}

Results are expressed as mean \pm SEM. ${ }^{*} P<0.05$ versus $\mathrm{I} / \mathrm{R}$ and RVP, one-way ANOVA.

aRegional ischaemia.

${ }^{\mathrm{b}} 6 \times 10 \mathrm{~s}$ global ischaemia was applied to induce IPost in the first 2 min of reperfusion. Coronary flow was measured by collecting coronary effluent for $2 \mathrm{~min}$ and then was expressed as $\mathrm{mL} \cdot \mathrm{min}^{-1}$.

Hearse et al., 1999) pacing before ischaemia was reported to limit myocardial injury. Since the presence of longer reperfusion-induced tachyarrhythmias was associated with lower infarct size in our meta-analysis, we wanted to test whether exogenous rapid pacing exerts protection. To the best of our knowledge, we demonstrated for the first time in the literature that the application of short periods of rapid ( 600 beats $\mathrm{min}^{-1}$ ) ventricular pacing at the beginning of reperfusion reduces infarct size and reperfusion-induced arrhythmias.

In the present study, both RVP and classic IPost decreased infarct size. The beneficial effect of RVP on infarct size was further confirmed by a reduction in $\mathrm{LDH}$ release into the coronary effluent. Infarct size is a key determinant of major clinical outcomes (mortality and morbidity of consequent heart failure) (Gibbons et al., 2004); therefore, development of procedures that effectively decrease infarct size along with reperfusion therapy is in the focus of preclinical and clinical studies (Ovize et al., 2010). IPost is a widely studied approach, and the infarct size-reducing effect of this procedure was confirmed in various mice, rat, rabbit, dog and swine animal models (Skyschally et al., 2009b) as well as in clinical trials (Ovize et al., 2010). However, some studies reported the ineffectiveness of IPost in animal models (Dow and Kloner, 2007; Skyschally et al., 2009b) and in clinical trials (Hahn et al., 2013). A possible explanation for the controversial results could be that the cardioprotective effect of IPost depends upon several factors such as (i) species, strain, gender and age of research animal; (ii) experimental model and set-up; (iii) the duration of index ischaemia before reperfusion; (iv) number and duration of brief I/R cycles; (v) technical difficulty to achieve complete reperfusion; (vi) temperature; and (vii) presence of co-morbidities. These confounding factors indicate the necessity to develop alternative methods of IPost and we suggest that RVP-induced postconditioning is a simple method that eliminates technical problems associated with the induction of IPost.

Besides infarct size reduction, RVP-induced postconditioning decreased reperfusion-induced ventricular arrhyth- mias as well. Reperfusion therapy is accompanied by the occurrence of arrhythmias (Krumholz and Goldberger, 1991). Some of them are benign (e.g. accelerated idioventricular rhythm, the most common type) but others are potentially life-threatening malignant arrhythmias such as VT or VF that need to be managed in the clinical practice to avoid fatal consequences. Based on the literature data (Kloner et al., 2006), IPost effectively decreases ventricular arrhythmias. However, in our present study, solely RVP-induced postconditioning reduced the incidence of reperfusion-induced VT with no significant effect on VF. The reason for the inability of RVP to improve post-ischaemic VF is not clear. However, one may speculate that some interacting triggers of reperfusion-induced VF (e.g. reactive oxygen intermediates and calcium) may interfere with the possible anti-VF effect of RVP (Hearse and Tosaki, 1988).

Here, we demonstrated that IPost and RVP-induced postconditioning enhanced peroxynitrite formation at the onset of reperfusion after an index ischaemia. In addition, postconditioning manoeuvres themselves (i.e. brief I/R and RVP) increased peroxynitrite formation in the absence of the index ischaemia. Since peroxynitrite is reported as a possible trigger of IPost (Kupai et al., 2009), based upon our current results, we propose that the enhanced peroxynitrite formation also plays a role in triggering RVP-induced postconditioning. Back in 1997, Yasmin et al. reported that the level of peroxynitrite increases during reperfusion, which contributes to reperfusion injury in isolated rat hearts (Yasmin et al., 1997). Further studies also confirmed that enhanced peroxynitrite formation plays a central role in numerous cardiovascular diseases by inducing oxidative, nitrative and nitrosative stress (Pacher et al., 2007). However, peroxynitrite was demonstrated to have physiological functions (Lefer et al., 1997) and to play a role in triggering ischaemic preconditioning (Altug et al., 2000; Altup et al., 2001; Csonka et al., 2001). We have previously reported for the first time that peroxynitrite is a trigger of IPost since the peroxynitrite scavenger, FeTPPS, interfered with the cardioprotective effect of IPost (Kupai et al., 2009). Our results were confirmed by Li et al. showing that perox- 
A

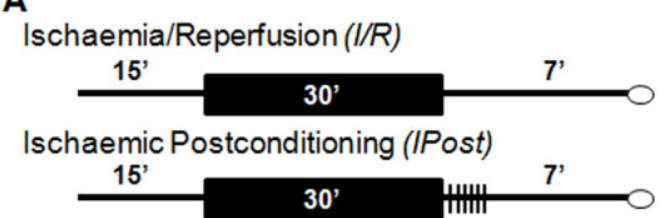

Rapid Ventricular Pacing (RVP)

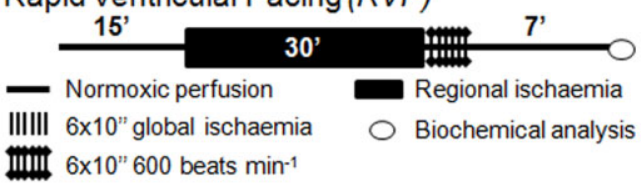

B

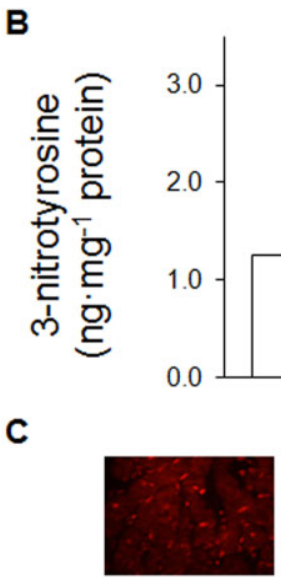

I/R

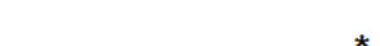

*

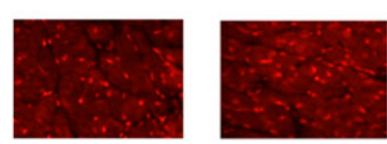

IPost

RVP
E

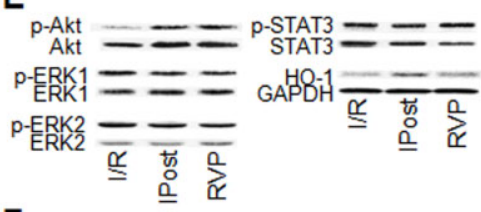

$\mathbf{F}$
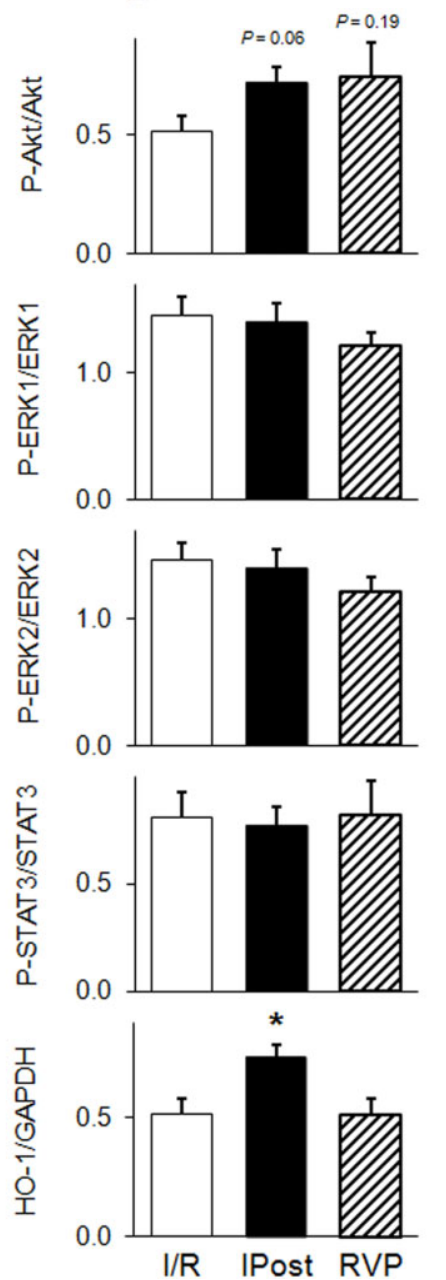

\section{Figure 4}

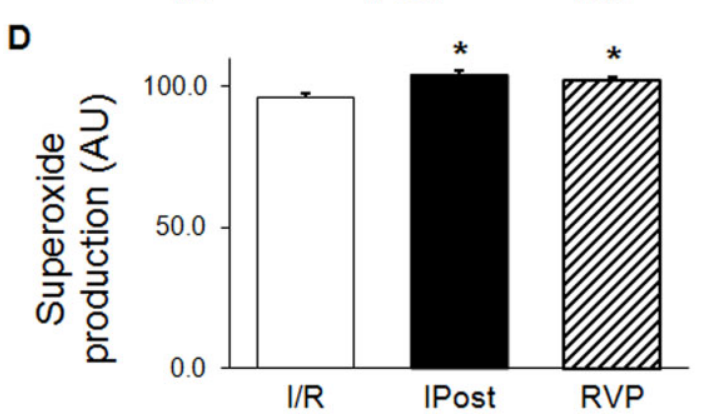

D

Postconditioning by RVP enhances formation of peroxynitrite and superoxide anion, effects on possible downstream targets. Experimental protocol (A), level of free cardiac 3-nitrotyrosine (B), representative images of in situ superoxide detection (C), quantification of in situ superoxide anion level (D), representative images (E) and quantification (F) of Western blots of possible downstream targets. Hearts were subjected to a 15 min equilibration period, followed by $30 \mathrm{~min}$ of regional ischaemia and 7 min reperfusion with or without ischaemic postconditioning or RVP. At the end of reperfusion, myocardial samples were taken from the ischaemic zone of the left ventricle for biochemical analysis. The peroxynitrite marker, 3-nitrotyrosine, was quantified by ELISA ( $n=5$ in each group). Transverse cardiac sections from three hearts per group were used for in situ detection of superoxide anion ( $n=60$ random images in each group). Activation of RISK (Akt, ERK1/2) and SAFE (STAT3) pathways as well as protein level of $\mathrm{HO} 1$ was assessed by Western blot. Values are expressed as mean $\pm \mathrm{SEM}$. ${ }^{*} P<0.05$ versus $\mathrm{I} / \mathrm{R}$, one-way ANOVA. $\mathrm{p}$-Akt, phospho(Ser $\left.{ }^{473}\right)$-Akt; p-ERK1, phospho(Thr $\left.{ }^{202}\right)$-ERK1; p-ERK2, phospho(Tyr $\left.{ }^{204}\right)$-ERK2; p-STAT3, phospho $\left(\right.$ Tyr $\left.^{705}\right)-$ STAT3.

ynitrite is a key mediator of IPost in vivo (Li et al., 2013). Nevertheless, the possible mechanisms lying downstream of peroxynitrite formation in postconditioning have not been elucidated.

Here, we also looked at possible targets of endogenous peroxynitrite formation induced by IPost or by RVP. Several studies have reported that the activation of RISK (Akt, ERK1/ ERK2) and SAFE (STAT3) pathways at the onset of reperfusion might play a role in the cardioprotective effect of IPost
(Hausenloy, 2009; Lecour, 2009). In other studies, overexpression of HO1 was shown to reduce infarct size in the heart (Bak et al., 2010) and was implicated in pulmonary and hepatic IPost (Xia et al., 2009; Zeng et al., 2011). In our present study, both IPost and RVP-induced postconditioning nonsignificantly enhanced Akt phosphorylation without affecting ERK1/2 and STAT3 at the beginning of reperfusion. Although several studies showed increased phosphorylation of Akt and/or ERK due to IPost (Tsang et al., 2004; Yang et al., 
A

Normoxic perfusion

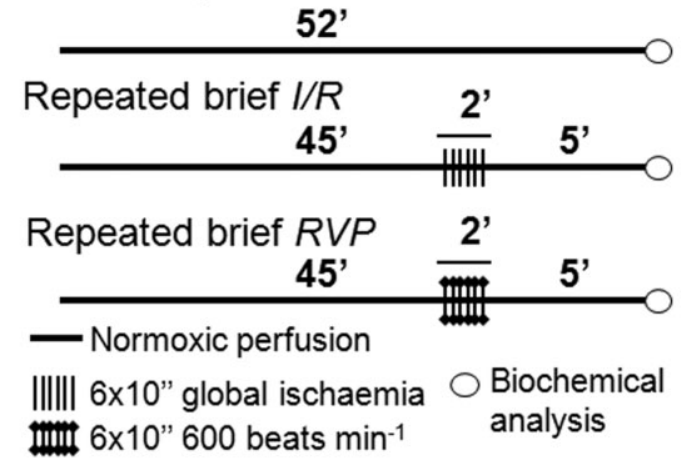

B

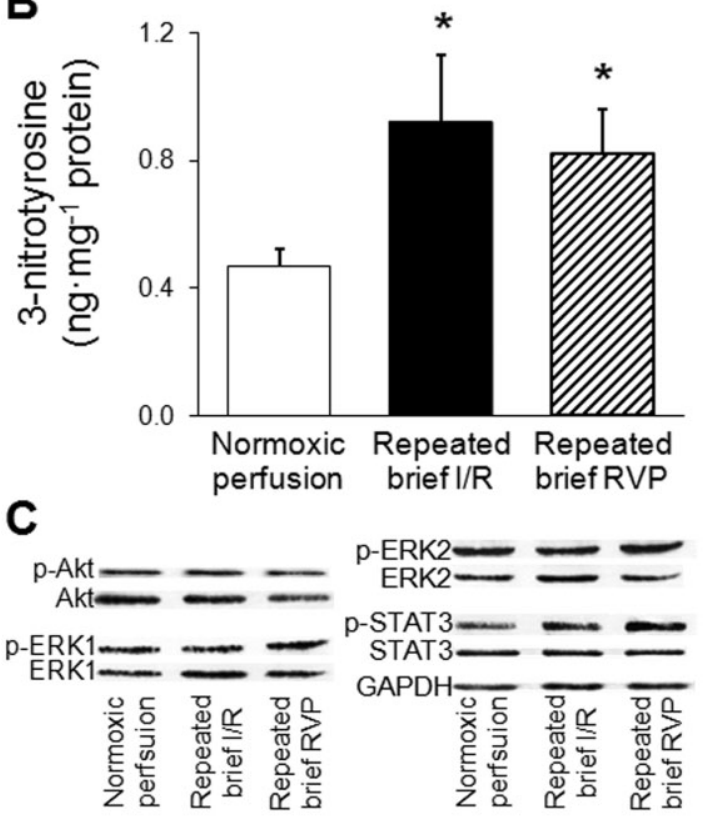

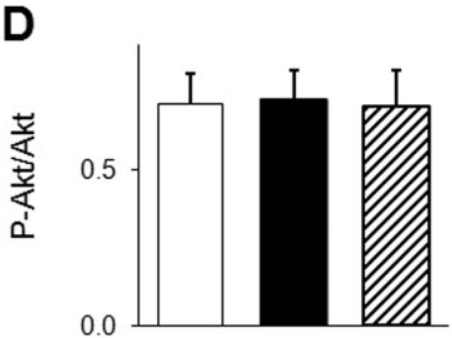
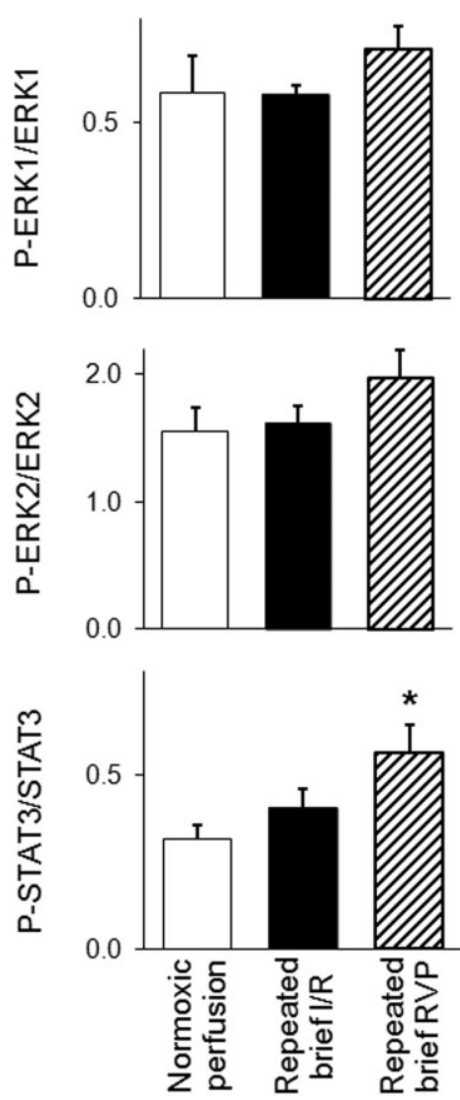

\section{Figure 5}

Postconditioning manoeuvres without a preceding index ischaemia enhance peroxynitrite formation, effects on possible downstream targets. Experimental protocol (A), level of free cardiac 3-nitrotyrosine (B), and representative images (C) and quantification (D) of Western blots of possible downstream targets. After 45 min normoxic perfusion, repeated $(6 \times 10 / 10 \mathrm{~s})$ brief cycles of no-flow global I/R $(n=7)$ or RVP at 600 beats $\mathrm{min}^{-1}$ /spontaneous rhythm of the hearts $(n=8)$ were applied followed by 5 min perfusion. In the normoxic perfusion control group $(n=8)$, hearts were perfused for $52 \mathrm{~min}$. At the end of perfusion, cardiac free 3-nitrotyrosine level was determined by ELISA and activation of RISK and SAFE pathways were examined by Western blots. Values are expressed as mean $\pm S E M$. ${ }^{*} P<0.05$ versus normoxic perfusion control, one-way ANOVA. p-Akt, phospho(Ser $\left.{ }^{473}\right)$-Akt; p-ERK1, phospho(Thr $\left.{ }^{202}\right)$-ERK1; p-ERK2, phospho(Tyr $\left.{ }^{204}\right)$-ERK2; p-STAT3, phospho $\left(\right.$ Tyr $\left.^{705}\right)$-STAT3.

2004), some recent papers suggested that postconditioning did not activate the RISK pathway in the early phase of reperfusion (Skyschally et al., 2009a; Fekete et al., 2013). We also found here that IPost, but not RVP, increased HO1 protein in the heart. This effect of IPost on HO1 is in agreement with the findings of others in the lung and liver (Xia et al., 2009; Zeng et al., 2011). We also examined the effect of postconditioning manoeuvres (i.e. repeated brief cycles of $\mathrm{I} / \mathrm{R}$ or RVP) in the absence of a preceding index ischaemia and found no activation of the RISK pathway. In these experiments, STAT3 phosphorylation was increased only by short periods of RVP protocol. Taken together, our present results indicate that (i) the downstream mechanisms of RVP-induced cardioprotection and IPost are partially different; (ii) HO1 is probably not involved in the cardioprotective effect of RVPinduced postconditioning; and (iii) the precise role of the RISK and SAFE pathways remains to be elucidated in future studies. The involvement of alternative pathways in the protective effect of RVP-induced postconditioning is likely and may include, for instance, activation of NO-cGMP-PKG, sphingosine-, PKC- or CGRP-mediated pathways (Heusch et al., 2008; Bice and Baxter, 2014). Since endogenous NO-cGMP plays a role in protection against reperfusion injury by attenuating infarct size (Penna et al., 2006) and 
reperfusion-induced VF (Pabla et al., 1995; Pabla and Curtis, 1996), investigation of the exact role of NO in RVP would be interesting.

Although we clearly demonstrated that RVP induces cardioprotection when applied at the onset of reperfusion, some further limitations of our study may be considered. Firstly, ventricular pacing was reported to have direct proarrhythmic effects caused by the stimulus itself independently of the heart rate (Nakata et al., 1990). Although in our study ventricular pacing lasts only for short periods $(6 \times 10 \mathrm{~s})$, and the incidence of reperfusion-induced VF was not increased in the RVP group when compared to I/R controls, consideration of pacing as an ectopic focus cannot be excluded. Secondly, in RVP-induced postconditioning, ventricles were activated in a non-physiological way in the present ex vivo study. Although the atrioventricular conduction system of rats was reported to be suitable for reaching $600 \mathrm{bpm}$ heart rate by atrial pacing in an in vivo model (Gonzalez et al., 1998), further in vivo studies are needed to investigate the infarct size-limiting effect of postconditioning induced by rapid atrial or ventricular pacing at different rates. Thirdly, our study suggests that rapid heart rate at the early phase of reperfusion may contribute to initiation of adaptive molecular mechanisms to prevent I/R-induced cellular damage. However, further studies are needed to analyse (i) the precise molecular nature of these mechanisms and (ii) if reperfusion-induced spontaneous arrhythmias also trigger adaptive mechanisms in the myocardium. Our findings may also suggest that reperfusion-induced tachyarrhythmias require attention in future studies focusing on cardioprotection assessed by infarct size.

In conclusion, the application of short periods of RVP at the onset of reperfusion beneficially affects the essential components of reperfusion injury: the infarct size and reperfusion-induced ventricular arrhythmias. In addition, RVP increases peroxynitrite formation, which likely plays a role in triggering cardioprotection similarly to IPost. Nevertheless, downstream mechanisms in RVP-induced protection seem to be partially different from that of IPost, and further research is needed to elucidate them. Since RVP exerted a cardioprotective effect similar to IPost, we feel that RVPinduced postconditioning may serve as an alternative experimental model of IPost. Moreover, RVP could be performed in a more controlled manner than applying brief $\mathrm{I} / \mathrm{R}$ cycles in IPost, which is an important technical advantage compared with IPost.

\section{Acknowledgements}

We are grateful to Nóra Bagi, Fatime Hawchar and Szilvia Török for their skilful technical assistance. We acknowledge the support of grants from the Hungarian Scientific Research Fund (OTKA K 79167), National Office for Research and Technology Grants (NKTH MED_FOOD, TÁMOP-4.2.1/B-09/1/ KONV-2010-0005, TÁMOP-4.2.2.A-11/1/KONV-2012-0035). This work was also supported by János Bolyai Research Scholarship of the Hungarian Academy of Sciences (T. C. and C. C.).

\section{Author contributions}

Z. V. V. and T. C. designed the experiments. M. P., Z. V. V., K. K., G. F. K. and R. G. performed the research. M. P., Z. V. V. and C. C. analysed the data. C. C. and T. C. interpreted the data. M. P. drafted the manuscript. M. P., Z. V. V. and T. C. revised the manuscript. M. P., Z. V. V., K. K., R. G., G. F. K., C. C. and T. C. approved the final version of the manuscript.

\section{Conflict of interest}

Not declared.

\section{References}

Alexander SPH, Benson HE, Faccenda E, Pawson AJ, Sharman JL, Spedding M et al. (2013) The Concise Guide to PHARMACOLOGY 2013/14: enzymes. Br J Pharmacol 170: 1797-1867.

Altug S, Demiryurek AT, Kane KA, Kanzik I (2000). Evidence for the involvement of peroxynitrite in ischaemic preconditioning in rat isolated hearts. Br J Pharmacol 130: 125-131.

Altup S, Demiryurek AT, Ak D, Tungel M, Kanzik I (2001). Contribution of peroxynitrite to the beneficial effects of preconditioning on ischaemia-induced arrhythmias in rat isolated hearts. Eur J Pharmacol 415: 239-246.

Bak I, Czompa A, Juhasz B, Lekli I, Tosaki A (2010). Reduction of reperfusion-induced ventricular fibrillation and infarct size via heme oxygenase-1 overexpression in isolated mouse hearts*. J Cell Mol Med 14: 2268-2272.

Bernier M, Curtis MJ, Hearse DJ (1989). Ischemia-induced and reperfusion-induced arrhythmias: importance of heart rate. Am J Physiol 256: H21-H31.

Bice JS, Baxter GF (2014). Postconditioning signalling in the heart: mechanisms and translatability. Br J Pharmacol 172: 1933-1946.

Csonka C, Csont T, Onody A, Ferdinandy P (2001). Preconditioning decreases ischemia/reperfusion-induced peroxynitrite formation. Biochem Biophys Res Commun 285: 1217-1219.

Csonka C, Kupai K, Kocsis GF, Novak G, Fekete V, Bencsik P et al. (2010). Measurement of myocardial infarct size in preclinical studies. J Pharmacol Toxicol Methods 61: 163-170.

Curtis MJ, Hearse DJ (1989). Reperfusion-induced arrhythmias are critically dependent upon occluded zone size: relevance to the mechanism of arrhythmogenesis. J Mol Cell Cardiol 21: 625-637.

Dow J, Kloner RA (2007). Postconditioning does not reduce myocardial infarct size in an in vivo regional ischemia rodent model. J Cardiovasc Pharmacol Ther 12: 153-163.

Engelen DJ, Gressin V, Krucoff MW, Theuns DA, Green C, Cheriex EC et al. (2003). Usefulness of frequent arrhythmias after epicardial recanalization in anterior wall acute myocardial infarction as a marker of cellular injury leading to poor recovery of left ventricular function. Am J Cardiol 92: 1143-1149.

Fekete V, Murlasits Z, Aypar E, Bencsik P, Sarkozy M, Szenasi G et al. (2013). Myocardial postconditioning is lost in vascular nitrate tolerance. J Cardiovasc Pharmacol 62: 298-303. 
Ferdinandy P, Csont T, Csonka C, Torok M, Dux M, Nemeth J et al. (1997a). Capsaicin-sensitive local sensory innervation is involved in pacing-induced preconditioning in rat hearts: role of nitric oxide and CGRP? Naunyn Schmiedebergs Arch Pharmacol 356: 356-363.

Ferdinandy P, Szilvassy Z, Horvath LI, Csont T, Csonka C, Nagy E et al. (1997b). Loss of pacing-induced preconditioning in rat hearts: role of nitric oxide and cholesterol-enriched diet. J Mol Cell Cardiol 29: 3321-3333.

Ferdinandy P, Csonka C, Csont T, Szilvassy Z, Dux L (1998). Rapid pacing-induced preconditioning is recaptured by farnesol treatment in hearts of cholesterol-fed rats: role of polyprenyl derivatives and nitric oxide. Mol Cell Biochem 186: 27-34.

Gibbons RJ, Valeti US, Araoz PA, Jaffe AS (2004). The quantification of infarct size. J Am Coll Cardiol 44: 1533-1542.

Gonzalez NC, Clancy RL, Moue Y, Richalet JP (1998). Increasing maximal heart rate increases maximal $\mathrm{O}_{2}$ uptake in rats acclimatized to simulated altitude. J Appl Physiol (1985) 84: 164-168.

Hahn JY, Song YB, Kim EK, Yu CW, Bae JW, Chung WY et al. (2013). Ischemic postconditioning during primary percutaneous coronary intervention: the effects of postconditioning on myocardial reperfusion in patients with ST-segment elevation myocardial infarction (POST) randomized trial. Circulation 128: 1889-1896.

Hausenloy DJ (2009). Signalling pathways in ischaemic postconditioning. Thromb Haemost 101: 626-634.

Hausenloy DJ, Yellon DM (2004). New directions for protecting the heart against ischaemia-reperfusion injury: targeting the reperfusion injury salvage kinase (RISK)-pathway. Cardiovasc Res 61: 448-460.

Hearse DJ, Tosaki A (1988). Free radicals and calcium: simultaneous interacting triggers as determinants of vulnerability to reperfusion-induced arrhythmias in the rat heart. J Mol Cell Cardiol 20: 213-223.

Hearse DJ, Ferrari R, Sutherland FJ (1999). Cardioprotection: intermittent ventricular fibrillation and rapid pacing can induce preconditioning in the blood-perfused rat heart. J Mol Cell Cardiol 31: 1961-1973.

Heusch G, Boengler K, Schulz R (2008). Cardioprotection: nitric oxide, protein kinases, and mitochondria. Circulation 118: 1915-1919.

Kilkenny C, Browne W, Cuthill IC, Emerson M, Altman DG (2010). Animal research: reporting in vivo experiments: the ARRIVE guidelines. Br J Pharmacol 160: 1577-1579.

Kloner RA, Dow J, Bhandari A (2006). Postconditioning markedly attenuates ventricular arrhythmias after ischemia-reperfusion. J Cardiovasc Pharmacol Ther 11: 55-63.

Kocsis GF, Pipis J, Fekete V, Kovacs-Simon A, Odendaal L, Molnar E et al. (2008). Lovastatin interferes with the infarct size-limiting effect of ischemic preconditioning and postconditioning in rat hearts. Am J Physiol Heart Circ Physiol 294: H2406-H2409.

Kocsis GF, Sarkozy M, Bencsik P, Pipicz M, Varga ZV, Paloczi J et al. (2012). Preconditioning protects the heart in a prolonged uremic condition. Am J Physiol Heart Circ Physiol 303: H1229-H1236.

Krumholz HM, Goldberger AL (1991). Reperfusion arrhythmias after thrombolysis. Electrophysiologic tempest, or much ado about nothing. Chest 99: 135S-140S.

Kupai K, Csonka C, Fekete V, Odendaal L, van Rooyen J, de Marais $\mathrm{W}$ et al. (2009). Cholesterol diet-induced hyperlipidemia impairs the cardioprotective effect of postconditioning: role of peroxynitrite. Am J Physiol Heart Circ Physiol 297: H1729-H1735.

Lecour S (2009). Activation of the protective survivor activating factor enhancement (SAFE) pathway against reperfusion injury: does it go beyond the RISK pathway? J Mol Cell Cardiol 47: 32-40.

Lefer DJ, Scalia R, Campbell B, Nossuli T, Hayward R, Salamon M et al. (1997). Peroxynitrite inhibits leukocyte-endothelial cell interactions and protects against ischemia-reperfusion injury in rats. J Clin Invest 99: 684-691.

Li J, Loukili N, Rosenblatt-Velin N, Pacher P, Feihl F, Waeber B et al. (2013). Peroxynitrite is a key mediator of the cardioprotection afforded by ischemic postconditioning in vivo. PLoS ONE 8: e70331.

McGrath J, Drummond G, McLachlan E, Kilkenny C, Wainwright C (2010). Guidelines for reporting experiments involving animals: the ARRIVE guidelines. Br J Pharmacol 160: 1573-1576.

Majidi M, Kosinski AS, Al-Khatib SM, Lemmert ME, Smolders L, van Weert A et al. (2009). Reperfusion ventricular arrhythmia 'bursts' predict larger infarct size despite TIMI 3 flow restoration with primary angioplasty for anterior ST-elevation myocardial infarction. Eur Heart J 30: 757-764.

Miki T, Itoh T, Sunaga D, Miura T (2012). Effects of diabetes on myocardial infarct size and cardioprotection by preconditioning and postconditioning. Cardiovasc Diabetol 11: 67.

Nakata T, Hearse DJ, Curtis MJ (1990). Are reperfusion-induced arrhythmias caused by disinhibition of an arrhythmogenic component of ischemia? J Mol Cell Cardiol 22: 843-858.

Ovize M, Baxter GF, Di Lisa F, Ferdinandy P, Garcia-Dorado D, Hausenloy DJ et al. (2010). Postconditioning and protection from reperfusion injury: where do we stand? Position paper from the Working Group of Cellular Biology of the Heart of the European Society of Cardiology. Cardiovasc Res 87: 406-423.

Pabla R, Curtis MJ (1996). Endogenous protection against reperfusion-induced ventricular fibrillation: role of neuronal versus non-neuronal sources of nitric oxide and species dependence in the rat versus rabbit isolated heart. J Mol Cell Cardiol 28: 2097-2110.

Pabla R, Bland-Ward P, Moore PK, Curtis MJ (1995). An endogenous protectant effect of cardiac cyclic GMP against reperfusion-induced ventricular fibrillation in the rat heart. Br J Pharmacol 116: 2923-2930.

Pacher P, Beckman JS, Liaudet L (2007). Nitric oxide and peroxynitrite in health and disease. Physiol Rev 87: 315-424.

Pawson AJ, Sharman JL, Benson HE, Faccenda E, Alexander SP, Buneman OP et al.; NC-IUPHAR (2014). The IUPHAR/BPS Guide to PHARMACOLOGY: an expert-driven knowledgebase of drug targets and their ligands. Nucl. Acids Res 42 (Database Issue): D1098-D1106.

Penna C, Cappello S, Mancardi D, Raimondo S, Rastaldo R, Gattullo D et al. (2006). Post-conditioning reduces infarct size in the isolated rat heart: role of coronary flow and pressure and the nitric oxide/cGMP pathway. Basic Res Cardiol 101: 168-179.

Skyschally A, van Caster P, Boengler K, Gres P, Musiolik J, Schilawa D et al. (2009a). Ischemic postconditioning in pigs: no causal role for RISK activation. Circ Res 104: 15-18.

Skyschally A, van Caster P, Iliodromitis EK, Schulz R, Kremastinos DT, Heusch G (2009b). Ischemic postconditioning: experimental models and protocol algorithms. Basic Res Cardiol 104: 469-483.

Tosaki A, Szekeres L, Hearse DJ (1987). Metoprolol reduces reperfusion-induced fibrillation in the isolated rat heart: protection is secondary to bradycardia. J Cardiovasc Pharmacol 10: 489-497. 
Tosaki A, Balint S, Szekeres L (1988). Pacing and reperfusion induced arrhythmias: protection by slow heart rate in the rat heart. Cardiovasc Res 22: 818-825.

Tsang A, Hausenloy DJ, Mocanu MM, Yellon DM (2004). Postconditioning: a form of 'modified reperfusion' protects the myocardium by activating the phosphatidylinositol 3-kinase-Akt pathway. Circ Res 95: 230-232.

Varga ZV, Kupai K, Szucs G, Gaspar R, Paloczi J, Farago N et al. (2013). MicroRNA-25-dependent up-regulation of NADPH oxidase 4 (NOX4) mediates hypercholesterolemia-induced oxidative/nitrative stress and subsequent dysfunction in the heart. J Mol Cell Cardiol 62: 111-121.

Varga ZV, Zvara A, Farago N, Kocsis GF, Pipicz M, Gaspar R et al. (2014). MicroRNAs associated with ischemia-reperfusion injury and cardioprotection by ischemic pre- and postconditioning:

protectomiRs. Am J Physiol Heart Circ Physiol 307: H216-H227.

Walker MJ, Curtis MJ, Hearse DJ, Campbell RW, Janse MJ, Yellon DM et al. (1988). The Lambeth Conventions: guidelines for the study of arrhythmias in ischaemia infarction, and reperfusion. Cardiovasc Res 22: 447-455.

Xia ZY, Gao J, Ancharaz AK (2009). Protective effect of ischemic postconditioning on lung ischemia-reperfusion injury in rats and the role of heme oxygenase-1. Chin J Traumatol 12: 162-166.
Yamada M, Hearse DJ, Curtis MJ (1990). Reperfusion and readmission of oxygen. Pathophysiological relevance of oxygen-derived free radicals to arrhythmogenesis. Circ Res 67: $1211-1224$.

Yang XM, Proctor JB, Cui L, Krieg T, Downey JM, Cohen MV (2004). Multiple, brief coronary occlusions during early reperfusion protect rabbit hearts by targeting cell signaling pathways. J Am Coll Cardiol 44: 1103-1110.

Yasmin W, Strynadka KD, Schulz R (1997). Generation of peroxynitrite contributes to ischemia-reperfusion injury in isolated rat hearts. Cardiovasc Res 33: 422-432.

Yellon DM, Hausenloy DJ (2007). Myocardial reperfusion injury. N Engl J Med 357: 1121-1135.

Zeng Z, Huang HF, Chen MQ, Song F, Zhang YJ (2011).

Contributions of heme oxygenase- 1 in postconditioning-protected ischemia-reperfusion injury in rat liver transplantation. Transplant Proc 43: 2517-2523.

Zhao ZQ, Corvera JS, Halkos ME, Kerendi F, Wang NP, Guyton RA et al. (2003). Inhibition of myocardial injury by ischemic postconditioning during reperfusion: comparison with ischemic preconditioning. Am J Physiol Heart Circ Physiol 285: H579-H588. 


\section{TÁRSSZERZŐI LEMONDÓ NYILATKOZAT}

Alulírott Dr. Varga Zoltán, mint megosztott első szerző kijelentem, hogy Dr. Pipicz Márton doktorjelölt, megosztott elsőszerzős társam az alábbiakban megjelölt közös publikációnkat teljes mértékben felhasználhatja $\mathrm{PhD}$ értekezéséhez és tudomásom szerint ezen eredményeinket más még nem használta fel tudományos fokozat megszerzéséhez, illetve ezt a jövőben sem teszi.

Az értekezésben felhasználásra került közös publikáció:

Pipicz M.; Varga Z.V.; Kupai K.; Gaspar R.; Kocsis G.F.; Csonka C.; Csont T. Rapid ventricular pacing-induced postconditioning attenuates reperfusion injury: Effects on peroxynitrite, RISK and SAFE pathways. British Journal of Pharmacology 2015, 172, 3472-3483.

2017. október 22.

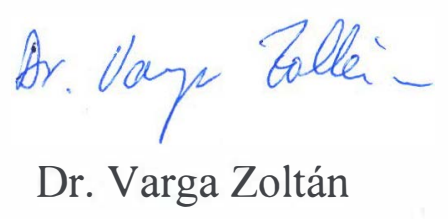

